\title{
Self-Assembled Mercaptan on Mesoporous Silica (SAMMS) Technology for Mercury Removal and Stabilization
}
X. Feng
X. Chen
J. Liu
D. E. Kurath
G. E. Fryxell
C. S. Ghormley
M. Gong
K. T. Klasson
Li-Q. Wang
K. M. Kemner

September 1997

Prepared for the

U.S. Department of Energy

under Contract DE-AC06-76RLO 1830

DETRIXITON OF THS DOCUMENT is UNWHTED

Pacific Northwest National Laboratory

Richland, Washington 99352

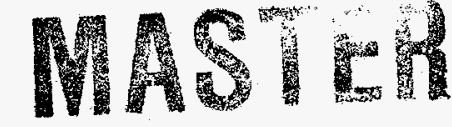




\title{
DISCLAIMER
}

This report was prepared as an account of work sponsored by an agency of the United States Government. Neither the United States Government nor any agency thereof, nor Battelle Memorial Institute, nor any of their employees, makes any warranty, express or implied, or assumes any legal liability or responsibility for the accuracy, completeness, or usefulness of any information, apparatus, product, or process disclosed, or represents that its use would not infringe privately owned rights. Reference herein to any specific commercial product, process, or service by trade name, trademark, manufacturer, or otherwise does not necessarily constitute or imply its endorsement, recommendation, or favoring by the United States Government or any agency thereof, or Battelle Memorial Institute. The views and opinions of authors expressed herein do not necessarily state or reflect those of the United States Government or any agency thereof.

\author{
PACIFIC NORTHWEST NATIONAL LABORATORY \\ operated by \\ BATTELLE \\ for the \\ UNITED STATES DEPARTMENT OF ENERGY \\ under Contract DE-AC06-76RLO 1830
}

Printed in the United States of America

Available to DOE and DOE contractors from the

Office of Scientific and Technical Information, P.O. Box 62, Oak Ridge, TN 37831;

prices available from (615) 576-8401.

Available to the public from the National Technical Information Service,

U.S. Department of Coinmerce, 5285 Port Royal Rd., Springfield, VA 22161 


\section{DISCLAMIER}

Portions of this document mey be illegible in electronic image prodnets. Images are produced from the best available original document. 


\section{Self-Assembled Mercaptan on Mesoporous Silica (SAMMS) Technology for Mercury Removal and Stabilization}

Principal Investigator and Project Manager:

Xiangdong Feng

Pacific Northwest National Laboratory

PO Box 999, P8-37

Richland, WA 99352

509-373-7284 (o), 509-376-1638 (f)

E-Mail: x_feng@pnl.gov

Co-Principal Investigators:

Jun Liu

Glen E. Fryxell

Investigators:

Meiling Gong

Li-Qiong Wang

Xiaobing Chen

Dean E. Kurath

Chris S. Ghormley

Collaborators:

K. Thomas Klasson

Oak Ridge National Laboratory

Ken M. Kemner

Argonne National Laboratory 
\begin{tabular}{|c|c|c|}
\hline & \\
\hline
\end{tabular} 


\section{Summary}

Self-Assembled Mercaptan on Mesoporous Silica (SAMMS), a proprietary new technology (X Feng, J Liu, and GE Fryxell, Self-assembled Mercaptans on Mesoporous Silica (SAMMS) for Mercury Separation and Stabilization, U.S. Patent Application filed on February 7, 1997, PNNL \#E-1479) for mercury removal from aqueous wastewater and mercury removal from organic wastes, such as vacuum pump oils, is being developed at Pacific Northwest National Laboratory (PNNL). SAMMS represents a new class of materials, (X Feng, GE Fryxell, LQ Wang, AY Kim, J Liu, and KM Kemner, 1997, "Functionalized Monolayers on Ordered Mesoporous Supports," Science, 276, 923-926) that integrates two frontiers of science: mesoporous ceramic materials (CT Kresge, ME Leonowicz, WJ Roth, JC Vartuli, and JS Beck. 1992. Nature 359:710) and self-assembled organic monolayers (BC Bunker, PC Rieke, BJ Tarasevich, AA Campbell, GE Fryxell, GL Graff, L Song, J Liu, and JW Virden. 1993. "Ceramic Thin Film Formation on Functionalist Interfaces Through Biomimetic Processing," Science, 261, 1286). Mesoporous ceramics are materials in which the pore size, ceramic substrate, and geometry can be manipulated. Its narrow pore size distribution can be specifically tailored from $15 \AA$ to $200 \AA$, and it provides a high surface area $\left(>900 \mathrm{~m}^{2} / \mathrm{g}\right)$ needed for high metal loading in chemical separation. Selfassembled monolayers of organic molecules bond to the ceramic substrate with prescribed densities and contain a free functional group that provides excellent molecular selectivity. The unique characteristics of SAMMS in mercury separation were studied at PNNL using simulated aqueous tank wastes and actual tritiated pump oil wastes from Savannah River Site (SRS); the preliminary results show that

- the apparent mercury absorption capacity was up to $0.64 \mathrm{~g} / \mathrm{g}$ of SAMMS due to the high surface area of SAMMS $\left(\sim 1000 \mathrm{~m}^{2} / \mathrm{g}\right)$

- the $\mathrm{Hg}$-binding kinetics were fast (this was shown by reducing a 0.5 -ppm mercury solution down to $0.5 \mathrm{ppb}$ in less than 5 minutes because of the fast interfacial reaction between the thiol groups on the SAMMS surface and mercury in solutions)

- $\quad$ it had high selectivity for mercury without significant interference from other abundant cations (such as $\mathrm{Ca}^{2+}$ and $\mathrm{Na}^{+}$) and anions such as $\mathrm{CN}, \mathrm{CO}_{3}{ }^{2-}, \mathrm{Cl}, \mathrm{SO}_{4}{ }^{2-}$ and $\mathrm{PO}_{4}{ }^{3-}$ in wastewater with $\mathrm{Kd}$ up to $10^{8}$ for mercury and reduced mercury concentration below $10 \mathrm{ppt}$ in aqueous salt solutions because of its molecular recognition of the functional groups

- $\quad$ SAMMS bound effectively to mercuries in cationic and metallic forms and in complexes of chlorides and organics such as methylmercury

- it was effective for removing mercury from aqueous liquid wastes, pump oil wastes, and mercury vapor because of its proper mixture of hydrophobic moity and a hydrophilic end functional grou (a single treatment of the SRS tritiated pump oil wastes using SAMMS powders removed $91 \%$ of its mercury content.)

- the mercury-laden SAMMS passed U.S. Environmental Protection Agency (EPA) Toxicity Characteristic Leach Procedure (TCLP) tests because of the strong chemical binding between mercury and thiol groups and stable ceramic matrixes

- mercury-SAMMS was stable up to $150^{\circ} \mathrm{C}$ in air and $70^{\circ} \mathrm{C}$ in aqueous solutions and is also expected to have strong biological durability due to its proper pore size for preventing bacteria from forming methylating mercury

- no secondary wastes were generated during application and disposal because of the simple column type operation without resorting to any additional chemicals

- the SAMMS is regenerable, using concentrated hydrochloric acid if it is desired because of the ion exchangeable nature of thiol groups under strong acidic conditions

- $\quad$ SAMMS is also applicable in removing radionuclides (e.g., $\mathrm{Pu}, \mathrm{Np}$, and $\mathrm{Am}$ ), anions $\left(\mathrm{H}_{2} \mathrm{~A}_{5} \mathrm{O}_{4}^{-}\right.$, $\mathrm{CrO}_{4}^{2-}, \mathrm{ReO}_{4}^{-}$), and dense nonaqueous phase liquids (DNAPLs) because of its flexibility in 
incorporating a range of functional groups

- preliminary cost estimates indicated lower life-cycle cost for applications of SAMMS in comparison with existing technologies because of simplicity in operation and manufacture and high waste loadings. 


\section{Glossary}

SAMMS self-assembled mercaptan on mesoporous silica

DOE U.S. Department of Energy

UEFPC Upper East Fork Poplar Creek

NPDES National Pollution Discharge Emission Standard

EPA

U.S. Environmental Protection Agency

RCRA Resource Conservation and Recovery Act

TEM transmission electron microscopy

EDS electron energy-dispersive spectroscopy

NMR nuclear magnetic resonance

SP. $\quad$ single pulse

EXAFS extended $x$-ray absorption fine structure

PNNL Pacific Northwest National Laboratory

SRS Savannah River Site

BET Bruneau, Emmett, Taylor

SIAC sulfur-impregnated activated carbon

TCLP Toxicity Characteristic Leach Procedure

NRWTP Nonradiological Wastewater Treatment Plant

DNAPL dense nonaqueous phase liquids

MWFA Mixed Waste Focus Area 


\section{Acknowledgments}

This work is funded by the Efficient Separations and Processing Crosscutting Program, Office of Science and Technology of the U.S. Department of Energy. Financial support from Pacific Northwest National Laboratory (PNNL) through Laboratory Directed Research and Development (LDRD) funding on the basic science part of the research related to this project is also acknowledged. Pacific Northwest National Laboratory is operated for the U.S. Department of Energy by Battelle under Contract DE-AC0676RLO 1830. The authors thank Tim Kent (Oak Ridge National Laboratory) for providing valuable information on the current system for mercury removal at the Nonradiological Wastewater Treatment Plant. The authors also thank Kriston Brooks and Larry Bagaasen for obtaining capital cost estimates for skid mounted and installed column systems, Mike Lilga for reviewing this report, Jim Buelt, Joe Perez, Nick Lombardo, Bill Kuhn, Jud Virden, Bill Bonner, Bruce Bunker, Rod Quinn, and John Sealock for consistent support of the development of this technology. 


\section{Contents}

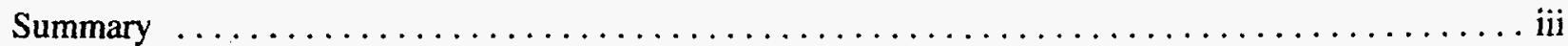

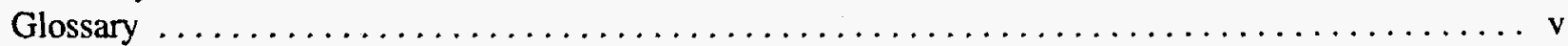

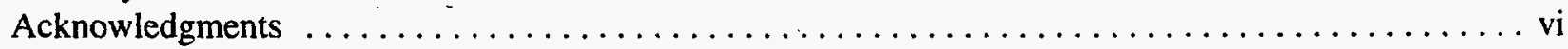

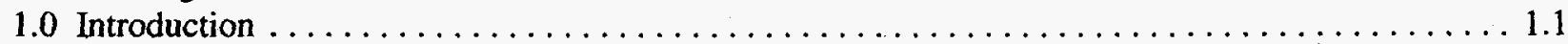

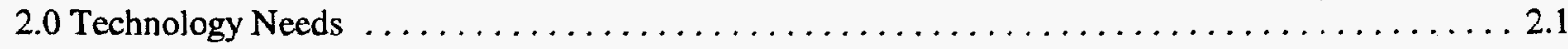

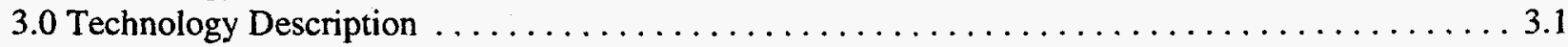

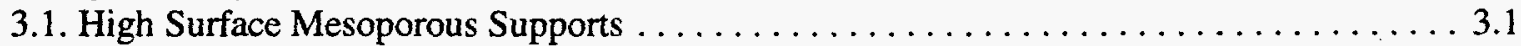

3.2. Self-Assembled Functional Groups on Mesoporous Oxide Surfaces . . . . . . . . . 3.1

3.3. Molecular Structure and Chemical Bonding of SAMMS Materials . . . . . . . . . . 3.4

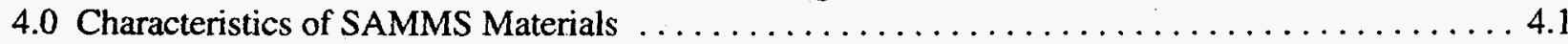

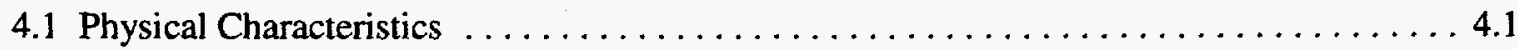

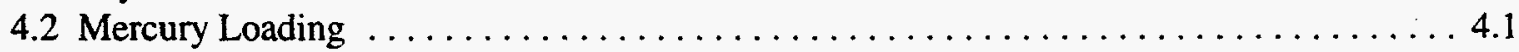

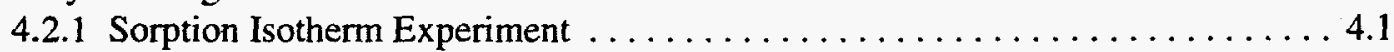

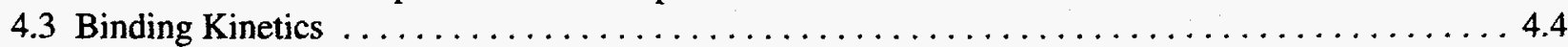

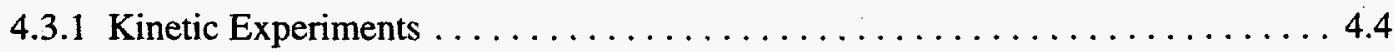

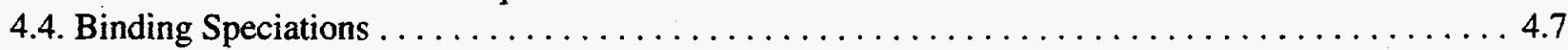

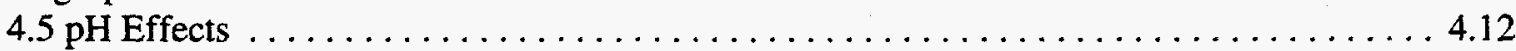

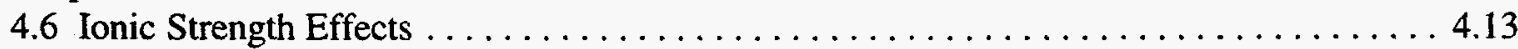

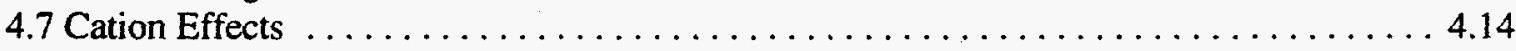

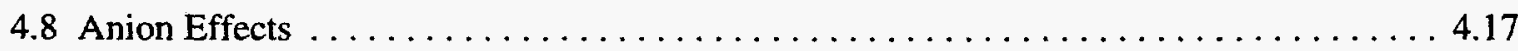

4.9 Demonstration on Simulated Aqueous and Oil Wastes and Actual SRS (Savannah River Site)

Tritiated Pump Oil Wastes . . . . . . . . . . . . . . . . . . 4.17

4.10 Toxicity Characteristic Leach Procedure (TCLP) on Mercury-SAMMS $\ldots \ldots \ldots \ldots 4.18$

4.11 Chemical Stability and Aqueous Durability of Mercury-SAMMS $\ldots \ldots \ldots \ldots \ldots \ldots .18$

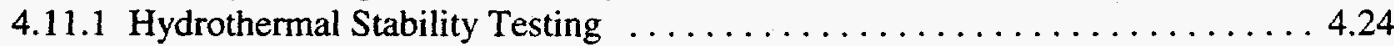

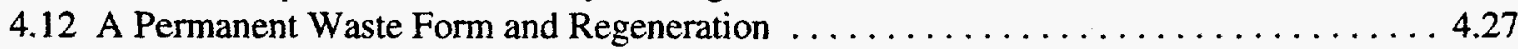

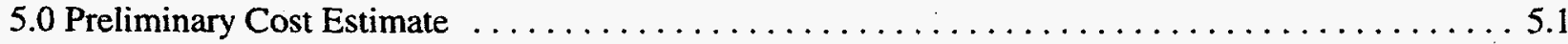

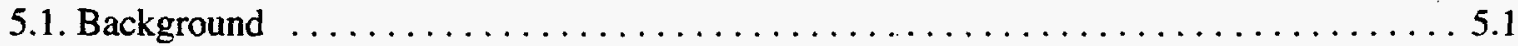

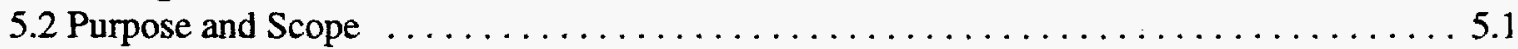

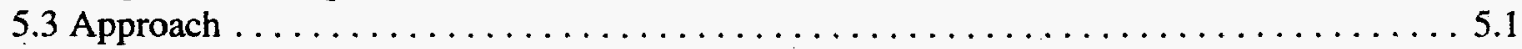

5.4 Mercury Removal at the Nonradiological Wastewater Treatment Plant . . . . . . . 5.1

5.4.1 Description of the Existing Mercury Removal System . . . . . . . . . . 5.1

5.4 .2 Description of Mercury Removal Using SAMMS $\ldots \ldots \ldots \ldots \ldots \ldots \ldots .2$

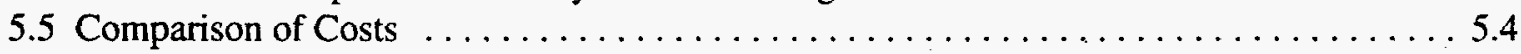

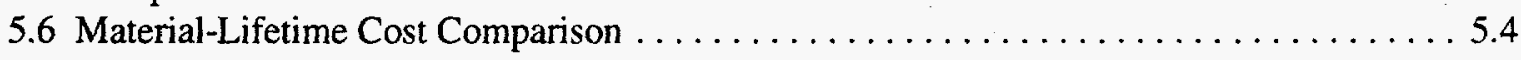

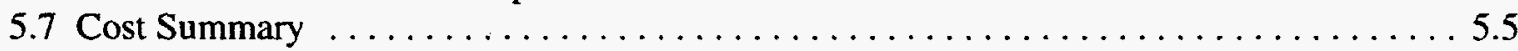

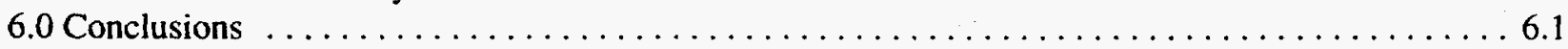

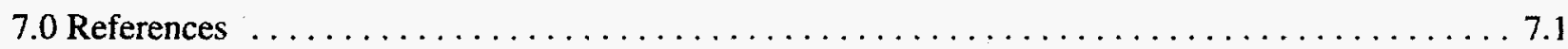

8.0 Patents Publications and Press Highlights $\ldots \ldots \ldots \ldots \ldots \ldots \ldots \ldots \ldots \ldots \ldots \ldots \ldots \ldots \ldots \ldots \ldots \ldots \ldots$

Appendix A: Production Cost Estimate for SAMMS $\ldots \ldots \ldots \ldots \ldots \ldots \ldots \ldots \ldots \ldots \ldots \ldots \ldots$ 


\section{Figures}

3.1.(A) A Schematic Representation of Self-assembled Functional Monolayers; (B) TEM Micrograph of Mesoporous Silica, Showing Uniform and Ordered Porosity; (C ) A Schematic Representation of SAMMS

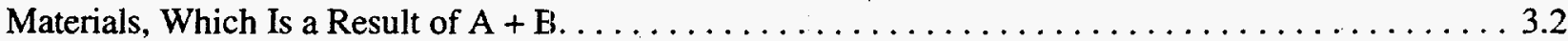

3.2. ${ }^{13} \mathrm{C}$ NMR Spectra of Monolayers of Mercaptan on Mesoporous Silica: (A) At $25 \%$ Coverage; (B) at

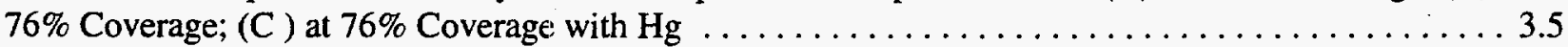

3.3. 29Si NMR Spectra of SAMMS with (A) $25 \%$ and (B) $76 \%$ Surface Coverage . . . . . . . 3.5

3.4. Schematic Conformations of Monolayers with Different Coverage. (A) Disordered Molecule at $25 \%$ Coverage; (B) Close-Packed at $76 \%$ Coverage; (C) Bound to $\mathrm{Hg}$ at $76 \%$ coverage. . ......... 3.6

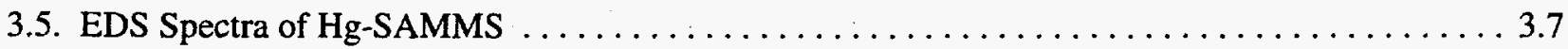

4.1. Equilibrium Mercury Loading of SAMMS \#2: (A) for $\mathrm{Hg}^{2}+$; (B) for $\mathrm{HgCl}_{2} \ldots \ldots \ldots \ldots .2$

4.2. Langmur Isotherm Fitting of SAMMS \#2: (A) for $\mathrm{Hg}^{2}+$; (B) for $\mathrm{HgCl}_{2} \ldots \ldots \ldots \ldots \ldots \ldots$

4.3. SAMMS Mercury Binding Kinetics: (A) in 500 ppn Mercury Solution; (B) in 10.0 ppm Mercury

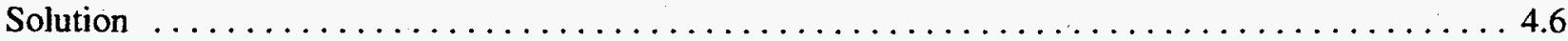

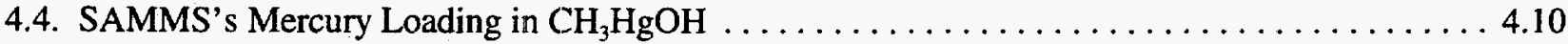

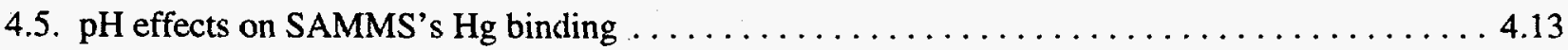

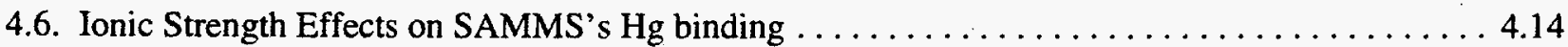

4.7. Cation Effects on SAMMS's Mercury Binding (A) at pH4 and (B) at $\mathrm{pH} 7 \ldots \ldots \ldots \ldots .16$

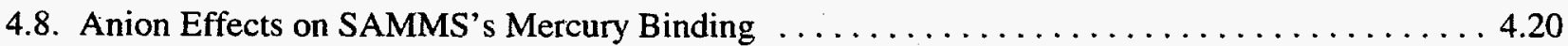

4.9. Mercury Removal from Actual SRS Tritiated Pump Oil Wastes with SAMMS . . . . . . 4.23

4.10. NMR Spectra of HG-SAMMS at Room Temperature, after Heating at $70^{\circ} \mathrm{C}$ in Air for 24 Hours, and

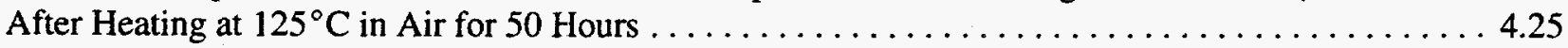

4.11. Thermo Rearrangement of Mercury-SAMMS During Heating $\ldots \ldots \ldots \ldots \ldots \ldots \ldots \ldots$ 


\section{Tables}

4.1. Equilibrium Mercury Loading in $\mathrm{Hg}\left(\mathrm{NO}_{3}\right)_{2}$ Solutions $\ldots \ldots \ldots \ldots \ldots \ldots \ldots \ldots \ldots \ldots \ldots$

4.2. Equilibrium Mercury Loadings in $\mathrm{HgCl}_{2}$ Solutions $\ldots \ldots \ldots \ldots \ldots \ldots \ldots \ldots \ldots \ldots \ldots \ldots \ldots \ldots \ldots$

4.3. SAMMS \#2 Mercury Binding Kd Values as a Function of Mercury Concentrations $\ldots \ldots \ldots 4.7$

4.4. SAMMS Binding with Organic Mercury, $\mathrm{CH}_{3}-\mathrm{Hg}-\mathrm{OH} \ldots \ldots \ldots \ldots \ldots \ldots \ldots \ldots \ldots \ldots$

4.5. $\mathrm{pH}$ Effects on SAMMS' Mercury Binding $\ldots \ldots \ldots \ldots \ldots \ldots \ldots \ldots \ldots \ldots \ldots \ldots \ldots \ldots \ldots \ldots \ldots .13$

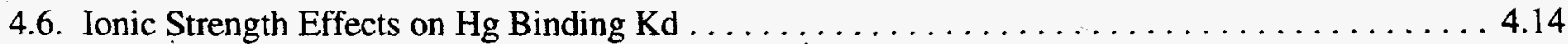

4.7. Cation Effects on SAMMS's Mercury Binding $\ldots \ldots \ldots \ldots \ldots \ldots \ldots \ldots \ldots \ldots \ldots \ldots \ldots$

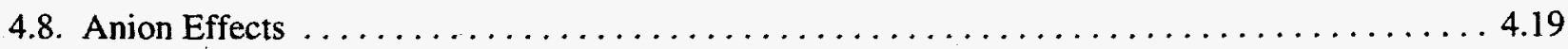

4.9. Analyzed RCRA Metal Concentrations (ppm) in Waste Solutions

Before and After SAMMS $\# 1$ Treatment $\ldots \ldots \ldots \ldots \ldots \ldots \ldots \ldots \ldots \ldots \ldots \ldots \ldots$

4.10. Testing Parameters of the Simulated Wastes Using SAMMS \#1 $\ldots \ldots \ldots \ldots \ldots \ldots \ldots .22$

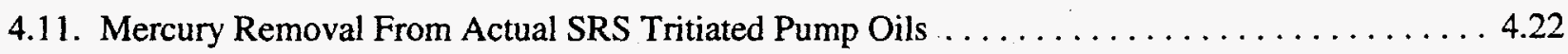

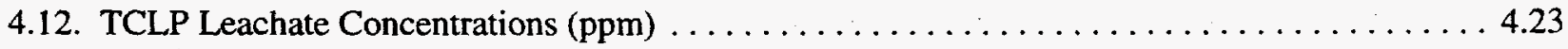

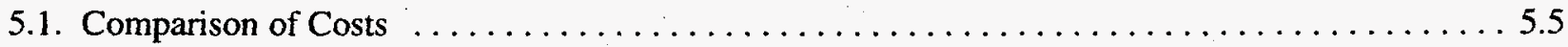

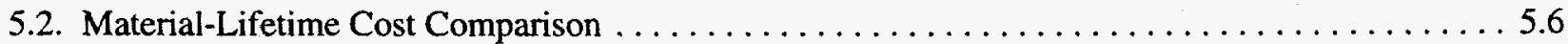

5.3. Preliminary Cost Estimates for Implementing SAMMS for Mercury Removal . . . . . . . . 5.7

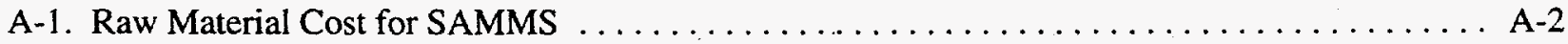




\subsection{Introduction}

Since they were discovered at Mobile Corporation five years ago (Beck et al. 1992; Kresge et al. 1992), mesoporous materials (Beck and Vartuli 1996; Liu et al. 1996; Huo et al. 1994; Maschmeyer et al. 1995; Tanev and Pinnavaia 1995; Bagshaw et al. 1995; Attard et al. 1995; Firouzi et al. 1995, Tianet al. 1997) have attracted considerable attention because of their high surface area of up to $1500 \mathrm{~m}^{2} / \mathrm{g}$ and well defined pore size and pore shape. The great potential of these materials in environmental and industrial processes has not been fully realized because most of these applications, such as separation, catalysis, and sensing, require the materials to have specific functionality (Sayari 1996; Anthony et al. 1993; Schierbaum 1994). However, the self-assembled organic monolayers can provide a substrate with the dense surface functionality (Ball 1994) to enable its high selectivity for fine chemical control (Ulman et al. 1991), sensing (Kumar et al. 1994), and chemical separation (Wirth et al. 1997). The sensitivity of the sensors and the loading capacity of the separation resins made from these self-assembled organic monolayers are limited by the surface area available on the substrates.

We have recently developed a new class of materials (Feng et al. 1997b) by coating the mesoporous materials with functionalized organic monolayers, resulting in an efficient scavenger of mercury. This is an effective combination of the high selectivity of the self-assembled organic monolayers with the high surface area of the ordered mesoporous silica as shown in Figure 3.1. The self-assembled mercaptan on mesoporous silica (SAMMS) provides molecular recognition, and mesoporous silica provides an extremely high capacity for metal binding, resulting in a breakthrough material for separation.

This paper explains the technology that has been developed to produce SAMMS. It also discusses the characteristics of SAMMS materials and its application for mercury removal and stabilization. Finally, cost estimates are provided for producing SAMMS materials and its application for mercury removal from a wastewater. 


\subsection{Technology Needs}

Chemical separations are particularly useful for environmental cleanup and remediation. Various industrial, military, agricultural, research, and hospital activities have resulted in severe contamination, especially metal contamination, in some areas. In these areas, metal contamination is present in air, in water, in sludge, in sediment, and in soil. Specifically, mercury appears in three primary forms:

1. metallic mercury: $\mathrm{Hg}^{0}$

2. inorganic mercury: divalent mercury, $\mathrm{Hg}^{2+}$; monovalent mercury, $\mathrm{Hg}_{2}{ }^{2+}$; neutral mercury compounds, $\mathrm{HgCl}_{2}, \mathrm{Hg}(\mathrm{OH})_{2}$

3. organic mercury: phenylmercury, $\mathrm{C}_{6} \mathrm{H}_{5} \mathrm{Hg}^{+}, \mathrm{C}_{6} \mathrm{H}_{5} \mathrm{HgC}_{6} \mathrm{H}$; alkoxyalkyl mercury, $\mathrm{CH}_{3} \mathrm{O}-\mathrm{CH}_{2}-\mathrm{CH}_{2}-\mathrm{Hg}^{+}$; methylmercury, $\mathrm{CH}_{3} \mathrm{Hg}^{+}, \mathrm{CH}_{3} \mathrm{HgCH}_{3}$.

These compounds can be ranked in order of decreasing toxicity as: methylmercury, mercury vapor, inorganic salts of mercury, and a number of organic forms, such as phenylmercury salts (Mitra 1986). Methylmercury, the most toxic form, is formed mainly by methylation of mercury by the methanogenic bacteria that are widely distributed in the sediments of ponds and in the sludge of sewage beds. In addition, methylation was used as a seed-dressing preparation in agriculture. Mercury poisoning in humans causes digestive disturbances, emaciation, diarrhea, speech stammering, delirium, paralysis of the arms and legs, and death by exhaustion.

The importance of mercury contamination is underscored by the fact that the U.S. Department of Energy (DOE) has identified the removal/separation/stabilization of mercury as the \#1 and \#4 priorities among 30 prioritized deficiencies. Over $50,000 \mathrm{~m}^{3}$ of mixed low-level and transuranic waste-containing mercury has been identified in the DOE complex.. At the DOE Oak Ridge Site, an estimated 2.5 million pounds of mercury was lost to soil and surface water and $914 \mathrm{~m}^{3}$ of mercury is contained in plant sumps. The headwaters of Upper East Fork Poplar Creek (UEFPC) are within the DOE Y-12 plant boundary, and 26,530,000 L of water per day are discharged to Lower East Fork Poplar Creek. The UEFPC is contaminated with low levels of mercury. A mercury-reduction program at the Oak Ridge Site has achieved point-source reduction, and mercury treatment systems are placed such that the mercury surface water concentration is declining. However, the program has not be able to meet the National Pollution Discharge Emission Standard (NPDES) permit that requires that treatment to $0.012 \mu \mathrm{g} / \mathrm{L}$ is needed at UEFPC by April 27, 2000. Exceeding the anticipated limit triggers the requirement of monitoring methyl mercury in edible portions of fish present in contaminated streams (UEFPC). If methyl mercury concentration exceeds $1 \mathrm{mg} / \mathrm{kg}$, the public must be protected from ingestion of fish.

Many mercury-bearing DOE wastes are aqueous and non-aqueous liquids, sludges, soils, absorbed liquids, partially or fully stabilized sludges, and debris. Many wastes, including DOE wastes, contain mercury in amounts of less than $260 \mathrm{ppm}$; these wastes are not required to be treated by retorting as specified by the U.S. Environmental Protection Agency (EPA) regulation for mercury. However, these wastes contain other contaminants that require treatment, and the presence of mercury complicates the design of offgas systems, stabilization of residues, and monitoring of all effluents. It would be advantageous to remove the mercury as a pretreatment to simplify downstream operation.

Other metals that are of interest for remediation and other separations include, but are not limited to, silver, lead, cadmium, uranium, plutonium, neptunium, americium, and combinations thereof. Inorganic anions are also of interest for separations and include $\mathrm{TcO}_{4}^{-}, \mathrm{CrO}_{4}^{-2}, \mathrm{AsO}_{4}^{-3}$. 
The existing technologies for Resource Conservation and Recovery Act (RCRA) metal and mercury removal from diluted wastewater include sulfur-impregnated carbon (Otanl et al. 1988), microemulsion liquid membranes (Larson and Wiencek 1994), ion exchange (Ghazy 1995), and colloid precipitate flotation (Ritter and Bibler 1992). These different treatment methods have their own unique characteristics that provide advantages for certain specific applications. In the sulfur-impregnated carbon process, metal is adsorbed to the carbon, not covalently bound to the matrix as with SAMMS. The carbon materials are inexpensive and also adsorb organics in addition to RCRA metals. The adsorbed metal may need secondary stabilization because the metal-laden carbon may not have the desired long-term chemical durability because of the weak bonding between metal and active carbons. In addition, a large portion of the pores in the active carbon is large enough for the entry of microbes to solubilize the mercury-sulfur compounds. The RCRA metal loading is not as high as that of mesoporous-based materials. The microemulsion liquid-membrane technique uses an oleic acid microemulsion liquid membrane containing sulfuric acid as the internal phase to reduce the wastewater mercury concentration effectively from 460 ppm to $0.84 \mathrm{ppm}$ (Larson and Wiencek 1994). This process involves multiple steps of extraction, stripping, demulsification, and recovery of mercury by electrolysis with the use of large volumes of organic solvents. The liquid membrane swelling has a negative impact on extraction efficiency. The slow kinetics of the RCRA metal-ion exchanger reaction requires long contact time. This process may also generate large volumes of organic secondary wastes. The ion exchange process (Ghazy 1995) uses Duolite ${ }^{\mathrm{TM}}$ GT-73 ion exchange organic resin to reduce the mercury level in wastewater from $2 \mathrm{ppm}$ to be below $10 \mathrm{ppb}$. The mercury loading was limited to about $0.145 \mathrm{~g} / \mathrm{mL}$ due to low surface area. In addition, the mercury-laden organic resin may not have the ability to resist microbe attack, and mercury may be released into the environment if it is disposed of as a long-term waste form. The reported successful removal of RCRA metal from water by colloid precipitate flotation reduces mercury concentration from $160 \mathrm{ppb}$ to about 1.6 $\mathrm{ppb}$ [8], which can address many of the remediation needs. This process involves the addition of $\mathrm{HCl}$ to adjust the wastewater to $\mathrm{pH} 1$, the addition of $\mathrm{Na}_{2} \mathrm{~S}$ and oleic acid solutions to wastewater, and the removal of colloids from the wastewater. In this process, the treated wastewater is potentially contaminated with the $\mathrm{Na}_{2} \mathrm{~S}$, oleic acid, and $\mathrm{HCl}$ by the treatment itself. The separated mercury needs further treatment to be stabilized as a permanent waste form for disposal.

No effective existing technologies have been developed for removing mercury from organic media such as pump oil. Some preliminary laboratory study of a zinc powder/filtration process was carried out by the Pantex Plant with certain success, but the work was discontinued ${ }^{(a)}$.

Thus, there remains a need for materials and methods for separations that have high selectivity and high capacity and do not require secondary treatment. There remains a need for separations of hazardous metals in complex compounds. More specifically, there remains a need for material that can reduce mercury concentration in groundwater to below $0.012 \mu \mathrm{g} / \mathrm{L}$ and works in organic liquids such as pump oils as well as in used organic solvents.

(a) Klein JE. "R\&D Needs for Mixed Waste Tritium Pump Oils (U)," Westinghouse Savannah River Company Inter-Office Memorandum, SRT-HTS-94-0235, July 11, 1994. 


\subsection{Technology Description}

The SAMMS materials are based on self-assembly of functionalized monolayers on mesoporous oxide surfaces (Feng et al. 1997b). Figure 3.1c shows a schematic drawing of the SAMMS material that is a combination of the self-assembled functional monolayers (Figure 3.1a) and mesoporous oxides (Figure $3.1 \mathrm{~b}$ showing a transmission electron microscopy [TEM] micrograph of the mesoporous silica).

\subsection{High Surface Mesoporous Supports}

The unique mesoporus oxide supports provide high surface area $\left(>1000 \mathrm{~m}^{2} / \mathrm{g}\right)$, thereby enhancing the metal-loading capacity. They also provide an extremely narrow pore-size distribution, which can be specifically tailored from $15 \AA$ to $200 \AA$, thereby minimizing biodegradation from microbes and bacteria ( $>20,000 \AA$ ). Mesoporous structures may be disposed of as stable waste forms.

Mesoporous silica materials were synthesized in cetyltrimethylammonium chloride/hydroxide, silicate, and mesitylene solutions (Beck et al. 1992). Typically, cetyltrimethylammonium chloride/hydroxide (CTAC/OH) solution was prepared by batch contact of $29 \mathrm{wt} \%$ CTAC (Carsoquat CT429, Lonza, Inc.) with strongly basic ion exchange resin (DOWEX-1, Sigma Chemical Co., $0.2 \mathrm{~g}$ resin/g 29 wt\% CTAC solution), 13 g colloidal silica (Hi-Sil 233, PPG Industries), 51 g tetramethylammonium silicate (10\% $\mathrm{SiO}_{2}, 0.5 \mathrm{TMA} / \mathrm{Si}$ mole ratio, SACHEM, Inc.), and $28 \mathrm{~g}$ mesitylene (Eastman Kodak) were added in that order to each $100 \mathrm{~g} \mathrm{CTAC/OH}$ solution. The mixture was sealed in a Teflon-lined vessel and heated at $105^{\circ} \mathrm{C}$ for 1 week. The product was recovered by suction filtration, dried at ambient temperature, and calcined at $540^{\circ} \mathrm{C}$ for $1 \mathrm{~h}$ in flowing nitrogen, followed by $12 \mathrm{~h}$ in flowing air. The calcined mesoporous silica has a surface area of $900 \mathrm{~m}^{2} / \mathrm{g}$ and an average pore size of $55 \AA$, as determined by the gas adsorption technique using an AUTOSORB DEGASSER, QUANTACHROME, and TEM.

\subsection{Self-Assembled Functional Groups on Mesoporous Oxide Surfaces}

The self-assembled functional group provides three important functions: 1) molecular recognition for metals, 2) covalent bonding to the support materials, and 3) high population density of the functional groups on the substrate surfaces.

Molecular self-assembly is a unique phenomenon in which functional molecules aggregate on an active surface, resulting in an organized assembly with both order and orientation (Fryxell et al. 1996; Bunker et al. 1993; Tarasevich et al. 1996). In this approach, bifunctional molecules containing a hydrophilic head group and a hydrophobic tail group adsorb onto a substrate or an interface as closely packed monolayers. The driving forces for the self-assembly are the inter- and intra-molecular interactions between the functional molecules. The tail group and the head group can be chemically modified to contain certain functional groups to promote covalent bonding between the functional organic molecules and the substrate on one end, and the molecular bonding between the organic molecules and the metals on the other. By populating the outer interface with functional groups, an effective means for scavenging heavy metals is made available. 
A. Self-assembled monolayers

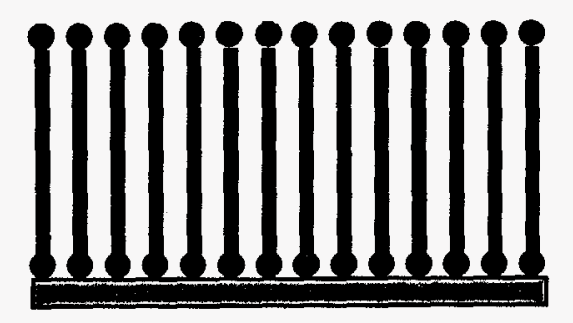

t

B. Ordered mesoporous oxide

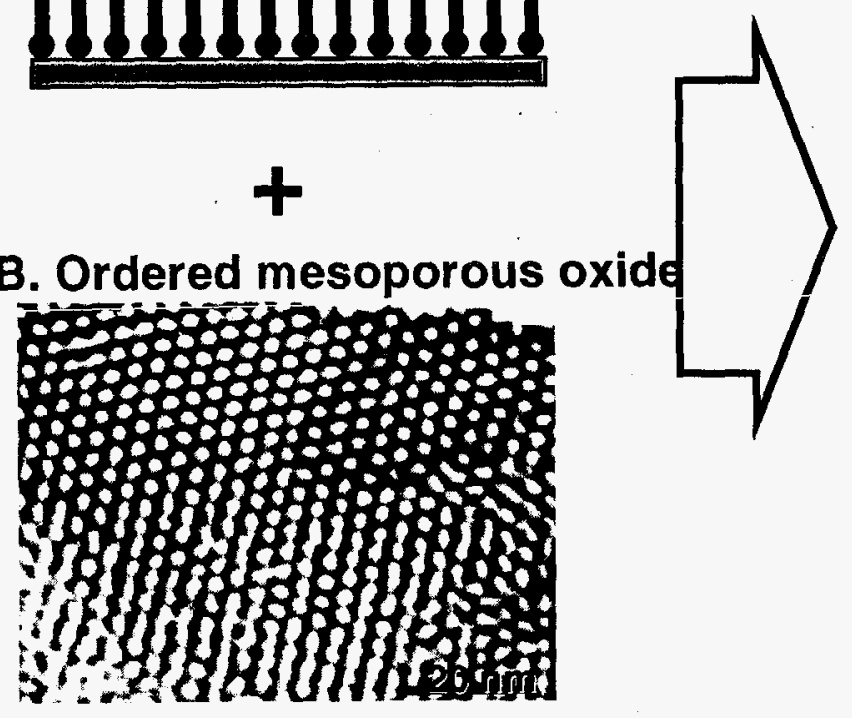

C. Self-assembled monolayers on mesoporous oxides (SAMMS)

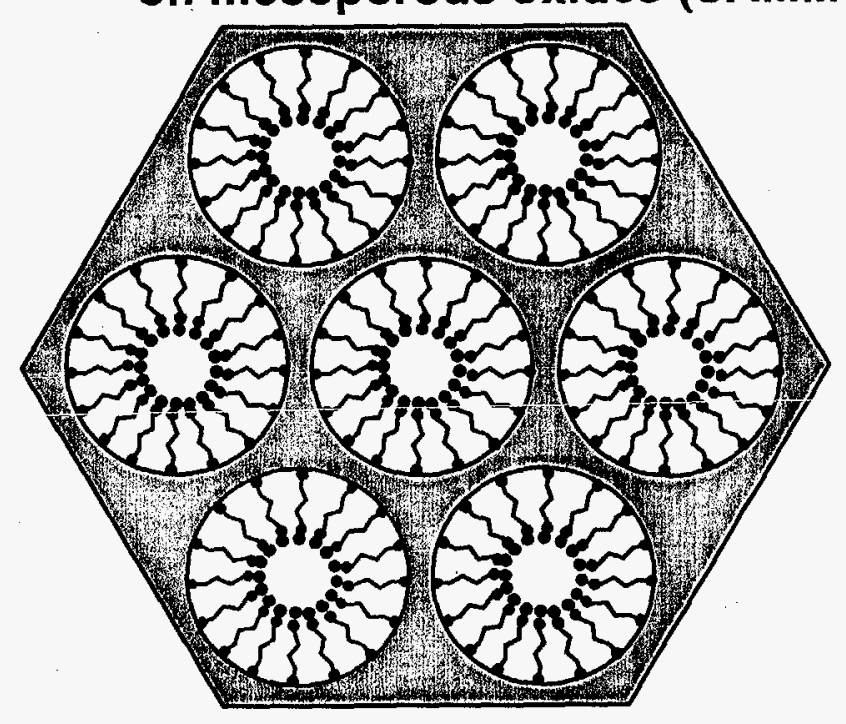

Figure 1. (A) A schematic representation of self-assembled functional monolayers

(B) TEM micrograph of mesoporous silica, showing uniform and ordered porosity

(C) A schematic representation of SAMMS materials, which is a result of A + B. 
Functional groups (thiol groups in this case) were introduced to the pore surface of mesoporous silica as the terminal groups of organic monolayers. The hydrocarbon chains aggregate and form closepacked arrays on the substrate. The siloxane groups then undergo hydrolysis and ultimately end up covalently attached to the substrate and crosslinked to one another, resulting in the novel material, called SAMMS.

The population density and the quality of the functionalized monolayers on the mesoporous materials are greatly affected by two factors: the population of silanol groups and adsorbed water molecules on the mesoporous silica surface. The silanols anchor the organic molecules to the silica surface. However, the calcining step used in preparing mesoporous silica dehydrates the silica surface and removes most of the silanols, which results in poor surface coverage (Gao and Reven 1995). A proper amount of adsorbed surface water is also important because the hydrolysis reaction is one of the critical first steps in the process of building the monolayer. Ideally, just enough water would be associated with the surface for the siloxane hydrolysis. The existence of free water is detrimental to the efficient formation of a clean monolayer because of polymerization of tris(methoxy)mercaptopropylsilane (TMMPS) in solution (Tripp and Hair 1992).

The initial strategy was to rehydrate the mesoporous silica surface. This process involved boiling a weighed sample of mesoporous silica in pure water for several hours, collecting the silica by filtration, weighing it again, and removing the surplus water content via azeotropic distillation with toluene. This method, although successful in the deposition of high quality monolayers up to $75 \%$ surface coverage, was time-consuming and laborious. Recently, we have developed a more efficient approach by wetting the silica surface with 2 to 2.5 monolayers of water (based on available surface area). Experimentally, this approach is accomplished by adding the requisite amount of water to a suspension of mesoporous silica in toluene and stirring the mixture for an hour to allow complete dispersal of the aqueous phase across the ceramic interface. When the mesoporous ceramic interface is properly hydrated, the monolayer is constructed by adding one equivalent (or a slight excess) of the desired alkoxysilane (based on available surface area), stirring the mixture, and heating it in toluene reflux for several hours. Currently, we can systematically vary the population densities of functional groups on the mesoporous materials from $10 \%$ up to $100 \%$ of the full surface coverage.

The relative surface coverage was estimated based on 1) the surface area of the support, 2) the weight change after the functionalized monolayers were attached, and 3) the ideal loading density that can be achieved on flat surfaces. These results were also verified by electron energy-dispersive spectroscopy (EDS). We systematically varied the population densities of functional groups on the mesoporous materials from 10 to $100 \%$ of the full surface coverage.

The population density of organic monolayers for $100 \%$ coverage on silica was determined using ${ }^{13} \mathrm{C}$ solid state nuclear magnetic resonance (NMR) methods on dense fumed silica spheres with a known surface area $\left(150 \mathrm{~m}^{2} / \mathrm{g}\right)$ and tetrakis(trimethylsilyl)silane (TMS) $)_{4} \mathrm{Si}$ as an internal standard. Integration of the peaks from functionalized monolayers and from the internal standard allowed the determination of the number of alkylsiloxanes on the substrate. 


\subsection{Molecular Structure and Chemical Bonding of SAMMS Materials}

The structure of the functionalized monolayers and the chemical bonding can be studied by solidstate NMR experiments (Wang et al. 1996; Badia et al. 1996). The 75.0 MHZ ${ }^{13} \mathrm{C}$ solid-state NMR experiments were carried out with a Chemagnetics spectrometer (300 MHZ - 89-mm wide-bore Oxford magnet) using a double-resonance probe. For both unloaded and mercury-loaded SAMMS samples, single-pulse (SP) Bloch-decay and cross-polarization (CP) methods were used with ' $\mathrm{H}$ decoupling. The dried powders were loaded into 7-mm Zirconia PENCILTM rotors and spun at 3 to $4 \mathrm{kHz}$. Spectra were collected by using an SP excitation Bloch-decay method with a 5- $\mu \mathrm{S}\left(90^{\circ}\right){ }^{13} \mathrm{C}$ pulse and a 10 -s repetition delay. For all experiments, $40-\mathrm{ms}$ accuisition times and a $50-\mathrm{KHz}$ spectral window were employed. The number of transients was 1000 to 3000 . The power levels of the carbon and proton channels were set so that the Hartmann-Hahn match was achieved at $55 \mathrm{kHz}$ in CP experiments with 3-ms contact time and 5-s repetition delay. A Lorentzian line broadening of $24 \mathrm{~Hz}$ was used for all ${ }^{13} \mathrm{C}$ spectra. The $59.3 \mathrm{MHZ}{ }^{29} \mathrm{Si}$ NMR spectra were also taken for both samples using the SP Bloch-decay method with ${ }^{1} \mathrm{H}$ decoupling. A Lorentzian line broadening of $50 \mathrm{~Hz}$ and a 30 -s repetition delay were used for ${ }^{29} \mathrm{Si}$ spectra. Both ${ }^{13} \mathrm{C}$ and ${ }^{29} \mathrm{Si}$ NMR chemical shifts were referenced to TMS at $0 \mathrm{ppm}$.

Single-pulse ${ }^{13} \mathrm{C}$ NMR spectra along with the peak assignments [Si-CH2(3)-CH2(2)-CH2(1)-SH\} for $25 \%, 76 \%$, and mercury-laden $76 \%$ functionalized monolayers samples, respectively, are shown in Figure 3.2. For $25 \%$ functionalized monolayers coverage on mesoporous silicates (Figure 3.2A), the peak at $12.8 \mathrm{ppm}$ was attributed to the methylene carbon group C3, directly bonded to the Si atom. The peak at $28.3 \mathrm{ppm}$ was attributed to the other two methylene carbons ( $\mathrm{C} 2$ and $\mathrm{C} 1$ ). An additional peak at $24.7 \mathrm{ppm}$ (Figure 3.2B) was observed for $76 \%$ functionalized monolayers coverage. This peak was assigned to the methylene carbon ( $\mathrm{Cl}$ ) next to the -SH group, based on the chemical shifts reported for $\mathrm{CH}_{3}\left(\mathrm{CH}_{2}\right)_{7} \mathrm{SH}$ (Wang et al. 1996; Badia 1996).

The difference in Figure 3.2A and Figure 3.2B is attributed to a different molecular conformation for the organic monolayers at different coverages. At low surface coverage, the carbon chains can adapt a wide range of conformations; therefore, the peaks for $\mathrm{C} 2$ and $\mathrm{C} 1$ cannot be distinguished because of conformational heterogeneity. At higher population densities, all of the carbon chains are near one another and have a more upright orientation with respect to the silica surface. The molecules have a higher degree of ordering that narrows the linewidths in the ${ }^{13} \mathrm{C}$ spectrum and allows the peaks for all three carbons to be resolved better. The close-packed conformation of the carbon chains is also evident in ${ }^{29} \mathrm{Si}$ NMR results (Figure 3.3). It is important to recognize that relative peak intensities in ${ }^{29} \mathrm{Si}$ CP-MAS are not strictly quantifiable because of differences in relaxation behavior. Therefore, we have used the Bloch decay pulse sequence (single-pulse excitation) with long recycle times to obtain data that allow us to quantify the molecular composition of these materials. The large peak at $-111 \mathrm{ppm}$ is from the silica support. In Figure 3.3A, three additional peaks from -50 to $-80 \mathrm{ppm}$ are identified for the $25 \%$ functionalized monolayers coverage, corresponding to three different environments for the siloxane groups in the functionalized monolayers (Sinclorf 1983): 1) isolated groups that are not bound to any neighboring siloxanes, 2) terminal groups that are only bound to one neighboring siloxane, and 3) cross-linked groups that are bound to two neighboring siloxanes. Among the three, the most dominant peak comes from terminal group (2). For $76 \%$ functionalized monolayers coverage, the molecules are closer to one another, and the most predominant peak corresponds to the cross-linked siloxane group (3). The isolated siloxane group (1) is absent. The transition from disordered conformation at low surface coverage to close-packed conformation at high coverage is illustrated in Figure 3.4. 


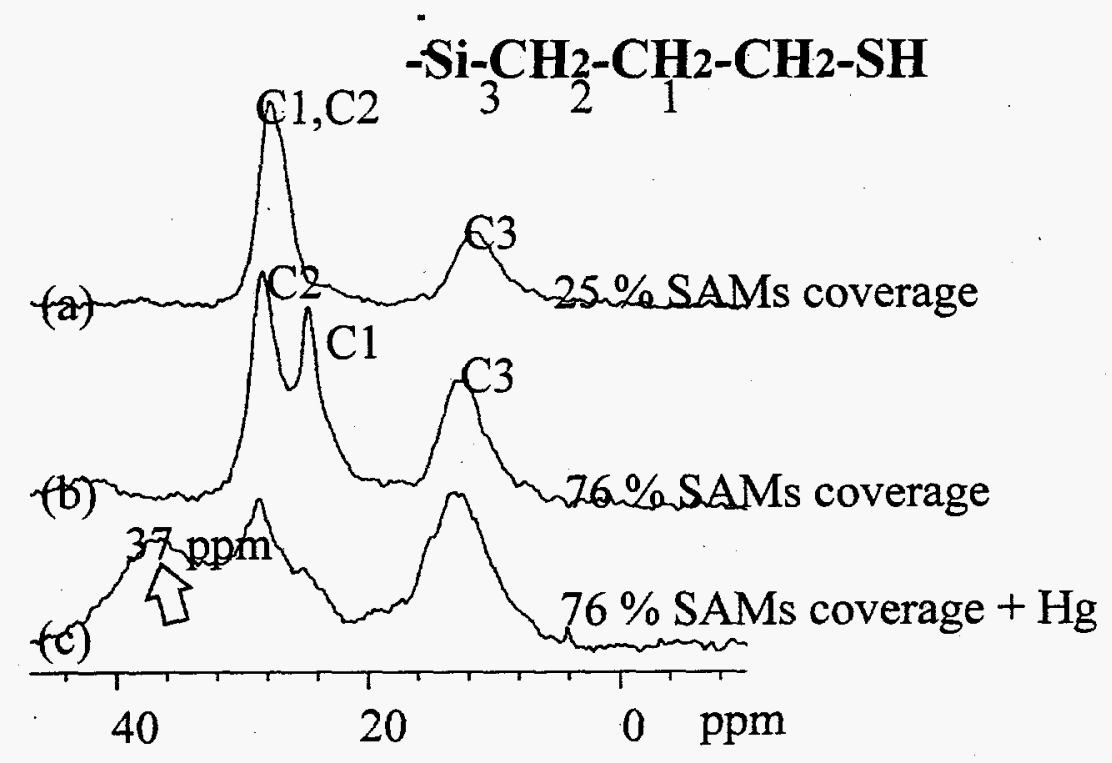

Figure 3.2. ${ }^{13} \mathrm{C}$ NMR spectra of monolayers of mercaptan on mesoporous silica: (A) At $25 \%$ coverage; (B) at $76 \%$ coverage; (C ) at $76 \%$ coverage with $\mathrm{Hg}$

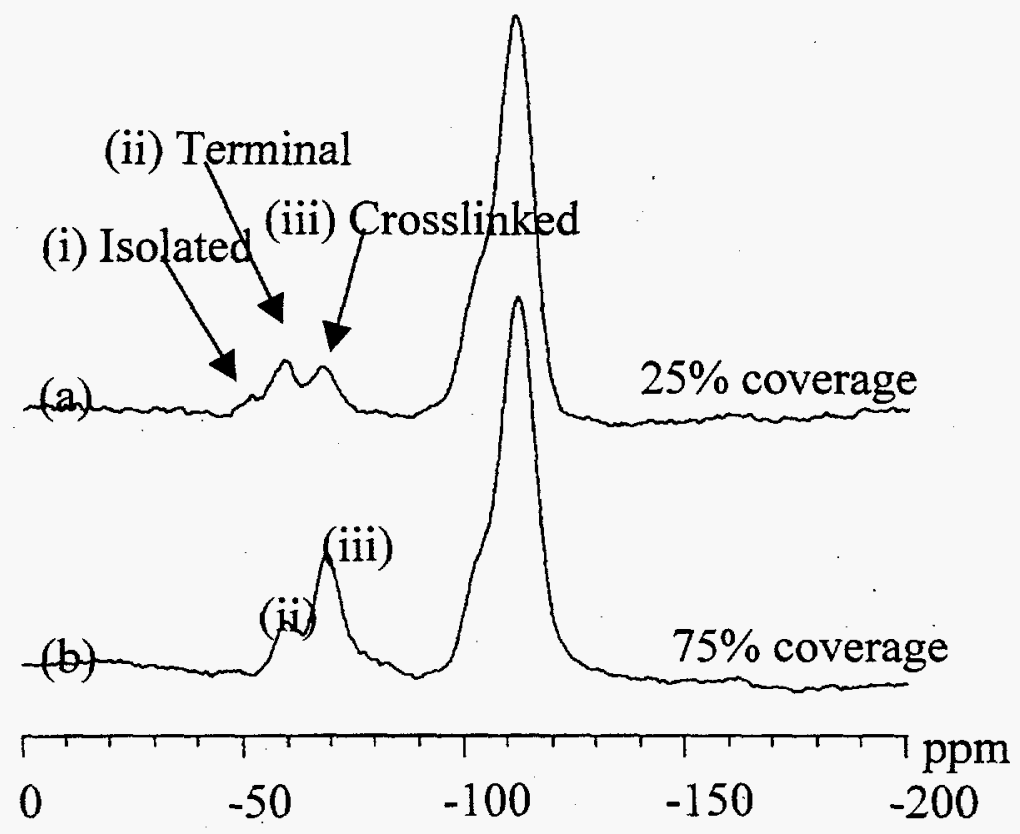

Figure 3.3. ${ }^{29} \mathrm{Si} \mathrm{NMR} \mathrm{spectra} \mathrm{of} \mathrm{SAMMS} \mathrm{with}$ (A) at $25 \%$ and $(B) 76 \%$ surface coverage 


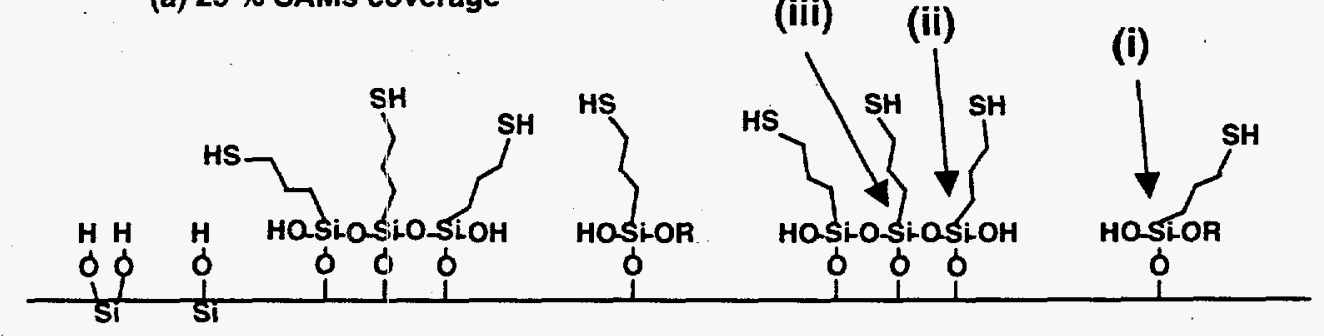

(b) $76 \%$ SAMs coverage

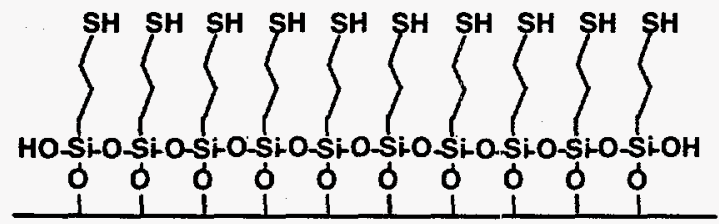

(c) Hg loaded $76 \%$ SAMs

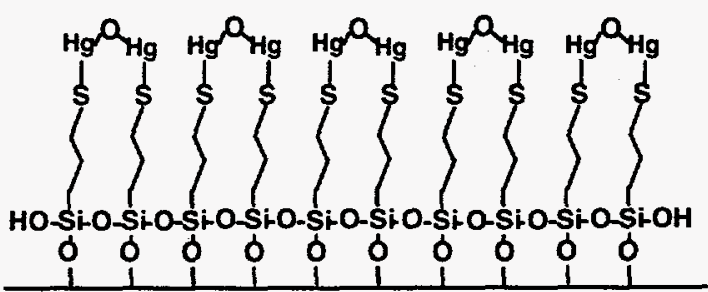

Figure 3.4. Schematic conformations of monolayers with different coverage. (A) Disordered molecule at $25 \%$ coverage; (B) Close-packed at $76 \%$ coverage; (C) Bound to $\mathrm{Hg}$ at $76 \%$ coverage.

The ${ }^{13} \mathrm{C}$ spectrum for the $76 \%$ functionalized monolayers coverage with mercury (Figure $3.2 \mathrm{C}$ ) shows that the three resonances corresponding to the $\mathrm{C} 1, \mathrm{C} 2$, and $\mathrm{C} 3$ methylene carbons observed in Figure 3.2B are still discernible, but become much broader. A new broad peak appears at $37 \mathrm{ppm}$, and the peak at $24.7 \mathrm{ppm}$ decreases significantly. This result suggests strong chemical bonding between the mercury and thiol group, which causes the shift of the peak corresponding to $\mathrm{C} 1$ attached to the thiol group. The next C2 group is also affected, but to a lesser degree. The fact that the peak at $24.7 \mathrm{ppm}$ is still present indicates that the thiol groups are not saturated with mercury yet.

The SAMMS material is a useful environmental remediation agent because it has a high affinity for binding mercury and other heavy metals. Figure 3.1B is a TEM micrograph of SAMMS with $76 \%$ coverage after contact with a solution containing mercury ions. The ordered porous structures were preserved in the chemical treatment processes for attaching the functionalized monolayers. Although most mercury was evaporated under the electron beam and therefore was not visible in the TEM image, some mercury was detected in the EDS spectrum (Figure 3.5). The EDS also detected sulfur from the thiol group. Compositional analysis indicates that the relative concentration for sulfur and silica is $5.2 \mathrm{mmol} / \mathrm{g}$ of silica, which is in excellent agreement with the gravimetric estimate $(5.6 \mathrm{mmol} / \mathrm{g})$. 


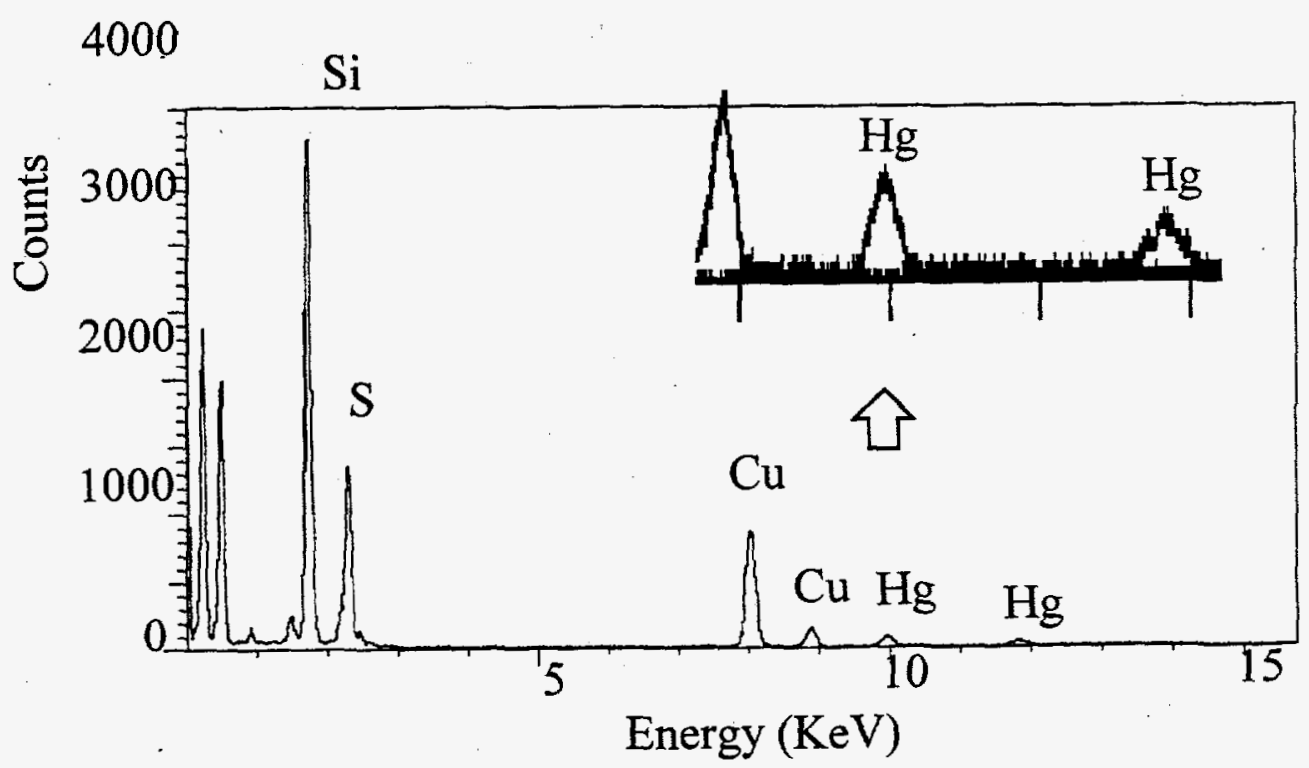

Figure 3. 5. EDS spectra of Hg-SAMMS

The chemical bonding between mercury and the thiol group was further confirmed by extended $\mathrm{x}$-ray absorption fine structure (EXAFS) studies. EXAFS experiments on the mercury-laden SAMMS were performed at the mercury $\mathrm{L}_{\mathbb{T}}$ absorption edge on beamline $\mathrm{X} 18 \mathrm{~B}$ at the National Synchrotron Light Source at Brookhaven National Laboratory. Measurements of tape mounts of mercury sulfide and mercury oxide standards were made in the transmission mode. SAMMS samples were measured in the fluorescence mode, utilizing the Stern/Heald configuration while simultaneously monitoring the absorption signal of the mercury sulfide reference on the downside of the experiment to allow investigation of the valence state of mercury in the sample. Data were reduced and analyzed according to recommended procedures (Stern and Heald 1979; Sayers and Bunker 1988). The National Synchrotron Light Source is supported by the U. S. Department of Energy, Office of Energy Research, Division of Materials Sciences and Division of Chemical Sciences.

A schematic of the proposed structure is illustrated in Figure 3.4C. When the mercury binds to the thiol group, the mercury-S and mercury-O bond lengths are $2.4 \pm 0.01 \AA$ and $2.14 \pm 0.01 \AA$, respectively. The mercury atoms on the two adjacent thiol groups are linked by the same oxygen atom with a mercury-mercury separation of $3.99 \pm 0.05 \AA$, and the bond angle of mercury-O-mercury is calculated to be $137^{\circ}$. 


\subsection{Characteristics of SAMMS Materials}

The SAMMS materials used for this study were from two batches of synthesized materials at Pacific Northwest National Laboratory (PNNL). The first batch of materials, labeled as SAMMS \#1, has about $25 \%$ surface coverage with functional groups; the second batch of the materials (SAMMS \#2) has a functional group coverage of over $80 \%$ of its surface. The mercury analysis was performed using a CETAC M-6000A Mercury Analyzer System with a detection limit of $10 \mathrm{ppt}$.

\subsection{Physical Characteristics}

The materials are white powders with a particle size ranging from 5 to $15 \mu \mathrm{m}$; the pore size within the particles is about $5 \mathrm{~nm}$. The surface area measured $871 \mathrm{~m}^{2} / \mathrm{g}$. The measurements of the BET surface area and the pore size were conducted using an Autosorb Degasser (Quantachrome). One of the best commercial mercury absorbers, Duolite GT-73 (referred as GT-73), manufactured by Rohm and Haas Company, was used in this study for comparison with SAMMS, and GT-73 is in the form of polymer beads with a size of over $300 \mu \mathrm{m}$.

\subsection{Mercury Loading}

\subsubsection{Sorption Isotherm Experiment}

In this experiment, $\mathrm{NaNO}_{3}$ was added to give a $0.1 \mathrm{M}$ of $\mathrm{Na}^{+}$concentration to ensure a rigorous test of selectivity. In the experiment, a 10-mg sample of SAMMS \#2 was added to 50-mL polypropylene centrifuge tubes containing variable amounts of $0.1 \mathrm{M} \mathrm{NaNO}_{3}$ solution. An aliquot containing a different amount of $0.1 \mathrm{M} \mathrm{Hg}\left(\mathrm{NO}_{3}\right)_{2}$ was added to each centrifuge tube containing the SAMMS \#2 to obtain initial mercury concentrations of 0 to $2.0 \cdot 10^{-3} \mathrm{mg} / \mathrm{L}$. The final volume of the solutions in each test was $50 \mathrm{~mL}$. The slurries were then shaken for 4 hours to reach equilibrium (see Section 4.3) before they were filtered. The filtrates were analyzed for $\mathrm{pH}$ and total mercury. The test at each mercury concentration was conducted in triplicate, and the sorption isotherm experiment was also performed using $\mathrm{HgCl}_{2}$.

The equilibrium mercury-loading capacity depends on the mercury concentrations in the liquid phase. Figure 4.1 illustrates the loading capacities of SAMMS \#2 in $0.1 \mathrm{M} \mathrm{NaNO}_{3}$ solutions containing different amounts of mercury. The equilibrium capacities changed from $83 \mathrm{mg} / \mathrm{g}$ at $0.24 \mathrm{ppb}$ of mercury to $635 \mathrm{mg} / \mathrm{g}$ at $670 \mathrm{ppm}$ of mercury in the form of $\mathrm{Hg}^{2+}$ (Figure $4.1 \mathrm{a}$ and Table 4.1). The loading capacity for $\mathrm{HgCl}_{2}$ (Figure 4.1b and Table 4.2) is slightly lower than that for $\mathrm{Hg}\left(\mathrm{NO}_{3}\right)_{2}$. For instance, the loadings for $\mathrm{HgCl}_{2}$ at a mercury concentration of $171 \mathrm{ppm}$ is $500 \mathrm{mg} / \mathrm{g}$. Mercury loading for $\mathrm{Hg}\left(\mathrm{NO}_{3}\right)_{2}$ is $610 \mathrm{mg} / \mathrm{g}$ at the same mercury concentration. The mercury-loading capacity in pump oil was measured only on SAMMS \#1 with a value of $1.2 \mathrm{mg} / \mathrm{g}$ at a mercury concentration of $0.635 \mathrm{ppm}$. 


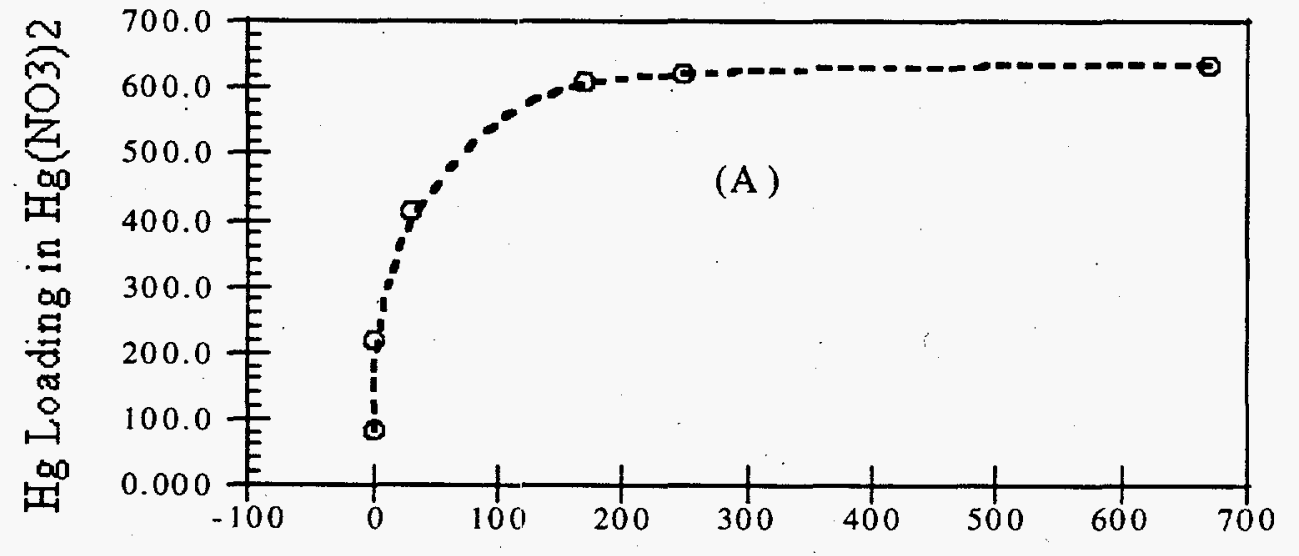

Equilibrium $\mathrm{Hg}$ Concentration, $\mathrm{mg} / \mathrm{L}$

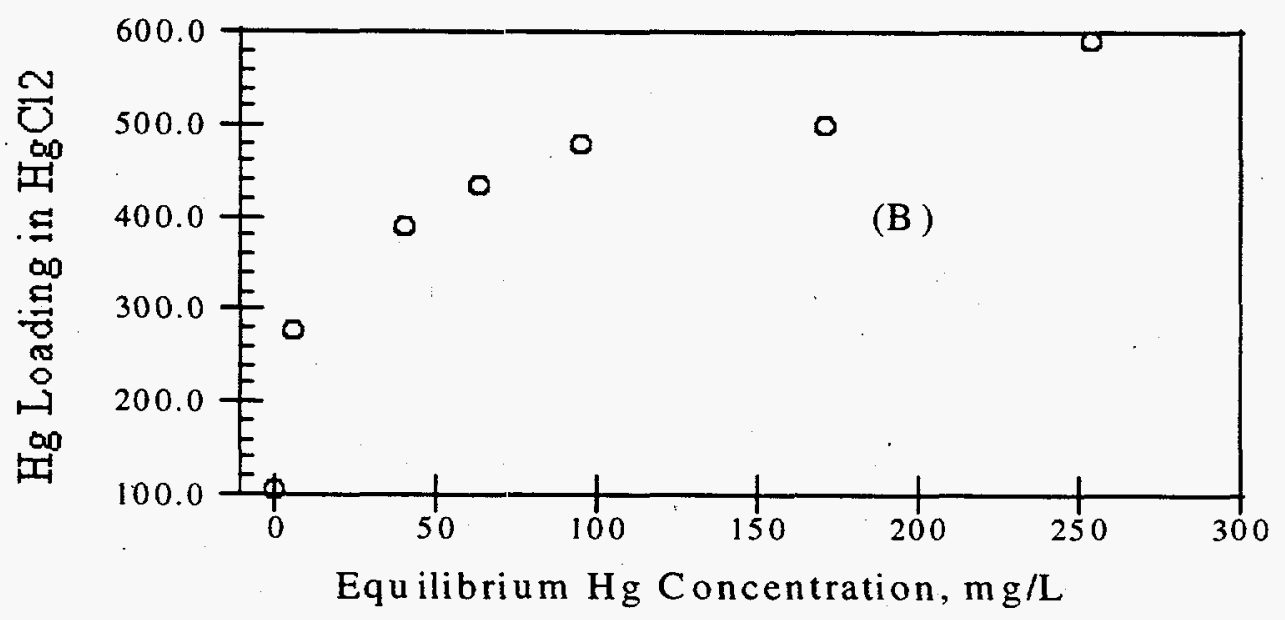

Figure 4.1. Equilibrium Mercury Loading of SAMMS \#2: (A) for $\mathrm{Hg}^{2}+$; (B) for $\mathrm{HgCl}_{2}$ 
Table 4.1. Equilibrium Mercury Loading in $\mathrm{Hg}\left(\mathrm{NO}_{3}\right)_{2}$ Solutions

\begin{tabular}{|l|c|c|c|c|c|}
\hline SAMMS & $\mathbf{p H}_{\mathrm{Ini}}$ & $\mathbf{p H}$ & $\mathbf{H g}$ Conc. $\mathbf{m g} / \mathrm{L}$ & Loading, $\mathbf{m g} \mathbf{H g} / \mathbf{g}$ & In Liquids \\
\hline$\# 2$ & $\mathrm{NA}$ & $\mathrm{NA}$ & 0.00024 & 83.00 & $0.1 \mathrm{M} \mathrm{NaNO}_{3}$ \\
\hline$\# 2$ & 3.43 & 3.35 & 1.3 & 218 & $0.1 \mathrm{M} \mathrm{NaNO}_{3}$ \\
\hline$\# 2$ & 3.28 & 3.08 & 30 & 415 & $0.1 \mathrm{M} \mathrm{NaNO}_{3}$ \\
\hline$\# 2$ & 2.98 & 2.81 & 170 & 610 & $0.1 \mathrm{M} \mathrm{NaNO}_{3}$ \\
\hline$\# 2$ & 2.90 & 2.73 & 250 & 621 & $0.1 \mathrm{M} \mathrm{NaNO}_{3}$ \\
\hline$\# 2$ & NA & NA & 670 & 635 & $0.1 \mathrm{M} \mathrm{NaNO}_{3}$ \\
\hline$\# 1 *$ & NA & NA & 0.635 & 1.2 & pump oil \\
\hline$\# 1 *$ & NA & NA & 0.066 & 0.24 & pump oil \\
\hline
\end{tabular}

* The contact time of SAMMS \#1 with pump oils was limited to two hours at room temperature; these data may not represent equilibrium data. $\mathrm{NA}=$ Not $A$ vailable

Table 4.2. Equilibrium Mercury Loadings in $\mathrm{HgCl}_{2}$ Solutions

\begin{tabular}{|l|c|c|c|c|c|}
\hline SAMMS & $\mathbf{p H}_{\mathbf{l n i}}$ & $\mathbf{p H}_{\text {Fin }}$ & Hg Conc. $\mathbf{m g} / \mathbf{L}$ & Loading, $\mathbf{~ m g ~ H g} / \mathbf{g}$ & $\mathbf{K d}$ \\
\hline$\# 2$ & 4.06 & 3.73 & 0.00 & 105.00 & $1 . \mathrm{E}+08$ \\
\hline$\# 2$ & 3.63 & 3.33 & 6.00 & 277.00 & 46083 \\
\hline$\# 2$ & 3.35 & 3.10 & 40.67 & 389.00 & 9570 \\
\hline$\# 2$ & 3.22 & 3.01 & 63.70 & 434.00 & 6813 \\
\hline$\# 2$ & 3.12 & 2.95 & 95.10 & 480.00 & 5042 \\
\hline$\# 2$ & 2.94 & 2.83 & 171.00 & 500.00 & 2924 \\
\hline$\# 2$ & 2.83 & 2.73 & 254.00 & 593.00 & 2336 \\
\hline
\end{tabular}


The mercury absorption in $0.1 \mathrm{M} \mathrm{NaNO}_{3}$ solutions exhibited a Langmuri isotherm curve (Figure 4.1a) and showed an excellent fit $\left(\mathrm{R}^{2}=0.999\right)$ to the Langmuri isotherm equation (Figure 4.2a), which follows the general form:

$$
\frac{C}{Q}=\frac{1}{K}+\frac{C}{b}
$$

where $C$ is the equilibrium concentration of mercury $(\mathrm{mg} / \mathrm{L}), \mathrm{Q}$ is the mercury equilibrium loading on SAMMS ( $\mathrm{mg} / \mathrm{g}), \mathrm{K}$ is the Langmuri adsorption constant $(\mathrm{g} / \mathrm{L})$, and $\mathrm{b}$ is the maximum amount of mercury that can be bound by SAMMS (mg/L). Fitting by least-square yields a value for $\mathrm{K}$ of $61.4 \mathrm{~g} / \mathrm{L}$ and a value for $b$ of $650 \mathrm{mg} / \mathrm{L}$.

The perfect fit to a Langmuri Isotherm curve may suggest a monolayer adsorption of mercury on the SAMMS surface, which is consistent with the molecular structure shown in Figure 3.4 with SAMMS over $76 \%$ surface coverage as derived from the NMR and EXAFS study discussed in Section 3.3. The maximum loading of $650 \mathrm{mg} / \mathrm{L}$ deternined from the Langmuri Isothermo equation (4.1) is also consistent with the observed maximum loading of $635 \mathrm{mg} / \mathrm{L}$.

\subsection{Binding Kinetics}

\subsubsection{Kinetic Experiments}

The experiments involved two total mercury concentrations of $\sim 0.5$ and $10 \mathrm{mg} / \mathrm{L}$ in $0.1 \mathrm{M} \mathrm{NaNO}_{3}$. A total of $0.24 \mathrm{~g}$ of SAMMS \#2 or Duolite GT-73 was weighed into $500-\mathrm{mL}$ bottles. In each test, $500 \mathrm{~mL}$ of the mercury solution was used. The solution to SAMMS ratio was approximately $2080 \mathrm{~mL} / \mathrm{g}$ in each test. The bottles containing these slurries were shaken at room temperature for 8 hours. From each bottle, a $10-\mathrm{mL}$ aliquot of the well-mixed slurry was collected at time intervals of $5,10,30,60,180,360$, and 480 minutes, and the aliquots were filtered immediately using a $10-\mathrm{mL}$ plastic syringe mounted on a filter holder containing a $0.2-\mu \mathrm{m}$ membrane filter. The filtrates were analyzed for total mercury concentration. A set of mercury solutions without the addition of any SAMMS was also treated in the same way as the SAMMS solutions to serve as blanks.

For a 500-ppb mercury solution (Figure 4.3a), SAMMS, at a solution-to-SAMMS ratio of 2080, reduced its concentration to $0.5 \mathrm{ppb}$ within 5 minutes, and reduced to $10 \mathrm{ppt}$ within 6 hours.

Figure 4.3b shows that SAMMS, at a solution-to-SAMMS ratio of 2080, reduced the 10-ppm mercury concentration to $3.1 \mathrm{ppb}$ within 5 minutes, to $1.6 \mathrm{ppb}$ in 10 minutes, and then stabilized at about $1.2 \mathrm{ppb}$. The corresponding behavior of the commercial mercury absorber, GT-73, also is shown in Figure 4.3. The curves in Figure 4.3a have not indicated an equilibrium (the 10-ppt detection limits of mercury analysis limited our ability to see concentration difference netween the last two data points for SAMMS), especially for GT-73. A longer test duration, such as 24 hours, may be needed for future study. 

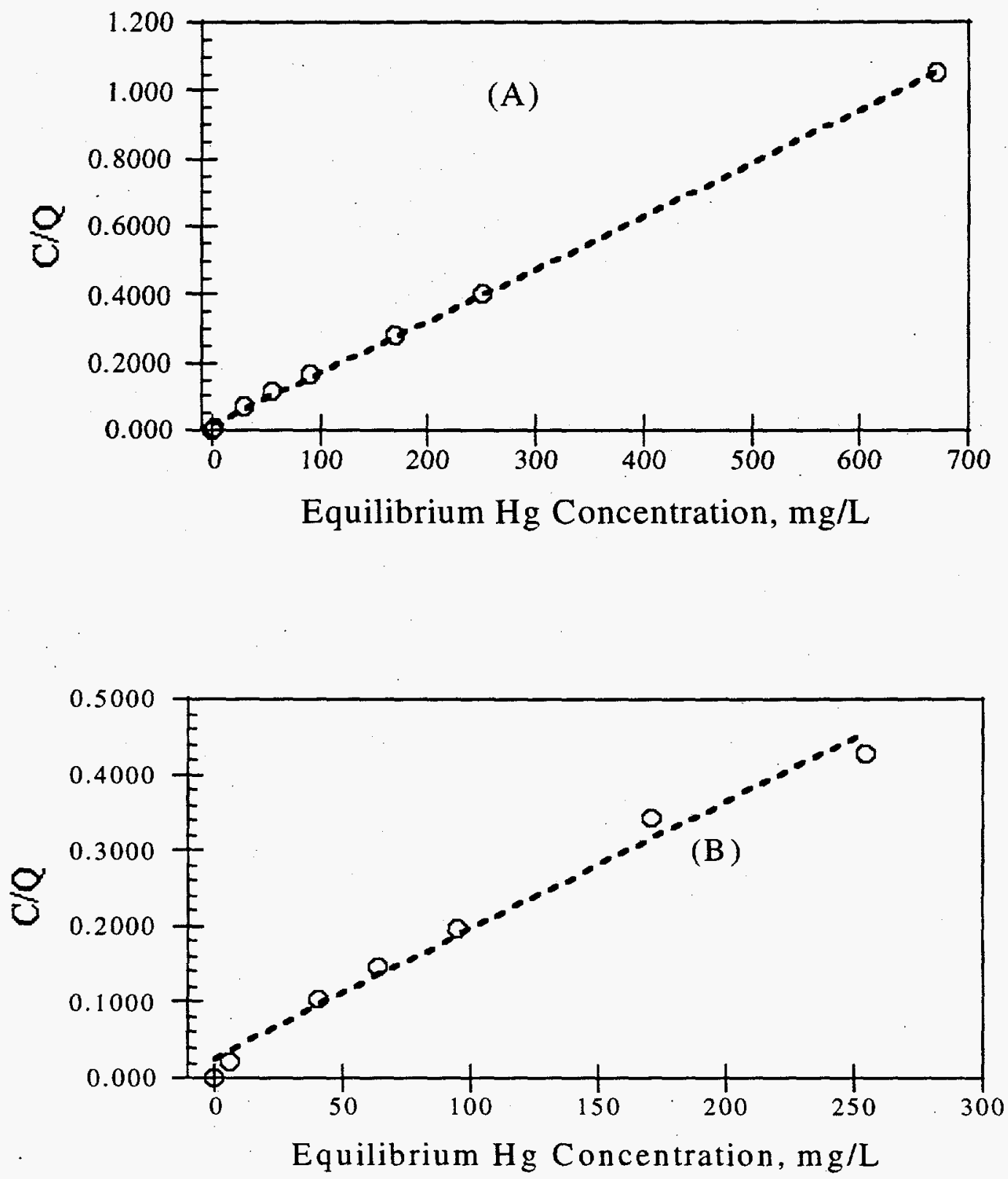

Figure 4.2. Langmur Isotherm Fitting of SAMMS\#2: (A) $\mathrm{Hg}^{2}+$; (B) for $\mathrm{HgCl}_{2}$ 

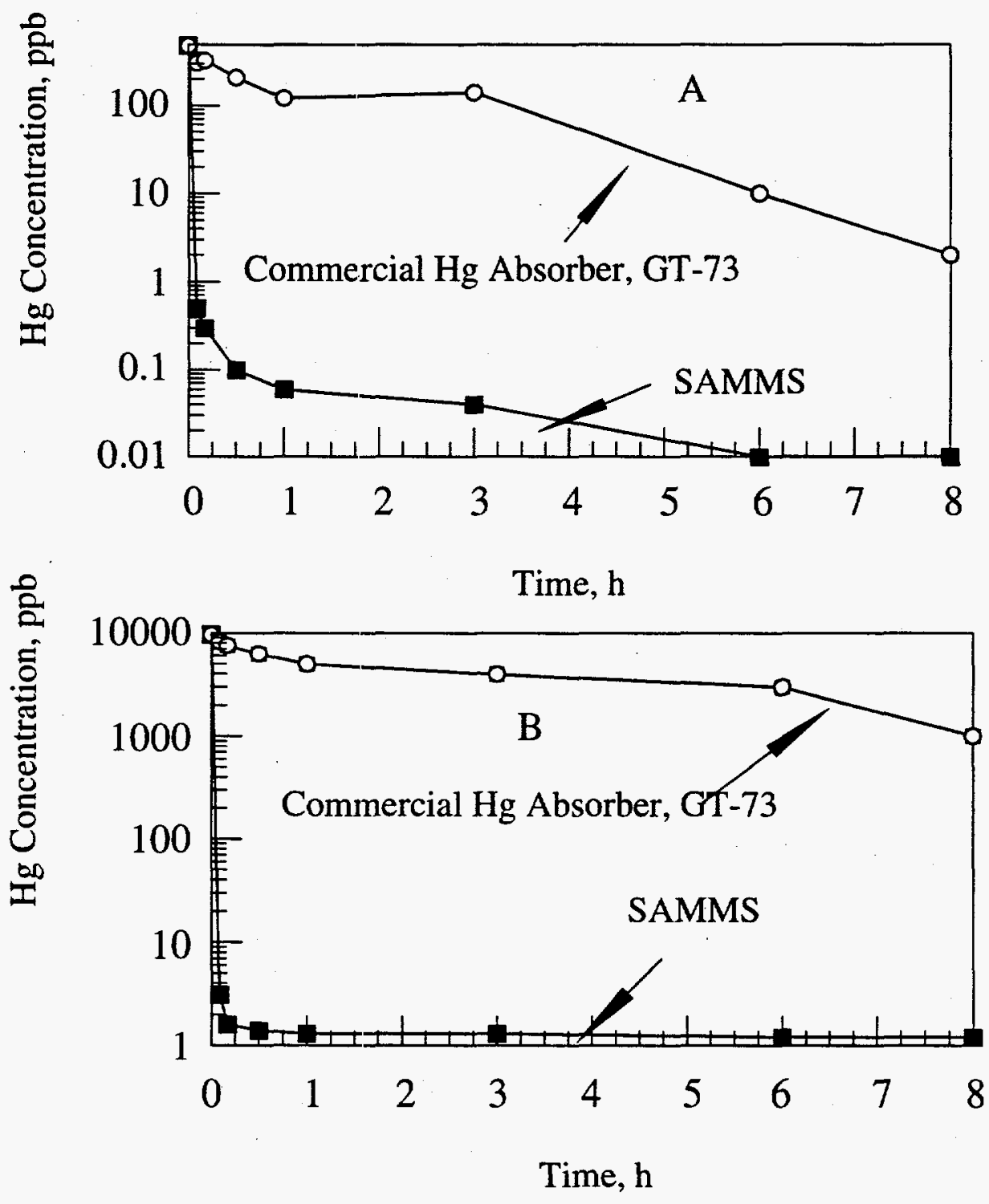

Figure 4.3. SAMMS Mercury Binding Kinetics: (A) in 500 ppn Mercury solution; (B) in 10.0 ppm Mercury Solution 
From the practical point of view, the mercury binding of SAMMS is fast, and the current data yielded a near-zero time dependance of the binding kinetics. Shorter time durations are needed to derive the binding kinetics of SAMMS within the first 5 minutes of contact with mercury solutions.

Table 4.3 shows that the mercury distribution coefficient, $\mathrm{Kd}$, values are up to $10^{8}$ in aqueous solutions containing $0.1 \mathrm{M} \mathrm{NaNO}_{3}$. The $\mathrm{Kd}$ was calculated through the concentration differences before and after mercury binding to SAMMS and the amount of mercury bound to SAMMS as follows:

$$
K d=\frac{\left(C_{0}-C\right) V}{C m}
$$

where

$\mathrm{C}_{0}=$ initial mercury concentration in $\mu \mathrm{g} / \mathrm{mL}$

$\mathrm{C}=$ mercury concentration after contacting the solution with SAMMS in $\mu \mathrm{g} / \mathrm{mL}$

$\mathrm{V}=$ volume of the mercury solution that is in contact with SAMMS in $\mathrm{mL}$

$\mathrm{m}=$ dry mass of the SAMMS used in $\mathrm{g}$

Table 4.3. SAMMS \#2 Mercury Binding Kd Values as a Function of Mercury Concentrations

\begin{tabular}{|c|c|c|c|c|}
\hline Initial Hg, $\mathbf{~ g / L}$ & Final Hg, $\mathbf{~ g / L}$ & Hg solution, $\mathbf{~ L ~}$ & SAMMS \#2, & Kd \\
\hline 0.487 & 0.00 & 500.00 & 0.24 & $1.01 \cdot 10^{8}$ \\
\hline 9.70 & 0.0012 & 500.00 & 0.24 & $1.68 \cdot 10^{7}$ \\
\hline 974 & 669 & 500.00 & 0.24 & 950.00 \\
\hline
\end{tabular}

$\mathrm{Kd}$ values are a function of intial mercury concentration, solution volume, mass of absorbents, and the detection limit. The $\mathrm{Kd}$ value in Table 4.3 could be higher than $1.01 \cdot 10^{8}$ if the ercury detection limit were lower than 10 ppt.

\subsection{Binding Speciations}

The discussion in the Introduction Section showed that mercury contamination involves multiple speciations of mercury. To test the ability of SAMMS in binding to many different speciations of mercury, SAMMS was tested with cationic ions $\mathrm{Hg}^{2+}$, complex $\mathrm{HgCl}_{2}$, organic $\mathrm{CH}_{3}-\mathrm{Hg}-\mathrm{OH}$, and metallic mercury.

Binding to cationic $\mathrm{Hg}^{2+}$, and complex $\mathrm{HgCl}_{2}$ : The data in Sections 4.2 and 4.3 showed that SAMMS bonds effectively to cationic $\mathrm{Hg}^{2+}$ and complex $\mathrm{HgCl}_{2}$. In solutions with $\mathrm{pH}$ higher than 4, the possible mercury speciations are $\mathrm{Hg}(\mathrm{OH})_{2}$ and $\mathrm{Hg}(\mathrm{OH})^{+}$according to Baes and Mesmer (Baes 1976). The $\mathrm{Hg}(\mathrm{OH})^{+}$species in a $\mathrm{Hg}\left(\mathrm{NO}_{3}\right)_{2}$ solution may be the main contributor to the rection with SAMMS through the following binding reactions: 


$$
\begin{gathered}
H g(\mathrm{OH})^{+}+\mathrm{H}-\mathrm{S}-\mathrm{SAMMS}=\mathrm{HO}-\mathrm{Hg}-\mathrm{S}-\mathrm{SAMMS}+\mathrm{H}^{+} \\
M M S-\mathrm{S}-\mathrm{Hg}-\mathrm{OH}+\mathrm{HO}-\mathrm{Hg}-\mathrm{S}-\mathrm{SAMMS}=\mathrm{SAMMS}-\mathrm{S}-\mathrm{Hg}-\mathrm{O}-\mathrm{Hg}-\mathrm{S}-\mathrm{SAMMS}+\mathrm{H}_{2} \mathrm{O}
\end{gathered}
$$

The above reactions are consistent with the observed $\mathrm{pH}$ (Table 4.1) decreasing due to the release of hydronium ions in Reaction (3) while $\mathrm{Hg}(\mathrm{OH})_{2}$ reacting with HS-SAMMS does not result in a change of $\mathrm{pH}$ since only neutral $\mathrm{H}_{2} \mathrm{O}$ is reduced in the reaction. The final products with an oxo bridge $(\mathrm{Hg}-\mathrm{O}-\mathrm{Hg})$ formation on the surface of SAMMS shown in Reaction (4) are in agreement with the EXAFS measurements discussed in Section 3.3. In a $\mathrm{HgCl}_{2}$ solution containing $0.1 \mathrm{~m} \mathrm{NaNO}_{3}$, there is the following equilibria:

$$
\begin{gathered}
\mathrm{HgCl}_{2}+\mathrm{H}_{2} \mathrm{O}=\mathrm{Hg}(\mathrm{OH}) \mathrm{Cl}+\mathrm{H}^{+}+\mathrm{Cl}^{-} \\
\mathrm{HgCl}_{2}+\mathrm{H}_{2} \mathrm{O}=\mathrm{Hg}(\mathrm{OH})^{+}+\mathrm{H}^{+}+2 \mathrm{Cl}^{-}
\end{gathered}
$$

The $\mathrm{Hg}(\mathrm{OH})^{+}$species formed in Reaction (6) effectively binds to SAMMS through Reactions (3) and (4) as discussed above because we observed similar $\mathrm{pH}$ decreasing after SAMMS bound to mercury as in $\mathrm{Hg}\left(\mathrm{NO}_{3}\right)_{2}$ solutions. The $\mathrm{Hg}(\mathrm{OH}) \mathrm{Cl}$ species may also react with SAMMS through

$$
\begin{gathered}
\mathrm{Hg}(\mathrm{OH}) \mathrm{Cl}+\mathrm{H}-\mathrm{S}-\mathrm{SAMMS}=\mathrm{HO}-\mathrm{Hg}-\mathrm{S}-\mathrm{SAMMS}+\mathrm{H}^{+}+\mathrm{Cl}^{-} \\
\mathrm{Hg}(\mathrm{OH}) \mathrm{Cl}+\mathrm{H}-\mathrm{S}-\mathrm{SAMMS}=\mathrm{Cl}-\mathrm{Hg}-\mathrm{S}-\mathrm{SAMMS}+\mathrm{H}_{2} \mathrm{O}
\end{gathered}
$$

Reaction (7) resulted in the same product of that in Reaction (3) and is also consistent with the observed solution $\mathrm{pH}$ decrease shown in Table 4.2. The mercury binding in $\mathrm{HgCl}_{2}$ also showed a good Langmur Isotherm behavior (Figure 4.2b) with a least squre fitting of $R^{2}=0.9821, k=41.3 \mathrm{~g} / \mathrm{L}$, and $\mathrm{b}=588 \mathrm{mg} / \mathrm{g}$. Reaction (8) can be ruled out because of the inconsistency with the observed solution $\mathrm{pH}$ decreasing, although $\mathrm{Hg}(\mathrm{OH}) \mathrm{Cl}$ is the major species in the solution (Baes 1976). The different products on the SAMMS surface may be futher verified through surface studies using NMR and EXAFS.

Binding to Organic Mercury: Methylmercury, the most toxic form, is formed mainly by methylation of mercury by the methanogenic bacteria that are widely distributed in the sediments of ponds and in the sludge of sewage beds. Methylmercury can accumulate in fish in contaminated waterways. Mercury poisoning symptoms in humans includes digestion disturbances, emaciation, diarea, speech stammering, delirium, paralysis of the arms and legs, and death by exhaustion. The recently reported tragic death of a university researcher who was using methylmercury is a graphic illustration of the toxicity of this compound (Blayney et al, 1997). 
SAMMS was tested in solutions containing the most common and toxic methylmercury compound, $\mathrm{CH}_{3}-\mathrm{Hg}-\mathrm{OH}$, that is often found in groundwater. A $10-\mathrm{mg}$ sample of SAMMS \#2 was added into 50-mL polypropylene centrifuge tubes containing variable amounts of $0.1 \mathrm{M} \mathrm{NaNO}_{3}$ solution. An aliquot containing a different amount of $\mathrm{CH}_{3}-\mathrm{Hg}-\mathrm{OH}$ was added to each centrifuge tube containing the SAMMS \#2 and also to centrifuge tubes containing no SAMMS to obtain initial organic mercury concentrations. The final volume of the solution in each test was $50 \mathrm{~mL}$. The tubes were then shaken for 4 hours before they were filtered. The filtrates are analyzed for $\mathrm{pH}$ and total mercury.

The data in Table 4.4 show that SAMMS removed methylmercury from simulated waste containing $0.1 \mathrm{M} \mathrm{NaNO}_{3}$, decreasing the $\mathrm{Hg}$ concentration from $11.9 \mathrm{ppm}$ down to $70 \mathrm{ppb}$ at a ratio of solution volume to SAMMS of 5000. The mercury loading on SAMMS from methylmercury was as high as $566 \mathrm{~m} / \mathrm{g}$ of SAMMS, which is close to the mercury loading in $\mathrm{Hg}\left(\mathrm{NO}_{3}\right)_{2}$ solutions. The isothermo absorption curve is shown in Figure 4.4, which shows that the binding of organic mercury is close to a Langmuri Isotherm behavior at low mercury concentration. The behavior deviates from Langmuri behavior when the mercury concentration is higher. Another distinct difference between the mercury binding in $\mathrm{Hg}\left(\mathrm{NO}_{3}\right)_{2} / \mathrm{HgCl}_{2}$ and in $\mathrm{HgCH}_{3} \mathrm{OH}$ is the $\mathrm{pH}$ differences of the final solutions. The final solution $\mathrm{pH}$ went down as SAMMS bound to mercury in $\mathrm{Hg}\left(\mathrm{NO}_{3}\right)_{2} / \mathrm{HgCl}_{2}$. The solution $\mathrm{pH}$ went up substantially when SAMMS bound organic $\mathrm{HgCH}_{3} \mathrm{OH}$ at higher organic mercury concentrations as shown in Table 4.4. This may be explained by the folowing reactions according to Schwarzenbach and Schellenberg (Schwarzenbach and Schellenberg 1965):

$$
\mathrm{CH}_{3}-\mathrm{Hg}-\mathrm{OH}=\mathrm{CH}_{3} \mathrm{Hg}^{+}+\mathrm{OH}^{-}
$$

Table 4.4. SAMMS Binding with Organic Mercury, $\mathrm{CH}_{3}-\mathrm{Hg}-\mathrm{OH}$

\begin{tabular}{|c|c|c|c|c|c|}
\hline $\mathbf{H g}_{\text {Ini }}, \mathbf{p p m}$ & $\mathbf{H g}_{\text {Fin }}, \mathbf{p p m}$ & $\mathbf{p H}_{\mathbf{I n i}}$ & $\mathbf{p H}_{\text {Fin }}$ & $\mathbf{K d}$ & Loading $\mathbf{~ m g} / \mathbf{g}$ \\
\hline 11.9 & 0.07 & 5.50 & 5.11 & 788000 & 59 \\
\hline 38.7 & 0.29 & 5.81 & 5.20 & 658000 & 192 \\
\hline 98.1 & 14.8 & 6.03 & 6.79 & 28300 & 417 \\
\hline 148.0 & 36.8 & 6.13 & 7.08 & 15100 & 556 \\
\hline 187.0 & 73.8 & 6.16 & 7.43 & 7700 & 566 \\
\hline 253.0 & 183.1 & 6.31 & 7.71 & 1900 & 350 \\
\hline 362.7 & 288.0 & 6.41 & 7.86 & 1300 & 373 \\
\hline
\end{tabular}

At low mercury concentration, the Reaction (9) goes to almost completion and little unassociated $\mathrm{CH}_{3}-\mathrm{Hg}-\mathrm{OH}$ is left in solution. The initial $\mathrm{pH}$ is, therefore, the result of the dissociation of $\mathrm{CH}_{3}-\mathrm{Hg}-\mathrm{OH}$ in the $0.1 \mathrm{M} \mathrm{NaNO}_{3}$ solution. The $\mathrm{CH}_{3} \mathrm{Hg}^{+}$formed in Reaction (9) reacts with SAMMS through

$$
\mathrm{CH}_{3} \mathrm{Hg}^{+}+\mathrm{H}-\mathrm{S}-\mathrm{SAMMS}=\mathrm{CH}_{3}-\mathrm{Hg}-\mathrm{S}-\mathrm{SAMMS}+\mathrm{H}^{+}
$$




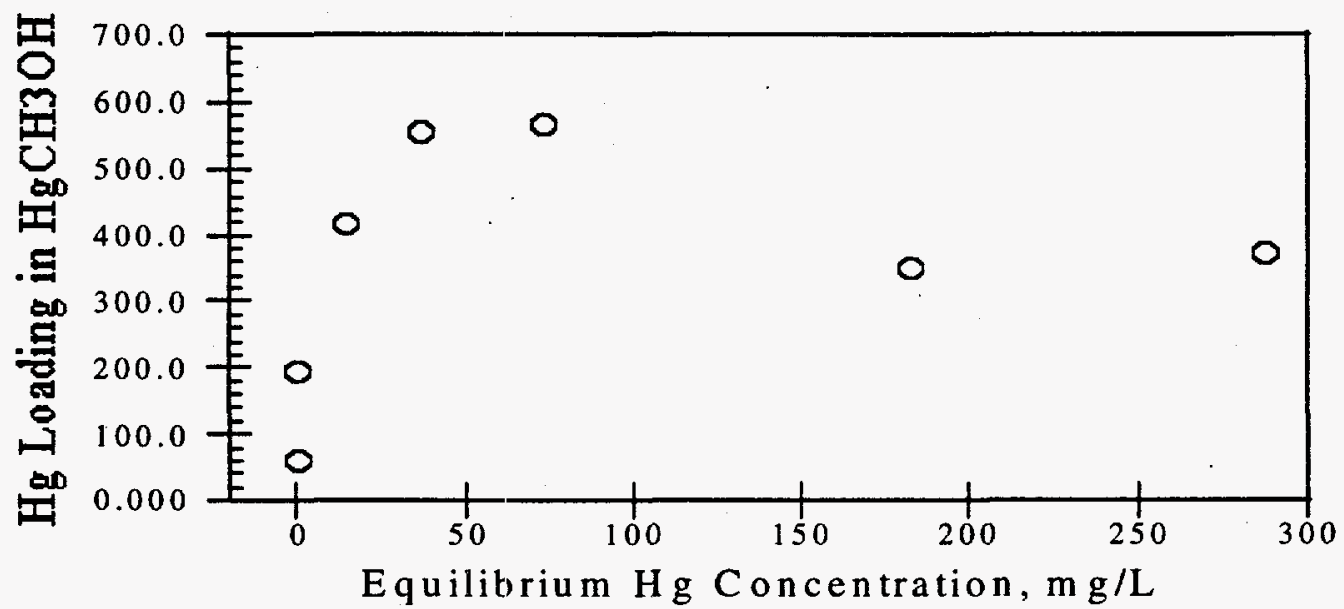

Figure 4.4. SAMMS's Mercury Loading in $\mathrm{CH}_{3} \mathrm{HgOH}$

As a result of Reaction (10), we observed the solution $\mathrm{pH}$ decrease when the organic mercury concentrations were low as shown in Table 4.4.

When the concentration of methylmercury is higer, the following reaction becomes significant (Schwarzenbach and Schellenberg 1965):

$$
\mathrm{CH}_{3} \mathrm{Hg}^{+}+\mathrm{CH}_{3} \mathrm{Hg}^{+}+\mathrm{OH}^{-}=\left(\mathrm{CH}_{3} \mathrm{Hg}\right)_{2} \mathrm{OH}^{+}
$$

As a result of Reaction (11), a high concentration of $\mathrm{OH}$ associated in the $\left(\mathrm{CH}_{3} \mathrm{Hg}\right)_{2} \mathrm{OH}^{+}$species. When SAMMS was added to the above reaction mixture, the SAMMS reacted with $\mathrm{CH}_{3} \mathrm{Hg}^{+}$through Reaction (10), resulting in the release of hydronium ions. At the same time, the consumption of $\mathrm{CH}_{3} \mathrm{Hg}^{+}$ had an even larger effect on the equilibrium of Reaction (11) since the equilirium (11) depends on the square term of $\mathrm{CH}_{3} \mathrm{Hg}^{+}$concentration. This means the back reaction of equilibrium (11) \{i.e., the dissociation of $\left.\left(\mathrm{CH}_{3} \mathrm{Hg}\right)_{2} \mathrm{OH}^{+}\right\}$resulted in more hydroxyl ion release than the hydronium ion release from Reaction (10) upon the same change in concentration of $\mathrm{CH}_{3} \mathrm{Hg}^{+}$. The net result was solution $\mathrm{pH}$ increase after adding SAMMS. This also promotes the dissociation of $\left(\mathrm{CH}_{3} \mathrm{Hg}\right)_{2} \mathrm{OH}^{+}$through the reverse of Reaction (11), which increases the solution $\mathrm{pH}$. There may be also other possiblities, such as the following: SAMMS binds to some complexed hydroxyl methylmercury complex, which releases hydroxyl ions instead of hydronium ions to account for the observed solution $\mathrm{pH}$ increase upon adding SAMMS. Some of the methylmercury bound SAMMS are being studied using NMR to see what species was bound to SAMMS in the methylmercury solution to help understand the reaction between SAMMS and methylmercury.

Binding to Metallic Mercury: Metallic mercury was reacted with SAMMS \#2 under four different conditions: 1) metallic liquid mercury directly contacts with dry SAMMS, 2) metallic mercury vapor contacts with dry SAMMS, 3) metallic liquid mercury directly contacts with SAMMS in aqueous solution, 
4) metallic liquid mercury contacts with an aqueous solution that is in contact with the SAMMS powders contained in a membrane bag (i.e., metallic mercury and SAMMS powders were not in direct contact).

In condition 1, where metallic mercury direct contacts with dry SAMMS, a 0.25 -g sample of SAMMS \#2 was mixed with $0.5 \mathrm{~g}$ metallic mercury using a stir bar within a flask for 3 days. The SAMMS powders changed color from white to grey during this period. At the end of 3 days, distilled water was added into the flask. Some of the SAMMS were found to float on top of the solutions and some of them sinked to the bottom of the solution together with some unreacted mercury.

The SAMMS floating on the top of the solution were separated from the unreacted mercury. The floated SAMMS were collected and dried in a hood at room temperature overnight. A total of $0.2076 \mathrm{~g}$ of the dried SAMMS powders was treated with $8 \mathrm{~mL}$ concentrated $\mathrm{HCl}$, and the solution was analyzed and found to have a mercury concentration of $210 \mathrm{ppm}$, which is equivalent to $8 \mathrm{mg} \mathrm{Hg} / \mathrm{g}$. It is noted that analyzing only the floated SAMMS is not the accurate way to represent the SAMMS binding capacity because the SAMMS powders that absorbed most of the $\mathrm{Hg}^{2+}$ in mercury salt solutions are those SAMMS that sank to the bottom of the aqueous solution. The floating SAMMS did not have high mercury loading because of insufficient contact with the wastes. The SAMMS that sank to the bottom of the solution was difficult to separate from the unreacted mercury, so it has not been analyzed.

In condition 2 , mercury vapor was generated from a distillation flask that was connected to another flask containing dry SAMMS \#2 powders. The flasks were open to each other and were placed in a $50^{\circ} \mathrm{C}$ water bath to generate low mercury vapor to react with SAMMS for 2 days. The reacted SAMMS was then heated in a mercury-free atmosphere at $60^{\circ} \mathrm{C}$ to desorb the physically adsorbed mercury. A sample of $0.0821 \mathrm{~g}$ of the the SAMMS powders was then treated with $8 \mathrm{~mL} \mathrm{HCl}$ and generated a solution containing $10 \mathrm{ppm}$ mercury, which corresponds to $1 \mathrm{mg}$ mercury/g of SAMMS. The low mercury loading may be due to insufficient mercury vapor generated during the $50^{\circ} \mathrm{C}$ experiment or due to inability of SAMMS binding to metallic mercury in an oxygen-free environment.

In condition 3; where metallic mercury directly contacted with SAMMS in aqueous solution, a 0.1 g sample of metallic mercury was combined with $0.5 \mathrm{~g}$ SAMMS \#2 powders in 125 -mL bottles; then, a $100-\mathrm{ml}$ solution of $0.1 \mathrm{M} \mathrm{NaNO}_{3}$ was added into the bottles. The metallic mercury inside the bottle was broken down using ultrasonification, and the reaction was allowed to proceed for 3 days at room temperature. At the end of 3 days, the SAMMS floating on the top of the solution and that which sank to the bottom were separated, and mercury was extracted with concentrated $\mathrm{HCl}$. A control test was carried out in the same way without SAMMS. The aqueous solutions from both SAMMS samples and control were analyzed for mercury. The control showed a mercury concentration of $62.5 \mathrm{ppb}$, which is close to the metallic mercury solubility in water. The mercury concentration was below the detection limit of $10 \mathrm{ppt}$ in the SAMMS sample solution. This result suggests that the presence of SAMMS can effectively remove mercury from water at the presence of metallic mercury. It is expected that the metallic mercury at the bottom of ponds or rivers could be eventually transferred to SAMMS if sufficient time and sufficient amounts of SAMMS are provided and the SAMMS can maintain these water with a mercury contents below drinking water standards at all times. A sample of $0.0836 \mathrm{~g}$ of the floating SAMMS was treated with $8.0 \mathrm{~mL}$ of concentrated $\mathrm{HCl}$, and the treated solution was analyzed to have $0.688 \mathrm{ppm}$ mercury. The settled SAMMS powders were washed with $0.1 \mathrm{M} \mathrm{NaNO}_{3}$ solution and dried overnight. A sample of $0.4854 \mathrm{~g}$ of the SAMMS powders was treated with $8.0 \mathrm{~mL}$ of concentrated $\mathrm{HCl}$, and the solution was analyzed to have a mercury concentration of $360 \mathrm{ppm}$, which corresponds to a mercury loading of about 6 $\mathrm{mg} / \mathrm{g}$. 
In condition 4, $0.5 \mathrm{~g}$ of SAMMS \#2 powder was placed in a membrane bag and floated on top of a $0.1 \mathrm{M} \mathrm{NaNO}_{3}$ solution while $0.1 \mathrm{~g}$ metallic mercury was placed at the bottom of the $0.1 \mathrm{M} \mathrm{NaNO}_{3}$ solution. The metallic mercury inside the bottle was broken down using ultrasonification, and the reaction was allowed to proceed for 3 days at room temperature. A control experiment was performed using a membrane bag without SAMMS under the same conditions. At the end of 3 days, the mercury concentrations in the control solution and in the SAMMS solution were analyzed. The control solution had a mercury concentration of about $62.5 \mathrm{ppb}$, which shows that the membrane bag did not sorb mercury. The solutions containing SAMMS bags had a mercury concentration of about 15 and $11 \mathrm{ppb}$, respectively. This result indicates that the SAMMS powders in the bag can also absorb some of the mercury in solution, but it is not effective because most of the SAMMS powders in the membrane bags were essentially dry at the end of the test.

In all conditions, SAMMS bound to mercury with a mercury loading under the test conditions of 1 to $8 \mathrm{mg} / \mathrm{g}$. SAMMS reduced the solubilized mercury in solutions containing metallic mercury below 10 ppt.

\section{5 pH Effects}

It is seen from the above discussion that the binding reaction of SAMMS with mercury may involve release of hydronium ion, which affects solution acidity. It is necessary to study how solution $\mathrm{pH}$ affects the mercury separation of SAMMS, especially waste solutions that exist in a broader range of $\mathrm{pHs}$.

A 10-mg sample of SAMMS \#2 was added by pipetting 2 mL SAMMS working slurry into 50-mL polypropylene centrifuge tubes containing an aliquot of $48 \mathrm{~mL} 0.1 \mathrm{M} \mathrm{NaNO}_{3}$ solutions that were previously spiked with $0.1 \mathrm{M} \mathrm{Hg}\left(\mathrm{NO}_{3}\right)_{2}$ solution to provide an initial total mercury concentration of 0.0001 $\mathrm{M}$ and were adjusted to a range of $\mathrm{pH}$ from 3 to 10 using $0.1 \mathrm{M} \mathrm{HNO}_{3}$ or $\mathrm{NaOH}$. The slurries were then shaken for 4 hours before they were filtered with syringe filters. Each test at each $\mathrm{pH}$ was conducted in duplicate. Control tests at each $\mathrm{pH}$ without SAMMS were also conducted. The solutions were analyzed for $\mathrm{pH}$ and total mercury before and after equilibrium with SAMMS.

The results on $\mathrm{pH}$ effects are summarized in Table 4.5 and Figure 4.5. It clearly shows a pH effect on the mercury binding by SAMMS: SAMMS achieves the highest Kds in the pH range of 5.7 to 6.7 . The $\mathrm{Kd}$ value decreased six times when the solution $\mathrm{pH}$ was increased from $\mathrm{pH} 6.7$ to 9.2. The Kd decreased 48 times when the solution $\mathrm{pH}$ was decreased from 6.7 to 2 . This may be because the thiol group on SAMMS is a weak acid. At pH 6.7, it is almost fully dissociated as an anonic species that is most favorable to react with the positively charged mercury species as:

$$
H g(O H)^{+}+{ }^{-} S-S A M M S=H O-H g-S-S A M M S
$$

At lower $\mathrm{pH}$, the thiol group on SAMMS becomes protonated as a neutral species, and Reaction (12) becomes more difficult. At higher $\mathrm{pH}$, the mercury species become a neutral species such as $\mathrm{Hg}(\mathrm{OH})_{2}$ or negatively charged species such as $\mathrm{Hg}(\mathrm{OH})_{3}{ }^{-}$, and the above reaction is also less effective. 
Table 4.5. pH Effects on SAMMS' Mercury Binding

\begin{tabular}{|c|c|c|c|c|}
\hline $\begin{array}{c}\mathbf{p H} \\
\text { Ini }\end{array}$ & $\begin{array}{c}\mathbf{p H} \\
\mathbf{F i n}\end{array}$ & $\begin{array}{c}\mathbf{C}_{\text {ini }} \\
\mathbf{p p b}\end{array}$ & $\begin{array}{c}\mathbf{C}_{\text {fin }} \\
\mathbf{p p b}\end{array}$ & $\mathbf{K d}$ \\
\hline 2.0 & 2.0 & 19900.0 & 100.3 & $9.9 \mathrm{E}+05$ \\
\hline 3.0 & 2.9 & 19850.0 & 68.5 & $1.4 \mathrm{E}+06$ \\
\hline 4.0 & 4.0 & 19800.0 & 6.8 & $1.5 \mathrm{E}+07$ \\
\hline 4.5 & 4.6 & 19750.0 & 5.2 & $1.9 \mathrm{E}+07$ \\
\hline 5.0 & 5.1 & 19725.0 & 5.8 & $1.7 \mathrm{E}+07$ \\
\hline 6.0 & 5.7 & 19700.0 & 2.5 & $3.9 \mathrm{E}+07$ \\
\hline 7.0 & 6.2 & 19600.0 & 2.5 & $3.9 \mathrm{E}+07$ \\
\hline 8.0 & 6.7 & 19450.0 & 2.0 & $4.8 \mathrm{E}+07$ \\
\hline 9.5 & 7.0 & 19200.0 & 7.6 & $1.3 \mathrm{E}+07$ \\
\hline 10.0 & 9.2 & 18900.0 & 12.5 & $7.6 \mathrm{E}+06$ \\
\hline
\end{tabular}

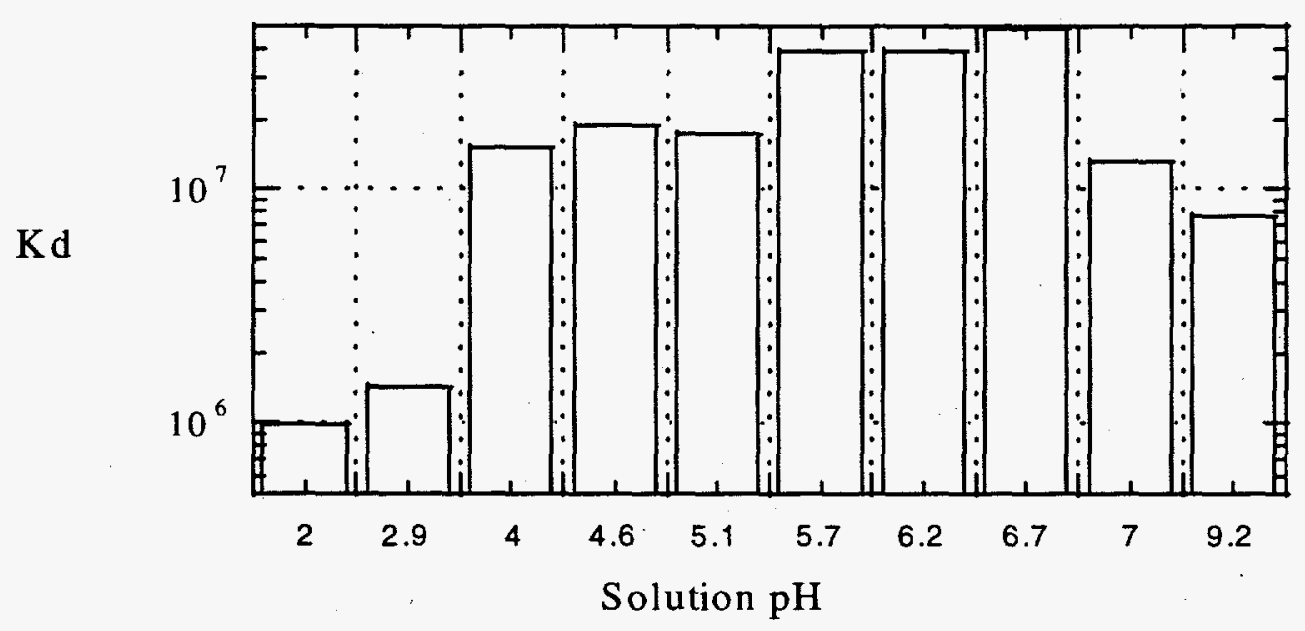

Figure 4.5. $\mathrm{pH}$ Effects on SAMMS' Hg Binding

\subsection{Ionic Strength Effects}

In general, the activities of the thiol groups on the SAMMS and the mercury ions in solutions are affected by solution ionic strength, and the SAMMS's efficiency of binding mercury may also be affected by waste solutions with very different ionic strength, such as low ionic strength groundwater to concentrated salty tank wastes. A $10-\mathrm{mg}$ sample of SAMMS is added by pipetting $2 \mathrm{~mL}$ SAMMS slurry into $50-\mathrm{mL}$ polypropylene centrifuge tubes containing an aliquot of $47.95 \mathrm{~mL}$ of $\mathrm{NaNO}_{3}$ solution (at $\mathrm{pH}$ 5.0) with the concentration ranging from 0 to $4.0 \mathrm{M}$. The slurries are spiked with $0.05 \mathrm{~mL}$ of $0.1 \mathrm{M}$ 
$\mathrm{Hg}\left(\mathrm{NO}_{3}\right)_{2}$ stock solution to provide an initial concentration of $20.8 \mathrm{mg} / \mathrm{L}$. The slurries are then shaken overnight before it is they are filtered with a syringe filter. The experiments were conducted in triplicate. The filtrates are analyzed for total mercury before/after equilibration with SAMMS.

The results are listed in Table 4.6 and Figure 4.6. In comparison with $\mathrm{pH}$ effects, the ionic strength effects on SAMMS's mercury-binding efficiency were much less pronounced. It showed a slightly decreasing $\mathrm{Kd}$ as the ionic strength of the solution was increased from deionized water to $1 \mathrm{M}$ $\mathrm{NaNO}_{3}$ solution. However the $\mathrm{Kd}$ differences are less than a factor of 3 . Furthermore, there were no obvious ionic strength effects on $\mathrm{Kd}$ when the $\mathrm{NaNO}_{3}$ concentration increased from 2 to $4 \mathrm{M}$.

Table 4.6. Ionic Strength Effects on $\mathrm{Hg}$ Binding $\mathrm{Kd}$

\begin{tabular}{|c|c|c|c|c|}
\hline $\begin{array}{c}\mathbf{N a N O} \\
\mathbf{M}\end{array}$ & $\begin{array}{c}\text { Cini } \\
\mathbf{p p b}\end{array}$ & $\begin{array}{c}\mathbf{C f i n} \\
\mathbf{p p b}\end{array}$ & $\begin{array}{c}\mathbf{p H} \\
\text { Final }\end{array}$ & $\mathbf{K d}$ \\
\hline 0.00 & 20800 & 1.9 & 3.4 & $5.47 \mathrm{E}+07$ \\
\hline 0.05 & 20800 & 1.9 & 3.5 & $5.53 \mathrm{E}+07$ \\
\hline 0.10 & 20800 & 2.9 & 3.5 & $3.54 \mathrm{E}+07$ \\
\hline 0.30 & 20800 & 3.2 & 3.6 & $3.25 \mathrm{E}+07$ \\
\hline 0.60 & 20800 & 4.3 & 3.6 & $2.44 \mathrm{E}+07$ \\
\hline 1.00 & 20800 & 5.5 & 3.5 & $1.88 \mathrm{E}+07$ \\
\hline 2.00 & 20800 & 1.9 & 3.4 & $5.47 \mathrm{E}+07$ \\
\hline 3.00 & 20800 & 2.0 & 3.3 & $5.31 \mathrm{E}+07$ \\
\hline 4.00 & 20800 & 1.9 & 3.2 & $5.59 \mathrm{E}+07$ \\
\hline
\end{tabular}

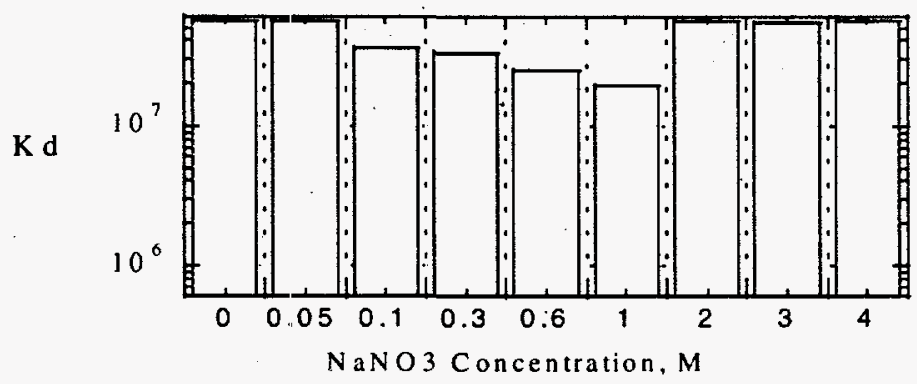

Figure 4.6. Ionic Strength Effects on SAMM S'Hg Binding

\subsection{Cation Effects}

Waste solutions always contain many other cations besides mercury. How the other cations compete with mercury to bind to mercury should depend on the characteristics of each cation. The thiol group HS- on SAMMS is a soft base, and it preferentially binds to soft acids such as $\mathrm{Hg}^{2+}$ and $\mathrm{Hg}(\mathrm{OH})^{+}$. Of course, other soft bases, such as $\mathrm{Ag}^{+}, \mathrm{Cu}^{+}$, and $\mathrm{Cu}^{2+}$, may also compete with mercury to bind the thiol groups that will affect the selectivity of SAMMS for mercury as well as the mercury loadings on SAMMS. 
In this experiment, SAMMS was added to a $0.1 \mathrm{M} \mathrm{NaNO}_{3}$ solution containing an equal molar concentration of mercury and a prospective cation such as $\mathrm{Ca}(\mathrm{II}), \mathrm{Fe}(\mathrm{II}), \mathrm{Pb}$ (II), $\mathrm{Cu}$ (II), $\mathrm{Cd}$ (II), $\mathrm{Ni}(\mathrm{I})$, and $\mathrm{Zn}$ (II) to see how each cation affects SAMMS's behavior in mercury binding. Three additional solutions containing three ( $\mathrm{Cd}, \mathrm{Ni}$, and $\mathrm{Zn})$, four $(\mathrm{Cu}, \mathrm{Pb}, \mathrm{Ca}, \mathrm{Fe})$, and seven $(\mathrm{Ca}, \mathrm{Cd}, \mathrm{Cu}, \mathrm{Fe}, \mathrm{Ni}, \mathrm{Pb}$, and $\mathrm{Zn}$ ) cations with the molar concentration ratio to mercury of 3,4, and 7, respectively, were also prepared. Half of each cation solution was adjusted to $\mathrm{pH} \mathrm{4}$, and the other half were adjusted to $\mathrm{pH} 7$. A 10-mg quantity of SAMMS was added to each $48.5 \mathrm{~mL}$ of the cation solution as $1.5 \mathrm{~mL}$ slurry, and the solution was then shaken for 4 hours before filtration and measurement of final $\mathrm{pH}$. The filtrate was analyzed for mercury. The results are shown in Table 4.7 and Figure 4.7.

In $\mathrm{pH} 7$ solutions, the effectiveness of cations in reducing mercury binding of SAMMS follows the order (Figure 4.7b):

$$
\mathrm{Cd}(\text { II) }>\mathrm{Pb} \text { (II) }>\mathrm{Fe} \text { (II) }>\mathrm{Cu} \text { (II) }>\mathrm{Ni} \text { (I) }>\mathrm{I}=\mathrm{Zn} \text { (II) }>\mathrm{Ca} \text { (II) }
$$

This order is similar to its sofness of the cations, i.e., $\mathrm{Cd}(\mathrm{II})$ is the softest cation and it reduced the mercury-binding $\mathrm{Kd}$ by 400 times from $1.14 \times 10^{8}$ down to $2.73 \times 10^{5}$. The hard ion $\mathrm{Ca}(\mathrm{II})$ exhibited no interference with mercury binding. It is also interesting to see (Figure $4.7 \mathrm{~b}$ ) that more cations in the solution diluted the interferring ability of cations (Table 4.7): the $\mathrm{Kd}$ in the single component Cd solution was $2.73 \times 10^{5}$ by comparing the results; $\mathrm{Kd}$ increased to $4.65 \times 10^{6}$ in the 3-cation solution where the $\mathrm{Cd}$ concentration was the same as the single component $\mathrm{Cd}$ solution, and the $\mathrm{Kd}$ reached $4.15 \times 10^{7}$ in the 7cation solution. These effects can also be see by comparing the following $\mathrm{Kds}$ at $\mathrm{pH} 7$ :

$\begin{array}{llcc}\frac{\mathrm{Kd}}{1.75 \times 10^{6}} & \frac{\mathrm{Pb}, \mathrm{M}}{1 \times 10^{-4}} & \begin{array}{c}\text { Other Cation, M } \\ \text { (not considering Na) }\end{array} & \frac{\text { Solution ID }}{\mathrm{Pb}} \\ 1.10 \times 10^{7} & 1 \times 10^{-4} & 0.0 & 4 \mathrm{Cat} \\ 4.15 \times 10^{7} & 1 \times 10^{-4} & 3 \times 10^{-4} & 7 \mathrm{Cat}\end{array}$

The cation effects on decreasing the mercury binding of SAMMS in $\mathrm{pH} 4$ solution (Figure $4.7 \mathrm{a}$ ) follows the order of

$$
\mathrm{Fe} \text { (II) }>\mathrm{Cd} \text { (II) }>\mathrm{Pb} \text { (II) }>\mathrm{Ni} \text { (I) }>\mathrm{Zn} \text { (II) }>\mathrm{Ca} \text { (II) }>\mathrm{Cu} \text { (II) } \text {. }
$$

This order is slightly different from the order at $\mathrm{pH}$ 7. In particular, the $\mathrm{Cu}(\mathrm{II})$ showed less interference than even $\mathrm{Ca}$. It is understandable that the effectiveness order changes with solution $\mathrm{pH}$ since the $\mathrm{pH}$ change induces the softness change on both the thiol groups (from SAMMS-S to SAMMS-SH) and on cations (different extent of hydrolysis on cations). The observation that at $\mathrm{pH} 7$, the single cation solution is more effective to interfere with SAMMS mercury binding than multiple cations at the same cation concentrations is also true at $\mathrm{pH} 4$. 


\section{(A): Cation Effects at $\mathrm{pH} 4$}

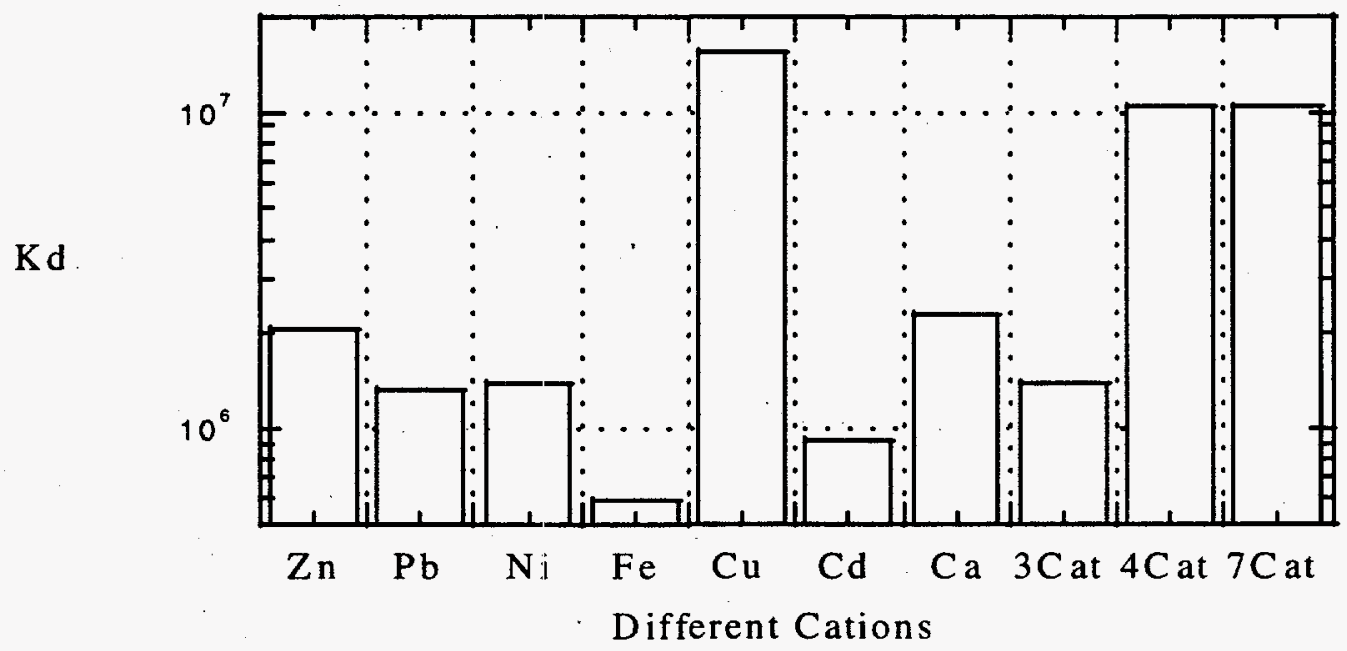

(B): Cation Effects on Kd at pH 7

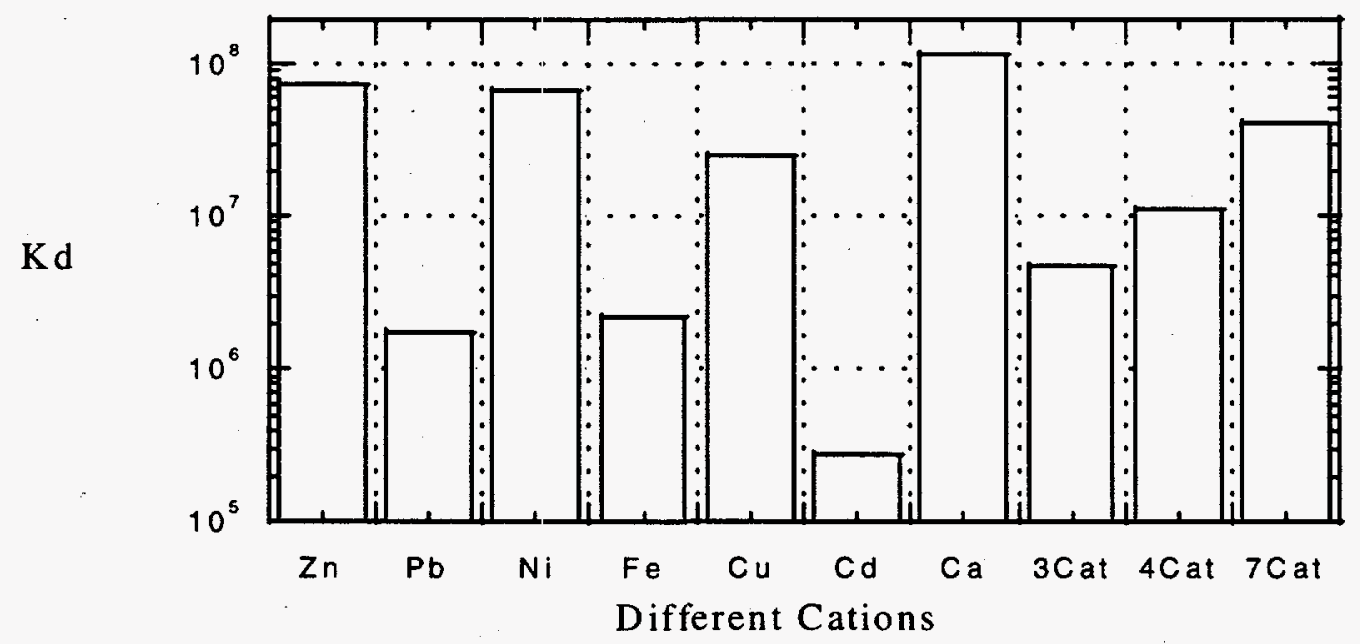

Figure 4.7. Cátion Effects on SAMM's Mercury Binding (A) at $\mathrm{pH} 4$ and (B) at $\mathrm{pH} 7$

In summary, the overal interference from common cations such as $\mathrm{Na}$ (seen from the ionic strength effect experiment discussed in Section 4.6), $\mathrm{Ca}, \mathrm{Zn}$, and $\mathrm{Ni}$ on mercury binding of SAMMS is minimal. The $\mathrm{Kd}$ for mercury binding is still as high as $2.73 \times 10^{5}$, even at the presence of the most interfering cation of $\mathrm{Cd}(\mathrm{II})$. The interference from cations is also minimal when more than seven cations exist since the $\mathrm{Kd}$ was observed to be at least $1 \times 10^{7}$ in these solutions. 
Table 4.7. Cation Effects on SAMMS's Mercury Binding

\begin{tabular}{|c|c|c|c|c|c|c|c|c|c|c|}
\hline \multicolumn{6}{|c|}{ At pH 4} & \multicolumn{5}{|c|}{ At $\mathrm{pH} 7$} \\
\hline & $\begin{array}{c}\mathrm{Hg} \text { (in) } \\
\text { ppb }\end{array}$ & $\begin{array}{c}\mathrm{Hg}(\mathrm{fi}) \\
\mathrm{ppb}\end{array}$ & $\mathrm{pH}(\mathrm{in})$ & $\mathrm{pH}(\mathrm{fi})$ & Kd & $\begin{array}{c}\mathrm{Hg}(\mathrm{in}) \\
\mathrm{ppb}\end{array}$ & $\begin{array}{c}H g(f i) \\
\text { ppb }\end{array}$ & $\mathrm{pH}$ (in) & $\mathrm{pH}(\mathrm{fi})$ & $\mathrm{Kd}$ \\
\hline $\mathrm{Zn}$ & 18700 & 45.3 & 4.02 & 3.93 & $2.06 \mathrm{E}+06$ & 19100 & 1.3 & 7.08 & 5.14 & $7.21 E+07$ \\
\hline $\mathrm{Pb}$ & 18400 & 68.3 & 3.94 & 3.74 & $1.34 E+06$ & 18800 & 53.7 & 6.94 & 4.20 & $1.75 E+06$ \\
\hline $\mathrm{Ni}$ & 18700 & 66.5 & 4.02 & 3.87 & $1.40 E+06$ & 19000 & 1.4 & 7.10 & 6.02 & $6.79 E+07$ \\
\hline $\mathrm{Fe}$ & 17900 & 151.5 & 4.06 & 3.98 & $5.86 \mathrm{E}+05$ & 15700 & 36.0 & 7.02 & .75 & $2.18 E+06$ \\
\hline $\mathrm{Cu}$ & 18600 & 6.1 & 3.80 & 3.58 & $1.54 \mathrm{E}+07$ & 19100 & 3.9 & 7.08 & 4.64 & $2.48 E+07$ \\
\hline $\mathrm{Cd}$ & 18200 & 99.5 & 4.00 & 3.69 & $9.10 E+05$ & 18800 & 338.3 & 7.13 & 4.27 & $2.73 E+05$ \\
\hline $\mathrm{Ca}$ & 18600 & 40.8 & 4.05 & 3.77 & $2.28 \mathrm{E}+06$ & 18600 & 0.8 & 6.88 & 5.77 & $1.14 \mathrm{E}+08$ \\
\hline 3Cat & 18100 & 65.6 & 3.89 & 3.71 & $1.38 E+06$ & 18100 & 19.5 & 6.83 & 4.18 & $4.65 E+06$ \\
\hline 4Cat & 18200 & 8.8 & 4.05 & 3.68 & $1.03 E+07$ & 17700 & 8.1 & 6.97 & 5.10 & $1.10 E+07$ \\
\hline 7 Cat & 18300 & 8.9 & 4.01 & 3.65 & $1.03 E+07$ & 18300 & 2.2 & 6.99 & 4.87 & $4.15 E+07$ \\
\hline
\end{tabular}

\subsection{Anion Effects}

Many anions in ground waters and in waste streams may form complexes with mercury in solution, which may affect the ability of SAMMS to remove mercury from the groundwater and waste streams.

In this experiment, $\mathrm{Hg}\left(\mathrm{NO}_{3}\right)_{2}$ solutions containing $\mathrm{Cl}, \mathrm{CN}, \mathrm{CO}_{3}{ }^{2-}, \mathrm{SO}_{4}{ }^{2-}$, and $\mathrm{PO}_{4}{ }^{3-}$ were prepared. The anion concentrations were $0.5,1,5$, and 10 times of mercury concentration on a molar basis. $\mathrm{NaNO}_{3}$ was used to maintain a constant ionic strength of 0.1 M. A 10-mg quantity of SAMMS was added to each of $50-\mathrm{mL}$ anion solution and was shaken for 4 hours before filtration with syringe filters. The filtrate was analyzed for mercury. Each anion solution was tested at both $\mathrm{pH} 4.0$ and 7.0 in duplicate.

The results are shown in Table 4.8 and Figure 4.8. At both $\mathrm{pH} 4$ and $7, \mathrm{CN}^{-}$was the least in reducing the SAMMS mercury binding $\mathrm{Kd}$, and the other anions reduced the $\mathrm{Kd}$ by about 5 times. Anion concentration changing by 100 times (from 0.1 to $10 \times 10^{-4} \mathrm{M}$ ) did not show substantial effects on the anion effects. At pH 7.0, the decreasing order of its ability to influence the mercury-binding Kd of SAMMS is

$$
\mathrm{Cl}^{-}>\mathrm{SO}_{4}{ }^{2-}>\mathrm{CO}_{3}{ }^{2-}>\mathrm{PO}_{4}{ }^{3-}>\mathrm{CN}^{-}
$$

This order did not change with the anion concentration range tested. At pH 4, the effects are similar to that at $\mathrm{pH}$, and it is difficult to determine the pattern in the order among $\mathrm{Cl}, \mathrm{CO}_{3}{ }^{2-}, \mathrm{SO}_{4}{ }^{2-}$, and $\mathrm{PO}_{4}{ }^{3-}$, especially when the anion concentration changes. Also, the influence of anions among $\mathrm{Cl}^{-}, \mathrm{CO}_{3}{ }^{2-}$, $\mathrm{SO}_{4}^{2-}$, and $\mathrm{PO}_{4}{ }^{3-}$ is of a similar magnitude.

\subsection{Demonstration on Simulated Aqueous and Oil Wastes and Actual SRS (Savannah River Site) Tritiated Pump Oil Wastes}

Preliminary trials of the mercury-binding capabilities of SAMMS \#1 were conducted in simulated wastewater of SRS radioactive waste-holding Tank L (compositions were shown in Table 4.9 as before SAMMS absorbtion) and simulated nonradioactive vacuum pump oil waste of the SRS Tritium Facilities. 


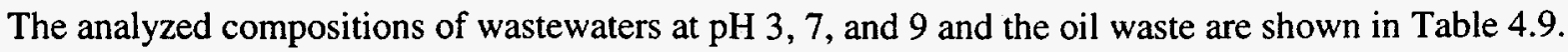
These waste solutions were mixed with SAMMS \#1 powders at volume ratios of waste-to-SAMMS ranging from 20 to 100 (Table 4.10) at room temperature for 2 hours. The remaining RCRA metals in solutions were analyzed using cold vapor atomic absorption for mercury and inductively coupled plasmaatomic emission spectroscopy (ICP-AES) for other metals, as shown in Table 4.9. SAMMS \#1 reduced the mercury concentration from $6.35 \mathrm{ppm}$ to $0.7 \mathrm{ppb}$ (below the drinking water limit of $2 \mathrm{ppb}$ ) by just one treatment of wastewater 38 times its volume. The distribution coefficient is as large as 340,000 at a pH range from 3 to 9 and with the presence of large concentrations of other cations (e.g., $2220 \mathrm{ppm} \mathrm{Na}$ and 7 ppm of $\mathrm{Ba}$ ). The RCRA metals, $\mathrm{Pb}, \mathrm{Ag}$, and $\mathrm{Cr}$, were also reduced to below RCRA levels at $\mathrm{pH} 7$ and 9 . SAMMS reduced the mercury level from $12.1 \mathrm{ppm}$ to $0.066 \mathrm{ppm}$ (the hazardous waste limit is $0.2 \mathrm{ppm}$ ) by treating 20 times the waste oil volume once.

Actual tritiated vacuum pump oil wastes generated in the SRS Tritium Facilities were tested at Oak Ridge National Laboratory using the SAMMS powders. Samples ( $3 \mathrm{~mL}$ ) of SRS tritiated pump oils were mixed with 0.01 to $0.3 \mathrm{~g}$ of SAMMS, and the mixtures were equilibrated for 48 hours before they were filtered and analyzed for mercury. All the tests were performed in duplicate. Another two sorbents, sulfur and sulfur-impregnated activated carbon (SIAC), were tested under similar conditions for comparison. A control test without sorbent was also tested with two different SRS pump oils. Laboratory batch tests successfully removed $91 \%$ of the mercury from samples of actual tritiated waste oils generated in the SRS Tritium Facilities. Only 2 to $29 \%$ of mercury was removed using sulfur-impregnated carbon and sulfur under the same test conditions.

The results in Table 4.11 and Figure 4.9 show that SAMMS was able to remove up to $91 \%$ of the mercury in the tritiated pump oils through the single treatment. The removing efficiencies for sulfur and sulfur-impregnated activated carbon were 28 and $9 \%$ respectively. The Kd for SAMMS in the actual tritiated pump oil was up to $3.47 \times 10^{5}$, and the observed mercury loading was up to $13.59 \mathrm{mg} / \mathrm{g}$.

\subsection{Toxicity Characteristic Leach Procedure (TCLP) on Mercury-SAMMS}

The RCRA-laden SAMMS \# 1 may be disposed of directly as solid wastes because they passed TCLP tests by showing up to 1000 tinnes lower release of RCRA metals (Table 4.12).

\subsection{Chemical Stability and Aqueous Durability of Mercury-SAMMS}

The chemical stability of mercury-SAMMS was evaluated by 1) evaluating the mercury loss and binding change using NMR after heating the mercury-SAMMS \#1 powders in the air for 75 and $125^{\circ} \mathrm{C}$ for 24 hours and $150^{\circ} \mathrm{C}$ in air for 50 hours, and 2) by measuring the mercury concentration in solution after mercury-SAMMS \#2 was heated in water at $70^{\circ} \mathrm{C}$ for 24 hours. 
Table 4.8. Anion Effects

\begin{tabular}{|c|c|c|c|c|c|}
\hline ID & pH, ini & pH, fin & Hg(in), ppb & Hg(in) ppb & $\mathbf{K d}$ \\
\hline $0.5 \mathrm{CL} 4$ & 4.00 & 3.85 & 19800 & 30.1 & $3.29 E+06$ \\
\hline $0.5 \mathrm{CN} 4$ & 4.00 & 3.97 & 19800 & 7.7 & $1.29 E+07$ \\
\hline $0.5 \mathrm{CO} 4$ & 4.00 & 4.00 & 19800 & 40.8 & $2.42 E+06$ \\
\hline $0.5 \mathrm{SO} 4$ & 4.00 & 4.09 & 19800 & 41.6 & $2.37 E+06$ \\
\hline $0.5 \mathrm{PO} 4$ & 4.00 & 4.04 & 19800 & 26.5 & $3.73 E+06$ \\
\hline $1 \mathrm{CL} 4$ & 4.00 & 3.72 & 19800 & 28.4 & $3.48 \mathrm{E}+06$ \\
\hline $1 \mathrm{CN} 4$ & 4.00 & 3.99 & 19800 & 6.1 & $1.64 \mathrm{E}+07$ \\
\hline $1 \mathrm{CO} 4$ & 4.00 & 4.01 & 19800 & 34.9 & $2.83 E+06$ \\
\hline $1 \mathrm{SO} 4$ & 4.00 & 4.02 & 19800 & 41.5 & $2.38 E+06$ \\
\hline $1 \mathrm{PO} 4$ & 4.00 & 4.03 & 19800 & 29.2 & $3.39 E+06$ \\
\hline $5 \mathrm{CL} 4$ & 4.00 & 3.61 & 19800 & 29.8 & $3.32 E+06$ \\
\hline $5 \mathrm{CN} 4$ & 4.00 & 4.04 & 19800 & 2.7 & $3.74 \mathrm{E}+07$ \\
\hline $5 \mathrm{CO} 4$ & 4.00 & 4.02 & 19800 & 27.0 & $3.67 \mathrm{E}+06$ \\
\hline $5 \mathrm{SO} 4$ & 4.00 & 4.03 & 19800 & 30.9 & $3.20 \mathrm{E}+06$ \\
\hline $5 \mathrm{PO} 4$ & 4.00 & 4.02 & 19800 & 26.4 & $3.75 E+06$ \\
\hline $10 \mathrm{CL} A$ & 4.00 & 3.63 & 19800 & 36.4 & $2.71 E+06$ \\
\hline $10 \mathrm{CN} 4$ & 4.00 & 4.05 & 19800 & 3.1 & $3.25 \mathrm{E}+07$ \\
\hline $10 \mathrm{CO} 4$ & 4.00 & 4.00 & 19800 & 35.2 & $2.81 \mathrm{E}+06$ \\
\hline $10 S O 4$ & 4.00 & 4.02 & 19800 & 34.6 & $2.86 \mathrm{E}+06$ \\
\hline $10 P O 4$ & 4.00 & 4.04 & 19800 & 27.4 & $3.61 \mathrm{E}+06$ \\
\hline $0.5 \mathrm{CL} 7$ & 7.00 & 5.28 & 19600 & 33.0 & $2.97 \mathrm{E}+06$ \\
\hline $0.5 \mathrm{CN} 7$ & 7.00 & 5.64 & 19600 & 3.0 & $3.27 \mathrm{E}+07$ \\
\hline $0.5 \mathrm{CO} 7$ & 7.00 & 5.60 & 19600 & 18.1 & $5.42 \mathrm{E}+06$ \\
\hline $0.5 S 07$ & 7.00 & 5.44 & 19600 & 25.7 & $3.82 \mathrm{E}+06$ \\
\hline $0.5 \mathrm{PO} 7$ & 7.00 & 6.36 & 19600 & 12.0 & $8.16 \mathrm{E}+06$ \\
\hline $1 \mathrm{CL} 7$ & 7.00 & 5.30 & 19600 & 29.9 & $3.28 E+06$ \\
\hline $1 \mathrm{CN} 7$ & 7.00 & 5.27 & 19600 & 3.1 & $3.21 \mathrm{E}+07$ \\
\hline $1 \mathrm{CO} 7$ & 7.00 & 6.00 & 19600 & 21.1 & $4.65 E+06$ \\
\hline $1 \mathrm{SO} 7$ & 7.00 & 6.20 & 19600 & 24.1 & $4.07 \mathrm{E}+06$ \\
\hline $1 \mathrm{PO} 7$ & 7.00 & 6.83 & 19600 & 11.4 & $8.63 E+06$ \\
\hline $5 \mathrm{CL} 7$ & 7.00 & 4.60 & 19600 & 30.1 & $3.26 \mathrm{E}+06$ \\
\hline $5 \mathrm{CN} 7$ & 7.00 & 5.69 & 19600 & 1.7 & $5.94 \mathrm{E}+07$ \\
\hline $5 \mathrm{CO} 7$ & 7.00 & 7.07 & 19600 & 16.1 & $6.08 \mathrm{E}+06$ \\
\hline $5 S 07$ & 7.00 & 5.92 & 19600 & 17.9 & $5.47 \mathrm{E}+06$ \\
\hline $5 \mathrm{PO} 7$ & 7.00 & 6.93 & 19600 & 12.9 & $7.62 E+06$ \\
\hline $10 \mathrm{CL} 7$ & 7.00 & 4.40 & 19600 & 27.0 & $3.62 \mathrm{E}+06$ \\
\hline $10 \mathrm{CN} 7$ & 7.00 & 6.01 & 19600 & 3.1 & $3.16 \mathrm{E}+07$ \\
\hline $10 \mathrm{CO} 7$ & 7.00 & 7.28 & 19600 & 17.2 & $5.71 E+06$ \\
\hline $10 \mathrm{SO} 7$ & 7.00 & 5.89 & 19600 & 16.3 & $6.01 \mathrm{E}+06$ \\
\hline
\end{tabular}


$0.5 \mathrm{E}-4 \mathrm{M}$ at $\mathrm{pH} 7$

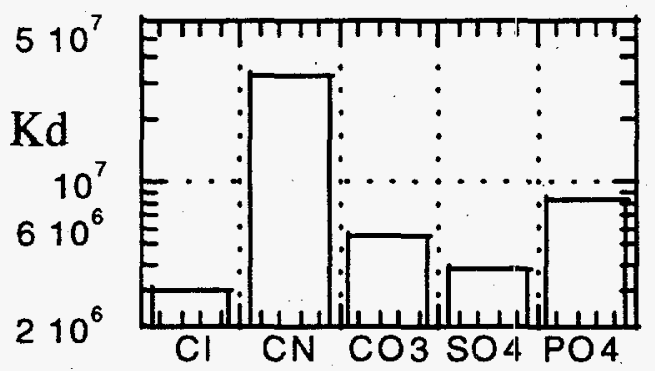

1.0 E-4 M at pH 7

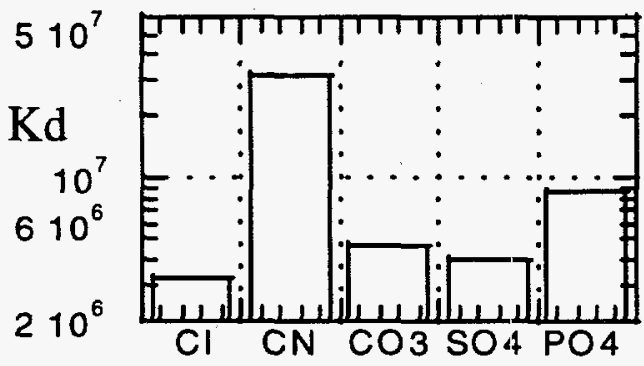

5.0 E-4 M at pH 7

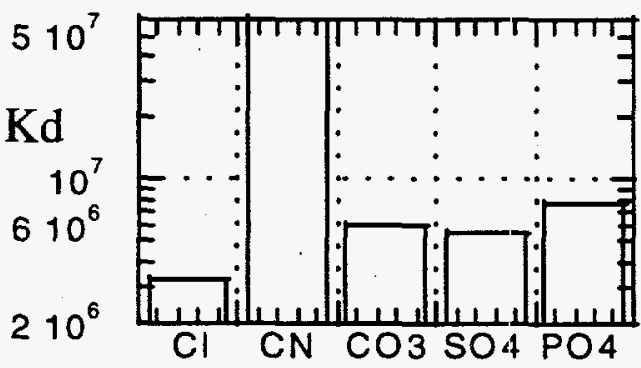

$10 \mathrm{E}-4 \mathrm{M}$ at $\mathrm{pH} 7$

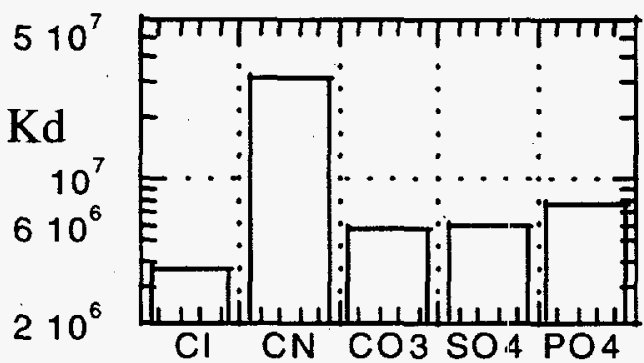

$0.5 \mathrm{E}-4 \mathrm{M}$ at $\mathrm{pH} 4$

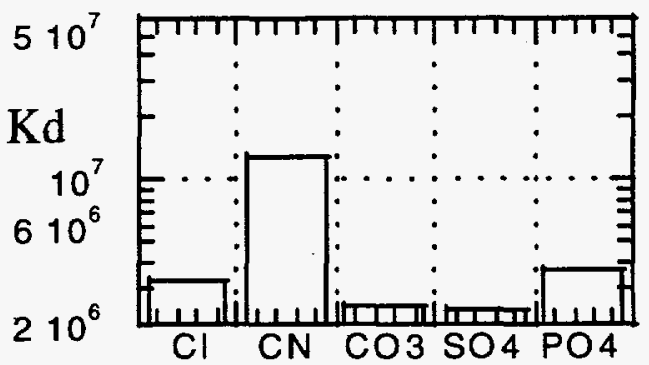

$1.0 \mathrm{E}-4 \mathrm{M}$ at $\mathrm{pH} 4$

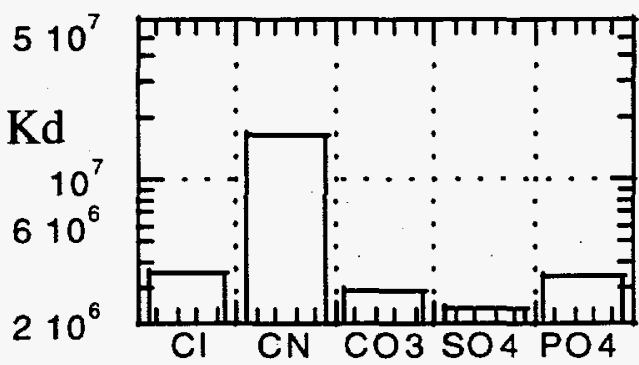

5.0 E-4 $\mathrm{M}$ at pH 4

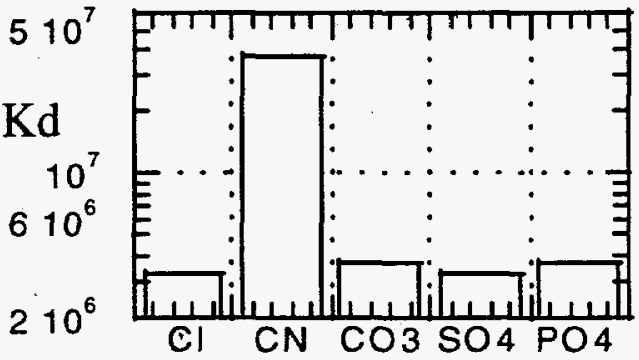

$10 \mathrm{E}-4 \mathrm{M}$ at $\mathrm{pH} 4$

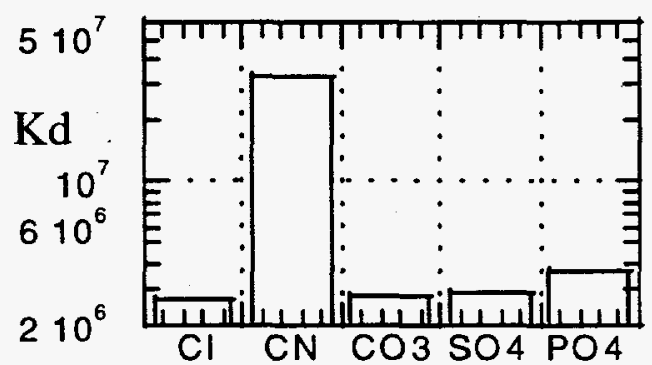

Figure 4.8. Anion Effects on SAMMS's Mercury Binding. The anions have concentrations of $0.5 \times 10^{-4}, 1 \times 10^{-4}, 5 \times 10^{-4}$, and $10 \times 10^{-4}$ at $\mathrm{pH} 4$ and $\mathrm{pH} 7$ 
Table 4.9. Analyzed RCRA Metal Concentrations (ppm) in Waste Solutions

Before and After SAMMS \#1 Treatment

\begin{tabular}{|c|c|c|c|c|c|c|c|}
\hline & Hg & $\mathbf{A g}$ & $\mathrm{Cr}$ & $\mathbf{P b}$ & $\mathbf{B a}$ & $\mathbf{Z n}$ & $\mathbf{N a}$ \\
\hline \multicolumn{8}{|l|}{ Before: } \\
\hline WW at $\mathrm{pH} 3$ & 6.20 & 1.80 & 1.79 & 7.22 & 7.18 & 3.96 & 2220 \\
\hline $\mathrm{WW}$ at $\mathrm{pH} 7$ & 6.00 & 0.45 & 1.13 & 5.25 & 7.12 & 2.75 & 2212 \\
\hline $\mathrm{WW}$ at $\mathrm{pH} 9$ & 6.35 & 1.04 & 0.58 & 2.90 & 7.15 & 1.32 & 2222 \\
\hline Oil-1 & 12.10 & & & & & & \\
\hline \multicolumn{8}{|l|}{ After: } \\
\hline SAM-1-3 & 0.0108 & $<.005$ & 1.45 & 1.66 & 7.60 & 3.93 & 2236 \\
\hline SAM-1-7 & 0.0064 & $<.005$ & 0.70 & 0 & 7.35 & 2.23 & 2202 \\
\hline SAM-1-9 & 0.0056 & $<.005$ & 0.71 & 0 & 7.40 & 1.41 & 2218 \\
\hline SAM-2-3 & 0.0008 & $<.005$ & 1.67 & 2.26 & 8.64 & 5.06 & 2185 \\
\hline SAM-2-7 & 0.0008 & $<.005$ & 0.07 & 0 & 8.21 & 1.54 & 2114 \\
\hline SAM-2-9 & 0.0007 & $<.005$ & 0 & 0 & 8.82 & 1.19 & 2201 \\
\hline SAM-1-Oil & 0.635 & & & & & & \\
\hline SAM-2-Oil & 0.066 & & & & & & \\
\hline
\end{tabular}

Previous characterization of these mercury-laden materials indicates that the mercury is directly bound to the monolayer via an $\mathrm{Hg}$-S bond and that neighboring mercury atoms are linked by an oxo bridge (Hg-O-Hg) (Feng et al 1997b). The chemical shifts reported above for both the primary and secondary products are most consistant with oxygen-based functionality (Levy et al. 1980).

Subjecting the mercury-laden SAMMS to heat results in a slow, steady chemical change taking place at the monolayer interface. This chemistry is easily monitored by solid-state ${ }^{13} \mathrm{C}$ NMR (see Figure 4.10). The carbon resonance appearing at $13 \mathrm{ppm}$ in all of these spectra is readily assigned to the methylene bound to the silicon atom and can be used a type of internal standard since it remains unchanged throughout this chemistry.

The two peaks at 28 and $37 \mathrm{ppm}$ (assigned to the internal and thiol-bearing methylenes, respectively) are seen to slowly disappear during this thermolysis, suggesting that the terminal mercury thioalkoxide is undergoing some sort of chemical change. As the original signals decay, other features are seen to grow into the spectrum. The first, and most notable, of these is the peak at $55 \mathrm{ppm}$, first seen in the $75^{\circ} \mathrm{C}$ spectrum. Concomittantly, a partially obscured peak appears at approximately $20 \mathrm{ppm}$. As the 
Table 4.10. Testing Parameters of the Simulated Wastes Using SAMMS \#1

\begin{tabular}{|l|l|c|c|c|}
\hline & \multicolumn{1}{|c|}{ Types of Wastes } & $\mathbf{V}_{\text {waste }} \mathbf{V}_{\text {SAMMS }}$ & $\mathbf{K}_{\mathbf{d}}$ of $\mathbf{~ H g}$ & $\begin{array}{c}\text { Remaining Hg in } \\
\text { Waste }(\mathbf{p p b})\end{array}$ \\
\hline SAM-1-3 & Waterwater at pH 3 & 97 & 55670 & 10.8 \\
\hline SAM-1-7 & Waterwater at pH 7 & 97 & 90974 & 6.4 \\
\hline SAM-1-9 & Waterwater at pH 9 & 97 & 110056 & 5.6 \\
\hline SAM-2-3 & Waterwater at pH 3 & 38 & 290588 & 0.8 \\
\hline SAM-2-7 & Waterwater at pH 7 & 38 & 281213 & 0.8 \\
\hline SAM-2-9 & Waterwater at pH 9 & 38 & 340141 & 0.7 \\
\hline SAM-1-Oil & Waste pump oil & 100 & 1806 & 635 \\
\hline SAM-2-Oil & Waste pump oil & 20 & 3647 & 66 \\
\hline
\end{tabular}

Table 4.11. Mercury Removal From Actual SRS Tritiated Pump Oils

\begin{tabular}{|l|c|c|c|c|c|c|}
\hline Sorbent & $\begin{array}{c}\text { Sobent } \\
\mathbf{g}\end{array}$ & $\begin{array}{c}\text { Initial } \\
\mathbf{m g} / \mathbf{K g}\end{array}$ & $\begin{array}{c}\text { Final } \\
\mathbf{m g} / \mathbf{K g}\end{array}$ & $\mathbf{K d}$ & $\begin{array}{c}\text { Loading } \\
\mathbf{m g} / \mathbf{g}\end{array}$ & $\begin{array}{c}\text { Dec. } \\
\%\end{array}$ \\
\hline Control-1 & 0.00 & 52.1 & 43.5 & & & \\
\hline SAMMS & 0.20 & 52.1 & 6.0 & $1.16 \mathrm{E}+05$ & 0.69 & 89 \\
\hline Sulfur & 0.20 & 52.1 & 37.3 & $5.95 \mathrm{E}+03$ & 0.22 & 28 \\
\hline SIAC & 0.20 & 52.1 & 47.3 & $1.52 \mathrm{E}+03$ & 0.07 & 9 \\
\hline Control-2 & 0.00 & 84.5 & 61.4 & & & \\
\hline SAMMS & 0.01 & 84.5 & 39.2 & $3.47 \mathrm{E}+05$ & 13.59 & 54 \\
\hline SAMMS & 0.05 & 84.5 & 34.8 & $8.57 \mathrm{E}+04$ & 2.98 & 59 \\
\hline SAMMS & 0.10 & 84.5 & 33.0 & $4.68 \mathrm{E}+04$ & 1.55 & 61 \\
\hline SAMMS & 0.30 & 84.5 & 7.6 & $1.01 \mathrm{E}+05$ & 0.77 & 91 \\
\hline
\end{tabular}

temperature is raised to $125^{\circ} \mathrm{C}$, both of these features are enhanced and are accompanied by a peak at about $25 \mathrm{ppm}$, as well as multiple overlapping poorly defined resonances between 62 and $75 \mathrm{ppm}$. Raising the temperature to $150^{\circ} \mathrm{C}$ results in further depletion of the original signals at 37 and $28 \mathrm{ppm}$, as well as the primary product signals at 55 and $20 \mathrm{ppm}$, while enhancing the signals at $25 \mathrm{ppm}$ and $62-75 \mathrm{ppm}$, consistent with these arising from secondary product formation.

The resonances observed for the primary product are consistent with the formation of a mercuric alkoxide; the terminal oxygen-bearing methylene is at $55 \mathrm{ppm}$ and in the internal methylene is found at $20 \mathrm{ppm}$ (the greater charge separation of the mercuric alkoxide results in more effective shielding of the internal methylene relative to the thioalkoxide). 
Table 4.12. TCLP Leachate Concentrations (ppm)

\begin{tabular}{|l|c|c|c|c|c|c|c|}
\hline & $\mathbf{H g}$ & $\mathbf{A g}$ & $\mathbf{C r}$ & $\mathbf{P b}$ & $\mathbf{B a}$ & $\mathbf{N i}$ & $\mathbf{Z n}$ \\
\hline SAM-1-Oil & 0.0043 & 0 & 0 & 0 & 0.37 & 0.10 & 0.57 \\
\hline SAM-2-Oil & 0.0018 & 0 & 0 & 0 & 0.18 & 0 & 0.29 \\
\hline SAM-1(pH 3,7,9) & 0.0009 & 0 & 0.24 & 0 & 0.70 & 0.20 & 1.05 \\
\hline SAM-2-3 & 0.0006 & 0 & 0.07 & 0 & 0.58 & 0.06 & 0.33 \\
\hline SAM-2-7 & 0.0006 & 0 & 0 & 0 & 0.55 & 0 & 0.31 \\
\hline SAM-2-9 & 0.0002 & 0 & 0 & 0 & 0.44 & 0 & 0.3 \\
\hline EPA TCLP Limits & 0.2 & 5.0 & 5.0 & 5.0 & 100 & & \\
\hline Land Disposal Limits & & 0.072 & 5.2 & 0.51 & & & 0.32 \\
\hline Drinking water limit & 0.002 & & & & & & \\
\hline
\end{tabular}

Note: " 0 " concentration means the concentration below the detection limits of ICP-AES

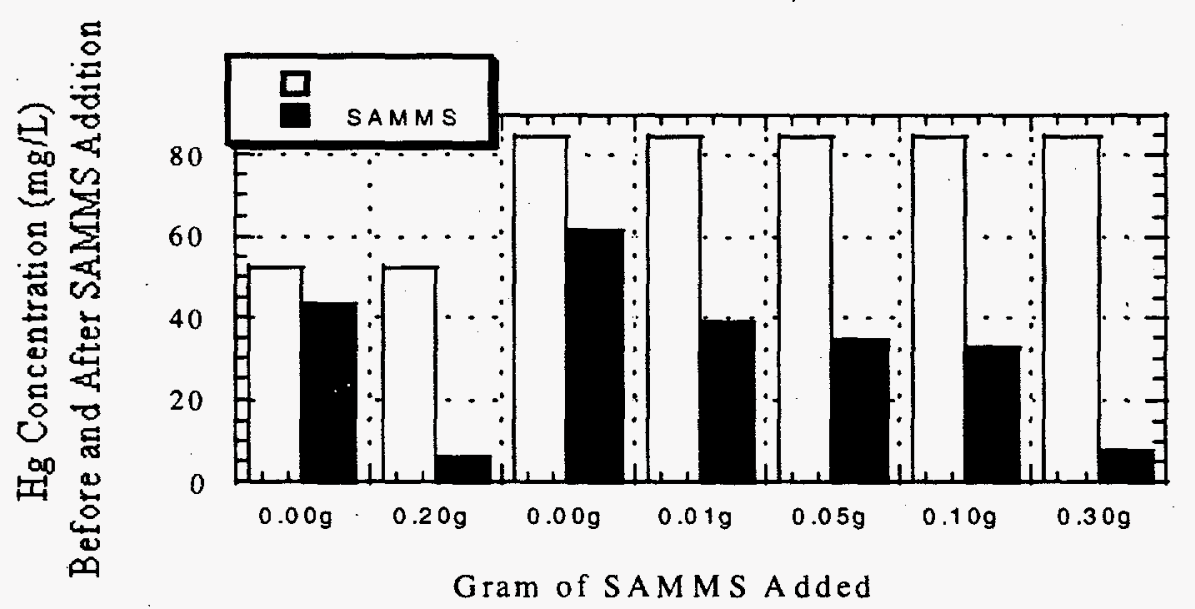

Figure 4.9. Mercury Removal from Actual SRS Tritiated Pump Oil Wastes with SAMMS 
The resonances observed for the secondary products are consistant with the hydrolysis, and possible condensation, of the sulfide-bridged mercuric alkoxide intermediate. The poorly resolved signal found at approximately $65 \mathrm{ppm}$ is quite characteristic of the formation of a primary alcohol (structure 3 of Figure 4.11) via hydrolysis of the intermediate mercuric alkoxide (structure 2) (Levy et al. 1980). This peak is seen to grow in at the same tirne as the signal at $25 \mathrm{ppm}$, which is readily assigned to the internal carbon of the primary alcohol. At the same time, a poorly defined peak at about $73 \mathrm{ppm}$ is seen, which is most consistant with formation of a terminal ether (structure 4) via condensation chemistry (Levy et al. 1980). The internal methylene resonance of the propyl ether is presumably buried beneath the several overlapping signals and is not visible in these spectra.

Mechanistically, this can be viewed as a Lewis acid-induced cleavage of the C-S bond, followed by rearrangement to afford a sulfur-bridged mercuric alkoxide (2). This rearrangement replaces a relatively weak C-S sigma bond with a much stronger $\mathrm{C}-\mathrm{O}$ sigma bond and the bridging oxide with a much more favorable sulfide bridge. These two factors clearly provide the thermodynamic driving force for this rearrangement.

It is worthwhile to note that even after several days at elevated temperatures, a significant portion of mercuric thioalkoxide still remains on the surface. In this mechanism, only half of the thioalkoxide is consumed, consistant with this observation.

The secondary reaction processes then slowly deplete the population of this intermediate product. Once formed, the bridging mercuric alkoxide can suffer one of two fates: simple hydrolysis (to afford the observed primary alcohol), or an interesting internal condensation reaction to afford the corresponding ether. Once again, the first step in this process is a Lewis acid-induced cleavage of a C-S sigma bond. However, the following step involves migration of an alkoxide instead of a metal-oxo bridge. Again, the driving force for this process is the formation of a strong $\mathrm{C}-\mathrm{O}$ bond at the expense of a weaker C-S bond, as well as the formation of mercuric sulfide.

In summary, the mercury bound to SAMMS is chemically stable. Upon heating to a higher temperature in air, molecular structuares of mercury-SAMMS are rearranged to form a more stable mercury configuration. However, the total amount of mercury bound to SAMMS did not change as a result of heating up to $150^{\circ} \mathrm{C}$. From the point of view of mercury-SAMMS as a permanent waste form, this NMR study may provide a molecular understanding of its chemical durability. A total mercury analysis may also be needed to confirm the proposed structural rearrangement, and a TCLP test on the heated mercury-SAMMS may also provide important information about its durability.

\subsubsection{Hydrothermal Stability Testing}

Samples of mercury-SAMMS \#2 with mercury loading of $503 \mathrm{mg} / \mathrm{g}$ were used for this evaluation. These samples were washed with a few mLs of deionized water before drying. A $0.05-\mathrm{g}$ quantity of the mercury-SAMMS \#2 was added to $50.0 \mathrm{~mL}$ deionized water in a Teflon vessel, mixed well, and kept at $70^{\circ} \mathrm{C}$ for 24 hours. The test was duplicated. At the end of the 24 hours, the solutions were filtered, and the filtrate was analyzed. The duplicate tests had mercury concentrations of 12.7 and $13.0 \mathrm{mg} / \mathrm{L}$, respectively. 


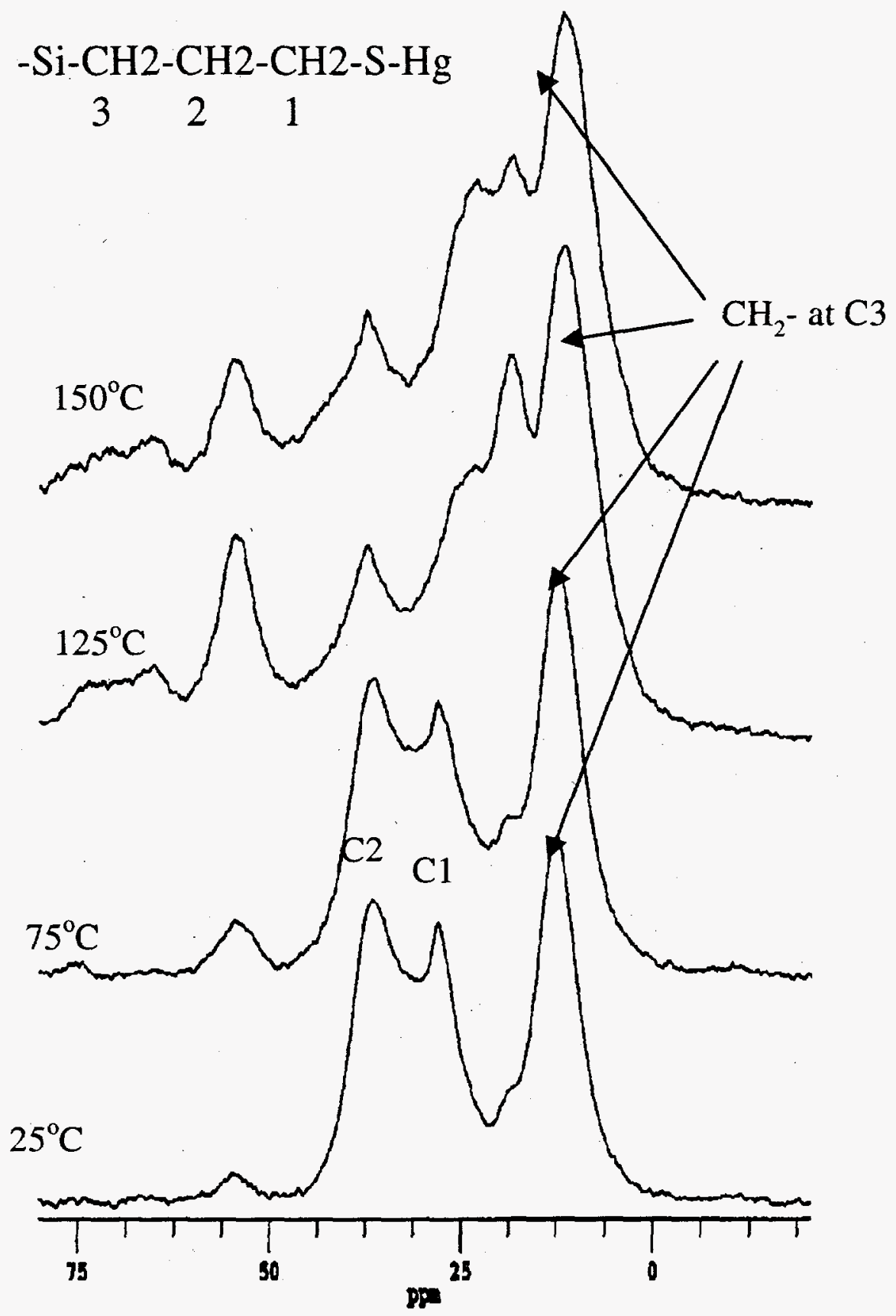

Figure 4.10. NMR Spectra of Mercury-SAMMS at Room Temperature, after Heating at 75 and $125^{\circ} \mathrm{C}$ in air for 24 Hours, and after Heating at $150^{\circ} \mathrm{C}$ in Air for 50 Hours 


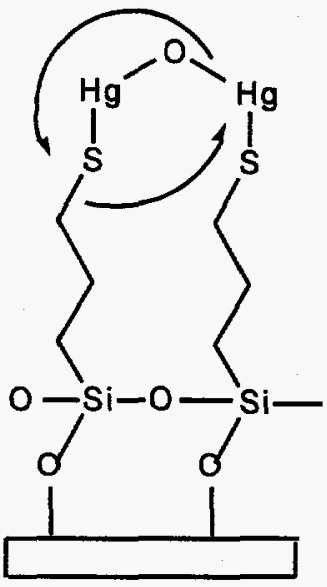

1

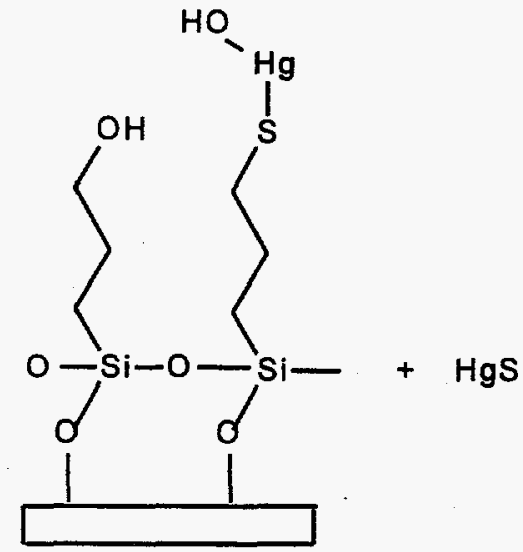

3

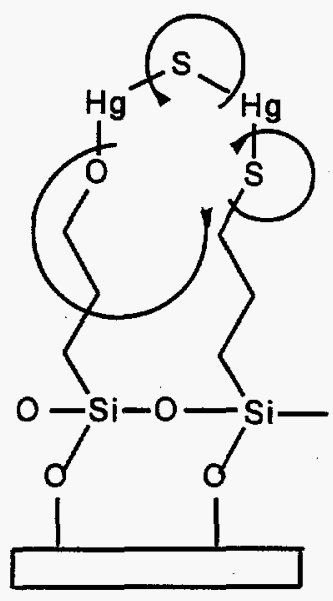

2

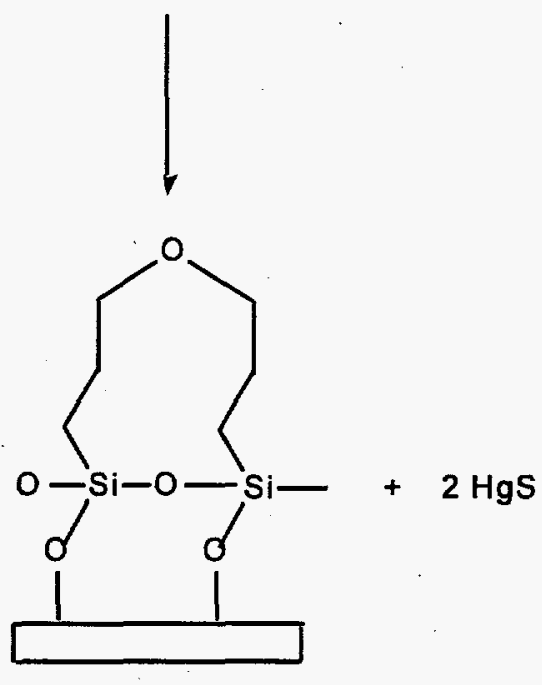

4

Figure 4.11. Thermo Rearrangement of Mercury-SAMMS During Heating

Because the mercury-SAMMS \#2 powders used for the tests were not washed thoroughly, some mercury released simply may have been due to the surface-adsorbed mercury; a blank test was carried out. In the duplicate blank tests, the same mercury-SAMMS \#2 powders were treated in the same way as for the $70^{\circ} \mathrm{C}$ tests, except that the mixture solutions were kept at room temperature. At the end of the 24 hours, the solutions were filtered and analyzed to find a mercury concentration of 10.5 and $10.6 \mathrm{mg} / \mathrm{L}$, respectively, which is very similar to the $70^{\circ} \mathrm{C}$ tests. This result may suggest that most of the mercury released was due to the adsorbed mercury instead of the high temperature $\left(70^{\circ} \mathrm{C}\right.$ in this instance) 
hydrolysis of the mercury-SAMMS. Previously, mercury-SAMMS \#1 was tested in a pH 4.7 sodium acetate solution of the TCLP test; only $0.02 \mathrm{ppb}$ mercury was found in the solution after 24 hours of testing at room temperature because these mercury-SAMMS \#1 powders were washed thoroughly with several liters of deionized water.

The mercury release results of the mercury-SAMMS \#2 are very similar at room temperature and at $70^{\circ} \mathrm{C}$, suggesting high stability of the mercury-SAMMS at $70^{\circ} \mathrm{C}$. A complete release of mercury from the 0.05 mercury-SAMMS in $50 . \mathrm{mL}$ water would result in a mercury concentration of $335 \mathrm{mg} / \mathrm{L}$. By subtracting the mercury released through the blank, the total release of mercury from the $70^{\circ} \mathrm{C}$ test is 2.2 and $2.4 \mathrm{mg} / \mathrm{g}$, respectively. In comparison to a total loading of $503 \mathrm{mg} / \mathrm{g}$, this corresponds to $0.4 \%$ at 24 hours heating at $70^{\circ} \mathrm{C}$.

\subsection{A Permanent Waste Form and Regeneration}

The mercury-loaded SAMMS not only passed TCLP tests, as shown in Section 4.10, but also had good chemical durability. The mercury-SAMMS therefore is expected to have good long-term durability as a permanent waste form because 1) the covalent binding between mercury and SAMMS has good resistance in ion exchange, oxidation, and hydrolysis over a wide $\mathrm{pH}$ range, and 2) the uniform and small pore size ( 2 to $40 \mathrm{~nm}$ ) of the mesoporous silica prevents bacteria (at least $2000 \mathrm{~nm}$ in size) from solubilizing the bound mercury (microbes are mainly responsible for solubilizing the mercury compounds in the environment into the deadly methylmercury, such as $\mathrm{CH}_{3}-\mathrm{Hg}-\mathrm{OH}$ ). The SAMMS technology is superior to many existing technologies because of the direct generation of a stable waste form that does not require secondary treatment. More systematic study is needed to fully demonstrate SAMMS's advantages as a permanent waste form.

There is still interest, however, in its capability to be regenerated for some special application such as mercury recycle. The following regeneration experiments were carried out.

The Regeneration of Mercury-SAMMS (all the tests are duplicated).

1. First loading with mercury: $0.5163 \mathrm{~g}$ of SAMMS \#2 was added to $1 \mathrm{~L}$ of $0.1 \mathrm{M} \mathrm{NaNO}_{3}$ solution containing $330 \mathrm{mg} \mathrm{Hg} / \mathrm{L}$, and the mixture was agitated for 4 hours at room temperature. The mixture was filtered, and the mercury-SAMMS powders were washed with high purity water and air-dried overnight. By analyzing the mercury concentrations of the blank solution (where no SAMMS was used, but same agitation and filtering were applied) and the final solution (filtrate from the SAMMS added solution), a mercury loading of $445 \mathrm{mg}$ mercury/g of SAMMS \#2 was obtained.

2. First regeneration: $0.2 \mathrm{~g}$ of mercury-SAMMS (dried overnight) was added to $10.0 \mathrm{~mL}$ high purity concentrated $\mathrm{HCl}(37 \mathrm{wt} \%)$ solution for 4 hours. The solid SAMMS was then separated by filtration. By analyzing the mercury concentration in the filtrate and comparing it with the available mercury on the SAMMS, it was found that $100 \%$ of the mercury was released from the SAMMS. The analyzed Si concentration in the concentrated $\mathrm{HCl}$ was only $2.90 \mathrm{ppm}$, suggesting the silica matrix of the mercury-SAMMS was not damaged by the concentrated acid.

3. Regeneration with $2 \mathrm{~N} \mathrm{HCl}: 0.2 \mathrm{~g}$ of mercury-SAMMS (dried overnight) was added to $20.0 \mathrm{~mL}$ high purity $2 \mathrm{~N} \mathrm{HCl}$ solution for 4 hours. The solid SAMMS was then separated by filtration. By 
analyzing the mercury concentration in the filtrate and comparing it with the available mercury on the SAMMS, it was found that less than $14 \%$ of the bound mercury was released from the SAMMS.

4. Second loading with mercury: The regenerated SAMMS (through concentrated $\mathrm{HCl}$ ) was washed with high purity water thoroughly and air-dried overnight. A sample of $0.075 \mathrm{~g}$ regenerated SAMMS was added to $150 \mathrm{~mL}$ of $0.1 \mathrm{M} \mathrm{NaNO}_{3}$ solution containing $330 \mathrm{mg} \mathrm{Hg} / \mathrm{L}$, and the mixture was agitated for 4 hours at room temperature. The mixture was filtered, and the mercurySAMMS powders were washed with high-purity water and air-dried overnight. By analyzing the mercury concentrations of the blank solution and the final solution, a mercury loading of $210 \mathrm{mg}$ $\mathrm{Hg} / \mathrm{g}$ of SAMMS was obtained. This was about $50 \%$ of the original loading. This may due to partial oxidation of the functional group on the SAMMS, and a regeneration in the presence of reducing agents may restore the thiol group to its reduced state and recover the full capacity of the SAMMS.

5. Second Regeneration: $0.095 \mathrm{~g}$ of mercury-SAMMS (dried overnight) was added to $10.0 \mathrm{~mL}$ high purity concentrated $\mathrm{HCl}$ solution for 4 hours. The solid SAMMS was then separated by filtration. By analyzing the mercury concentration in the filtrate and comparison with the available mercury on the SAMMS, the bound mercury was found $100 \%$ released from the SAMMS.

6. Third loading with mercury: The regenerated SAMMS was washed with high purity water thoroughly and air-dried overnight. A 0.069-g quantity of regenerated SAMMS was added to 137 $\mathrm{mL}$ of $0.1 \mathrm{M} \mathrm{NaNO}_{3}$ solution containing $330 \mathrm{mg} \mathrm{Hg} / \mathrm{L}$, and the mixture was agitated for 4 hours at room temperature. The mixture was filtered, and the mercury-SAMMS powders were washed with high purity water and air-dried overnight. By analyzing the mercury concentrations of the blank solution and the final solution, a mercury loading of $233 \mathrm{mg} \mathrm{Hg} / \mathrm{g}$ of SAMMS was obtained, which was again about $50 \%$ of the original capacity. This may suggest no further oxidation of the SAMMS. The regeneration experiments will be repeated in the future with the presence of reducing agents.

The mercury-laden SAMMS, therefore, can be regenerated with concentrated $\mathrm{HCl}$. The first treatment resulted in almost $100 \%$ release of the bound mercury. The regenerated mercury recovered only $50 \%$ capacity. The second regeneration showed again $100 \%$ release of mercury. The SAMMS after the second generation showed again a $50 \%$ of the original capacity in its third time in binding mercury. The complete regeneration of the SAMMS may need reducing agents. A $2 \mathrm{~N} \mathrm{HCl}$ solution can release only $14 \%$ of the bound mercury. 


\subsection{Preliminary Cost Estimate}

\subsection{Background}

The Nonradiological Wastewater Treatment Plant (NRWTP) at the Oak Ridge National Laboratory currently treats wastewater to remove hazardous metals and organics before discharge to nearby creeks. Changes in the NPDES permit may require treatment to very low levels of mercury (12 ppt). The current treatment system uses activated carbon to remove low levels of organics and mercury, but the effluent generally does not meet the 12-ppt limit. New highly selective separations materials offer an attractive way to meet the lower discharge limits.

\subsection{Purpose and Scope}

The purpose of this section is to develop and document preliminary costs for applying the SAMMS materials to remove mercury. The focus of this effort is on removing mercury from wastewater treated at the NRWTP. Additional applications of SAMMS for mercury removal, such as those at the Y12 plant, will be addressed in follow-on studies.

\subsection{Approach}

To develop cost estimates for implementing SAMMS for mercury removal requires that implementation methods be developed and assessed. The alternatives considered include 1) install a separate column system using SAMMS, 2) mix the SAMMS with the activated carbon in the existing columns, or 3) use a small skid mounted system with SAMMS for treatment at the source. Given the laboratory-scale status of the development of the SAMMS materials, an accurate cost estimate for production and implementation of SAMMS is difficult to provide. The uncertainties are minimized by developing cost estimates that are incremental to the existing treatment operation. A rough cost estimate for the production of commercial quantities of the materials was developed by determining the bulk cost of the chemicals required for synthesis and by obtaining costs of other separations materials that have some synthesis steps in common with the SAMMS.

\subsection{Mercury Removal at the Nonradiological Wastewater Treatment Plant}

This section contains the available cost information on SAMMS and applying SAMMS to the removal of mercury at the NRWTP. A description of the existing system is included along with a discussion of three alternatives for using SAMMS to meet the new effluent limit of $12 \mathrm{ppt}$ for mercury.

\subsubsection{Description of the Existing Mercury Removal System}

The NRWTP treats water at an average rate of $1200 \mathrm{Lpm}(320 \mathrm{gpm})$, which corresponds to a total annual volume of 637 million L (168 million gallons). There are numerous sources of the contaminated water, including building sumps and runoff and ground water. The flow to the NRWTP is variable due to rainfall, so the plant is sized for a maximum capacity of $2880 \mathrm{Lpm}(760 \mathrm{gpm})$. The most concentrated 
mercury sources are the building sumps where historical spills occurred. The flow to these sumps is from in leakage of groundwater and rainwater is highly variable and is roughly estimated to be in the range of 4 to $76 \mathrm{Lpm}$ (1 to $20 \mathrm{gpm}$ ). The mercury concentration varies from less than $0.0002 \mathrm{mg} / \mathrm{L}$ to a maximum of $0.8 \mathrm{mg} / \mathrm{L}$ for individual sump samples. Concentrations of mercury in the wastewater feed to the NRWTP are not available at this time.

The existing system in use at the NRWTP for treating the wastewater involves a number of sequential process steps that include chemical precipitation, clarification, filtration, air stripping, and activated carbon adsorption. Much of the heavy metal content, including some mercury, is removed in the precipitation step and separated from the bulk liquid in the clarification and filtration steps. Other important heavy metals that are partially removed include arsenic, chromium, copper, lead, nickel, selenium, silver, and zinc. Volatile organics are removed by the air stripping step. Activated carbon, which removes low levels of organics and mercury, is used to polish the water before it is discharged.

A typical operation uses three columns of activated carbon: two columns operate in series with a third on standby. Each column contains $9900 \mathrm{~kg}(22,000 \mathrm{lb})\left(239 \mathrm{~m}^{3}\left[785 \mathrm{ft}^{3}\right]\right)$ of activated carbon. The mercury concentration in the feed to the activated carbon beds typically ranges from $200 \mathrm{ppt}$ to $400 \mathrm{ppt}$ with an average close to $200 \mathrm{ppt}$. The mercury level in the effluent from the activated carbon beds is typically less than $50 \mathrm{ppt}$, but is sometimes detected at concentrations up to $100 \mathrm{ppt}$. Consequently, the plant as currently configured and operated does not meet the new effluent requirement for mercury (12 $\mathrm{ppt})$. The spent carbon is disposed of as low level waste at a cost of $\$ 60 / \mathrm{ft}^{3}$. The carbon is handled as LLW because it is slightly contaminated with ${ }^{137} \mathrm{Cs},{ }^{90} \mathrm{Sr}$, and ${ }^{60} \mathrm{Co}$. It is assumed that a carbon bed will process 2 years worth of wastewater and that the activated carbon amount is determined by the organic removal requirement. The annual carbon requirement is $11,000 \mathrm{lb}$, and the annual cost is $\$ 9400$ (@ $\$ 0.85 / \mathrm{lb}$ ). The total disposal cost of the carbon on an annual basis is $\$ 23,500 / \mathrm{yr}$.

\subsubsection{Description of Mercury Removal Using SAMMS}

To develop cost information, it is necessary to develop implementation alternatives. The following three alternatives for implementing the SAMMS for mercury removal at the NRWTP are considered: 1) install a separate column system using SAMMS, 2) mix the SAMMS with the activated carbon in the existing columns, 3) use a small skid-mounted system with SAMMS for source treatment.

\subsubsection{Separate Column System Using SAMMS}

In this alternative, it is proposed that a separate three-column system would be installed to treat the full amount of wastewater:1213 Lpm (320 gpm). Two of the columns would be placed in series with one column on standby. Two columns in series allows nearly complete loading of the first column while maintaining high decontamination factors for the mercury. The third column on standby would allow changeout of the mercury-loaded SAMMS without interrupting water treatment. Calculations based on isotherm data suggest that $1.6 \mathrm{~kg}$ of SAMMS should be sufficient for 1 year of operation. If it is assumed that the SAMMS can be fully loaded (i.e., in equilibrium with the feed at $0.0002 \mathrm{ppm}$ ), the mercury loading on the SAMMS is about $80 \mathrm{mg} \mathrm{Hg} / \mathrm{g}$ of SAMMS. One year of wastewater contains about $127,000 \mathrm{mg}$ of mercury. Dividing this value by the loading assumed for the SAMMS gives $1590 \mathrm{~g}$ or about $1.6 \mathrm{~kg}$.

The difficulty with this approach is attempting to contact such a large volume of water with a small volume of SAMMS in a column operation. Attempting to force such a large volume of water through a 
small bed volume would result in excessive pressure drop and would probably provide an inadequate residence time for the mercury removal process (i.e., $0.08 \mathrm{~s}$ at $1213 \mathrm{Lpm}[320 \mathrm{gpm}]$ ). For comparison, the activated carbon beds are sized to provide a residence time of $7.75 \mathrm{~min}(7.75$ bed volumes $/ \mathrm{h})$. Preliminary data indicate that the SAMMS have rapid kinetics for removing mercury, so the required column size may be less than the size of the carbon beds. In the absence of column testing data, it is not possible to accurately project a size for the columns.

Assuming the SAMMS are implemented in a 3-column system similar to the existing system (2 columns in series and 1 on standby), the capital cost is estimated to be about $\$ 5 \mathrm{M}$. This estimate was developed using cost data developed in the PAI Corporation engineering study. The columns are greatly over sized for this application, but this is necessary to avoid excessive pressure drops. While the column size can undoubtedly be made smaller, the costs would still be substantial. Assuming the columns are reduced in size by a factor of 10 and assuming the capital cost varies with an exponent of 0.6 , the capital cost would still be $\$ 1.25 \mathrm{M}$. Operating and maintenance costs for an extra ion exchange system were estimated to be about $\$ 100 \mathrm{k} / \mathrm{yr}$

\subsubsection{Mix with the Activated Carbon}

In this alternative, it is proposed that the SAMMS would be mixed with the activated carbon and used in the existing equipment. The activated carbon would remove the trace amounts of organics, and the SAMMS would enhance the mercury removal capability. In the absence of experimental data, it is difficult to accurately project the amount of SAMMS that would be required to adequately enhance the mercury removal capability, but 1 to $10 \mathrm{wt} \%$ seems reasonable. At the West Valley Demonstration Project (West Valley, New York), about $10 \mathrm{wt} \%$ titania is added to zeolite, to remove trace amounts of transuranics in addition to the cesium. However, the titania-loaded zeolite was only needed in every third or fourth column. With $9900 \mathrm{~kg}(22,000 \mathrm{lb})$ of activated carbon per column, the SAMMS requirement is 99 to $990 \mathrm{~kg}$ ( 220 to $2200 \mathrm{lbs}$ ) per column.

The capital cost of this approach would be $\$ 0$ since existing equipment would be used. Operating and maintenance costs would remain unchanged since neither operations nor equipment would be changed. The only additional costs would be for the SAMMS materials and a small incremental amount for waste disposal associated with the additional volume due to the SAMMS. Assuming the activated carbon requirement remains unchanged, a SAMMS loading of 1 to 10\% of the activated carbon, and a cost of $\$ 50 / \mathrm{kg}$ for the SAMMS, the purchase cost of the SAMMS would range from $\$ 2500 / \mathrm{yr}$ to $\$ 25,000 / \mathrm{yr}$. The incremental cost of waste disposal would range from 1 to $10 \%$ of the current cost for disposal or $\$ 235$ to 2,350/yr. Adding this to the cost of the SAMMS and rounding off to one significant figure gives a total incremental cost of $\$ 3 \mathrm{k} / \mathrm{yr}$ to $\$ 30 \mathrm{k} / \mathrm{yr}$.

\subsubsection{Small System for Source Treatment}

In this alternative, it is proposed that the SAMMS would be implemented in a small skid-mounted unit for removal of mercury at the source. This would allow a much smaller volume of water to be more easily contacted with the small volumes of SAMMS. The mercury loading on the SAMMS could also be improved because the mercury concentration is greater in the source streams. Two types of units are considered; skid-mounted columns and $3 \mathrm{M}$ cartridges.

The skid mounted unit with columns is assumed to have 3 columns in series ( 2 in series and 1 on standby). Two columns would be online with one on standby. Each column would contain about $13 \mathrm{ft}^{3}$ 
(368 L) of SAMMS and are sized to operate with a flowrate of 12.5 bed volumes per hour. The skid would also include a sand filter, surge tank, pumps, and automated valve switching. This skid is estimated to cost $\$ 65 \mathrm{k}$ based on a vendor quote. A separate quote of $\$ 18 \mathrm{k}$ was obtained for a manually operated system with similar components. It is assumed that the SAMMS would be used on a once-through basis and disposed of as LLW.

The total amount of SAMMS for a 3-column system is $39 \mathrm{ft}^{3}(1100 \mathrm{~L})$ and would cost about $\$ 55 \mathrm{k}$, bringing the total capital cost to $\$ 120 \mathrm{k}$ (skid + SAMMS). Based on equilibrium considerations, this probably is a large amount of SAMMS for the amount of mercury present. Based on the feed to the activated carbon columns (which contains an estimated $127 \mathrm{~g}$ of Hg/yr and requires an estimated $1.6 \mathrm{~kg}$ of SAMMS), each of the skid-mounted columns could theoretically treat 230 years of wastewater. The actual SAMMS requirement for source treatment may be somewhat greater than $1.6 \mathrm{~L} / \mathrm{yr}$, but an accurate estimate requires the results of an ongoing effort to characterize the source flowrates and mercury concentrations. The cost to dispose of a $13 \mathrm{ft}^{3}$ column is estimated to be about $\$ 780$, which is a negligible annual cost. Since these units would be separate from the NRWTP, additional labor costs would be incurred. These are estimated at 0.5 to 1 FTE for an incremental operational cost of $\$ 100 \mathrm{k}-\$ 200 \mathrm{k}$.

The $3 \mathrm{M}$ cartridges have been specifically designed to allow highly selective sorbents and ion exchange materials to be contacted with large amounts of water containing dilute levels of contaminates. The cartridges contain web material that supports small particles of the separations media. The support structure allows rapid flow without excessive pressure drop, and the small particles allow rapid diffusion in the particle. Skid mounted cartridges have been used to remove ${ }^{90} \mathrm{Sr}$ from $\mathrm{N}$-Springs groundwater at the Hanford site (Brown et al. 1996), to remove radioactivity from evaporator overheads at the West Valley Demonstration Project (Dinsmore et al. 1996) and to remove radioactivity from groundwater at the Idaho Site (Brewer, 1995). The units that have been used have a capacity of $37.9 \mathrm{Lpm}(10 \mathrm{gpm})$ and contain a sorbent mass of $857 \mathrm{~g}$ and cost $\$ 52 \mathrm{k}$. Two units would be required for $75.8 \mathrm{Lpm}(20 \mathrm{gpm})$ for a total capital cost of $\$ 104 \mathrm{k}$. Assuming the cartridges would need to be changed out twice per year (1.6 kg of SAMMS), the cost of the SAMMS would be $\$ 80 / \mathrm{yr}$. Each cartridge has a volume of about $1.7 \mathrm{~L}$. With 12 cartridges requiring disposal every year, the volume is $1 \mathrm{ft}^{3}$, and the disposal cost would be $\$ 60 / \mathrm{yr}$. Since these units would be separate from the NRWTP, additional labor costs would be incurred. These are estimated at 0.5 to 1 FTE for an incremental operational cost of $\$ 100 \mathrm{k}-\$ 200 \mathrm{k}$.

\subsection{Comparison of Costs}

The cost estimates developed in this study are compared to cost estimates obtained from the PAI Corp study (Table 5.1). These costs are incremental, relative to existing operations. While considerable uncertainty is associated with these estimates, it is apparent that the use of SAMMS has the potential to provide improved mercury removal for the least cost. The options considered in the PAI corp study involve substantial upgrades and additions to the NRWTP or completely new capabilities and therefore involve considerable capital and operating expense.

\subsection{Material-Lifetime Cost Comparison}

Given the uncertainty associated with the cost estimates for implementation, it is instructive to compare the costs associated with the use of the separations materials and waste disposal. This is shown in Table 5.2, where the costs are developed for removing $1 \mathrm{~kg}$ of mercury. The amount of SAMMS material 
is based on laboratory equilibrium data at a mercury concentration of $200 \mathrm{ppt}$. The amount of GT-73 material is based on an extrapolation of manufacturers data to $200 \mathrm{ppt}$ from higher concentrations. The amount of activated carbon is based on the performance of the full-scale columns. In the absence of capital and labor costs, it is apparent that the SAMMS are the most economical sorbent material for mercury removal.

Table 5.1. Comparison of Costs

\begin{tabular}{|l|c|c|}
\hline & Capital, \$M & $\begin{array}{c}\text { Operating and Maintenance, } \\
\text { \$M/yr }\end{array}$ \\
\hline Dilute to river & 18.5 & 0.37 \\
\hline Flow augmentation & 7.7 & 0.37 \\
\hline Alternative A & 1.15 & 0.57 \\
\hline Alternative B & 3.09 & 0.66 \\
\hline Alternative C & 3.91 & 0.82 \\
\hline Alternative B + IX/Evap & 7.32 & 1.15 \\
\hline Alternative C + IX/Evap & 8.15 & 1.31 \\
\hline & Alternatives for implementing SAMMS & \\
\hline Separate column system & $1.25-5.0$ & $0.1-0.2$ \\
\hline Mix SAMMS with Activated Carbon & 0 & $0.003-0.03$ \\
\hline Skid mounted columns & 0.12 & $0.1-0.2$ \\
\hline Skid mounted 3 M cartridges & 0.104 & $0.1-0.2$ \\
\hline
\end{tabular}

\subsection{Cost Summary}

The preliminary cost information developed in this report indicates that SAMMS offers a method for improved mercury removal that may be significantly less expensive than other options. The SAMMS is less expensive because of the relatively high mercury loading that can be achieved. This reduces the capital cost by reducing the size of the treatment system and by reducing the waste disposal volume. Also, contributing to a reduced cost is the fact that the SAMMS can be implemented as a one-time-use sorbent and then disposed of directly as a waste form. This mode of operation is relatively simple, resulting in reduced operating costs, and avoids the costs associated with secondary waste treatment. 
Table 5.2. Material-Lifetime Cost Comparison

\begin{tabular}{|l|c|c|c|}
\hline & SAMMS & GT-73 & Activated Carbon \\
\hline Material Cost, \$/kg & $\$ 50 / \mathrm{kg}$ & $\$ 42 / \mathrm{kg}$ & $\$ 1.78 / \mathrm{kg}$ \\
\hline $\begin{array}{l}\mathrm{Hg} \text { loading, } \\
\mathrm{g} / \mathrm{kg} @ 0.2 \mathrm{ppb}\end{array}$ & $80 \mathrm{~g} / \mathrm{kg}$ & $6.5 \mathrm{~g} / \mathrm{kg}$ & $0.025 \mathrm{~g} / \mathrm{kg}$ \\
\hline $\begin{array}{l}\text { Material Required for } \\
\text { Removal of } 1 \mathrm{~kg} \text { of } \mathrm{Hg}\end{array}$ & $13 \mathrm{~kg}$ & $154 \mathrm{~kg}$ & $40,000 \mathrm{~kg}$ \\
\hline $\begin{array}{l}\text { Waste Disposal Cost } \\
\text { per Kg of Hg Removed } \\
@ ~\end{array}$ & $\$ 60 / \mathrm{ft}^{3}$ & $\$ 489$ & $\$ 190,000$ \\
\hline $\begin{array}{l}\text { Total cost per kg of Hg } \\
\text { removed }\end{array}$ & $\$ 710$ & $\$ 6960$ & $\$ 261,000$ \\
\hline
\end{tabular}

The preliminary cost estimates for implementing SAMMS for mercury removal at the NRWTP are summarized in Table 5.3. These estimates are significantly less than the estimates associated with other options that have been evaluated. Estimates for upgrading or adding to the NRWTP include capital costs that range from $\$ 1.1 .5 \mathrm{M}$ to $\$ 8.15 \mathrm{M}$ and annual operating costs that range from $\$ 0.57 \mathrm{M}$ to $\$ 1.31 \mathrm{M}$ (PAI Corp.). The most expensive system evaluated had a capital cost of $\$ 18.5 \mathrm{M}$ and involved developing infrastructure to allow the wastewater to be diluted in a high flow river.

A rough cost estimate for the production of commercial quantities of the materials was developed by determining the bulk cost of the chemicals required for synthesis and by obtaining costs of other separations materials that have some synthesis steps in common with the SAMMS. The cost of the raw materials obtained in bulk were determined to be $\$ 20.77 / \mathrm{kg}$ of SAMMS with a market price estimated to be approximately $\$ 50 / \mathrm{kg}$ or $\$ 1400 / \mathrm{ft}^{3}$. This cost estimate may be compared to other separations materials that range from $\$ 29 / \mathrm{kg}$ for zeolite beta to $\$ 100 / \mathrm{kg}$ for crystalline-silico titanates (a cesium ion exchange material) to thousands of dollars per $\mathrm{kg}$ for high grade chromatography materials produced in relatively low quantities.

A comparison of the cost of the materials and waste disposal reflects the high capacity and selectivity of the SAMMS. The cost per kg of mercury removed was estimated to be $\$ 710$ for the SAMMS, $\$ 6960$ for GT-73 (a commercially available organic based sorbent), and $\$ 261,000$ for activated carbon. The high mercury loading on the SAMMS results in a small volume of material, minimizing the cost of material procurement and waste disposal.

A key issue in realizing the economy offered by SAMMS is to implement the materials in a manner that efficiently contacts the SAMMS with the wastewater and takes advantage of the highly selective characteristics of the SAMMS. The most promising options for achieving this are to mix the SAMMS with the existing activated carbon beds or to implement the SAMMS in small skid-mounted units for source treatment that involves smaller volumes of wastewater. Implementing the SAMMS in a large traditional column system appears to be as costly as other methods that have been considered and would be hugely oversized for the application. 
Table 5.3. Preliminary Cost Estimates for Implementing SAMMS for Mercury Removal

\begin{tabular}{|l|c|c|}
\hline & Capital Cost, \$M & Operating and Maintenance, \$M/yr \\
\hline Separate column system & $1.25-5.0$ & $0.1-0.2$ \\
\hline Mix SAMMS with activated carbon & 0 & $0.003-0.03$ \\
\hline Skid mounted columns & 0.12 & $0.1-0.2$ \\
\hline Skid mounted 3 M cartridges & 0.104 & $0.1-0.2$ \\
\hline NonSAMMS Alternatives & $1.15-18.5$ & $0.57-1.31$ \\
\hline
\end{tabular}




\subsection{Conclusions}

The data discussed above may provide some indications that SAMMS technology has the following characteristics.

1. High RCRA Metal Loading: The high surface area of the mesoporous oxides $\left(>1000 \mathrm{~m}^{2} / \mathrm{g}\right)$ ensures large capacity for metal loading (up to $0.64 \mathrm{~g} \mathrm{Hg} / \mathrm{g}$ of SAMMS).

2. High Selectivity: Self-assembled functional groups provide the high selectivity for RCRA metals, such as $\mathrm{Hg}, \mathrm{Ag}, \mathrm{Pb}$, and $\mathrm{Cd}$, without significant interference from other abundant cations (such as alkali and alkaline earths) and anions such as $\mathrm{Cl}^{-}, \mathrm{CO}_{3}{ }^{2-}, \mathrm{SO}_{4}{ }^{2-}$, and $\mathrm{PO}_{4}{ }^{3-}$ in wastewaters. There are almost no pH effects on the mercury binding of SAMMS between $\mathrm{pH} 4$ and 9 . At $\mathrm{pH} 2$ and 10 , the Kd of SAMMS for mercury may be reduced by more than 10 times, and the $\mathrm{pH} 2$ had a larger effect than that at $\mathrm{pH} \mathrm{10.} \mathrm{Almost} \mathrm{no} \mathrm{ionic} \mathrm{strength} \mathrm{effects} \mathrm{have} \mathrm{been} \mathrm{observed} \mathrm{on} \mathrm{the} \mathrm{Kd}$ of SAMMS for mercury between 0 and $4 \mathrm{M} \mathrm{NaNO}_{3}$ solutions.

3. High Affinity: The covalent binding between the thiol group of SAMMS and mercury provide the high affinity for mercury so that SAMMS is capable of reducing the mercury concentrations in salt solution and in groundwater below a 10-ppt level (the detection limit of the mercury analyzer).

4. Fast Kinetics: The high surface area on SAMMS and high affinity of its functional group for mercury result in fast binding kinetics so that SAMMS can reduce a $0.5 \mathrm{ppm}$ mercury in $0.1 \mathrm{M} \mathrm{NaNO}_{3}$ solution to $0.5 \mathrm{ppb}$ in less than 5 minutes at a solution-to-SAMMS ratio of 2000 . The kinetics in engineered SAMMS, such as beads and membranes, are to be investigated next year.

5. High Flexibility: SAMMS binds mercury in different forms, including metallic, organic, ionic, neutral such as $\mathrm{Hg}(\mathrm{OH})_{2}(\mathrm{aq})$, and complexes such $\mathrm{HgCl}_{2}$; removes mercury from aqueous wastes, organic oils, and mercury vapor; is expected to be applicable also to sludges and soils (which is going to be demonstrated in a project funded by DOE MWFA); and is demonstrated to be effective in $\mathrm{pH} 2$ to 10 . SAMMS removed $91 \%$ of the $\mathrm{Hg}$ in SRS tritiated pump oils waste through a single treatment with SAMMS powders.

6. Permanent Waste Form: The mercury-loaded SAMMS not only can pass TCLP tests, but also has good chemical durability as a permanent waste form because 1) the covalent binding between mercury and SAMMS has good resistance in ion exchange, oxidation (up to $150^{\circ} \mathrm{C}$ in air), and hydrolysis (up to $70^{\circ} \mathrm{C}$ in water) and 2) the uniform and small pore size ( 2 to $40 \mathrm{~nm}$ ) of the mesoporous silica prevents bacteria (at least $2000 \mathrm{~nm}$ in size) from solubilizing the bound mercury (microbes are mainly responsible for solubilizing the mercury compounds in the environment into the deadly methylmercury). The SAMMS technology is superior to many existing technologies because of the direct generation of a stable waste form that does not require secondary treatment.

7. No Secondary Wastes: During the application of SAMMS and disposal of merucry-SAMMS, no secondary wastes are generated, the mercury-SAMMS can be disposed of as nonhazardous waste, and the final waste volume is small because of the high waste loading of SAMMS.

8. Regenerability: SAMMS can be regenerated using concentrated $\mathrm{HCl}$ if such needs exist. This may be useful for some special applications such as using SAMMS as a mercury sensor. 
9. Multiple Applicability: SAMMS with different functional groups is being shown to be effective in removing cations such as $\mathrm{Pb}, \mathrm{Cd}$, and $\mathrm{Ag}$, actinides $\mathrm{Pu}, \mathrm{Np}$, and $\mathrm{Am}$ (Feng et al. 1998), anions such as As, $\mathrm{Cr}$, and $\mathrm{Re}$, and organics such as dense nonaqueous phase liquids (DNAPLs) (Liu et al. 1997).

10. Low Cost Implementation: The preliminary cost assessment of the SAMMS technology for RCRA metal removal indicates a lower lifetime cost than existing technologies. 


\subsection{References}

Anthony RG, CV Philips, and RG Dosch. 1993. Waste Management 13, 503.

Attard GS, JC Glyde, and CG Gottner. 1995. Nature, 378, 366.

Badia A, et al. 1996. Langmuir 12, 1262.

Baes, CF. Jr., and RE. Mesmer, 1976, The Hydrolysis of Cations, John Wiley \& Sons, New York

Bagshaw SA, E Prouzet, and TJ Pinnavaia. 1995. Science, 269, 1242.

Ball P. 1994. Designing the molecular world, Princeton University Press: Princeton, New Jersey.

Beck JS, JC Vartuli, WJ Roth, ME Leonowicz, CT Kresge, KD Schmitt, C T-W Chu, DH Olson, EW

Sheppard, SB McCullen, JB Higgins, and JL Schlenker. 1992. J. Am. Chem. Soc. 114:10834.

Beck JS., and JC Vartuli. 1996. Cur. Opin. Sol. St. Mater. Sci. 1, 76.

Blayney, M.B., J. S. Winn, D. W. Nierenberg, 1997, Chem \& Eng News, 12 May, 7

Brown GN, KJ Carson, JR DesChane, RJ Elovich, TM Kafka, and LR White. 1996. Ion exchange removal of strontium from simulated and actual N-Springs well water at the Hanford 100-N Area. PNNL11198, Pacific Northwest National Laboratory, Richland, Washington.

Brewer KN, TA Todd (Lockheed Idaho Technologies Company), TM Kafka and LR White (3M), and LA Bray (PNL). 1995. Decontamination of TAN Injection Well Water Using 3M Web Technology, INEL9510589, Lockheed Idaho Technologies Company, Idaho Falls, Idaho.

Bunker, BC, PC Rieke, BJ Tarasevich, AA Campbell, GE Fryxell, GL Graff, L Song, J Liu, and JW Virden. 1993. "Ceramic Thin Film Formation on Functionalist Interfaces Through Biomimetic Processing," Science, 261, 1286.

Dinsmore EF, G Smith, LABray, GN Brown, KC Carlson, TM Kafka, DCSeely, and LR White. 1996. Removal of specific radionuclides from process streams at the West Valley demonstration project using $3 M$ separation technology. 3M New Products Department, St. Paul, Minnesota.

Feng X, J Liu, and GE Fryxell. 1997a. "Self-assembled Mercaptans on Mesoporous Silica (SAMMS) for Mercury Separation and Stabilization," U.S. Patent Application filed on February 7, 1997a, PNNL \#E1479.

Feng X, GE Fryxell, LQ Wang, AY Kim, J Liu, and KM Kemner. 1997b. "Functionalized Monolayers on Ordered Mesoporous Supports," Science, 276, 923-926.

Feng X, L Rao, TR Mohs, GE Fryxell, Y Xia, J Lu, J Xu, and KN Raymond. 1998. "Removal of Am(III), Th(IV), Np(V), and U(VI)from Wastewater Using SAMMS," accepted for presentation at AIChE's 1998 Spring National Meeting, March 8-12, New Orleans, Louisiana. 
Firouzi A, et al. 1995. Science, 267, 1138.

Fryxell GE, PC Rieke, LL Wood, MH Engelhard, RE Williford, GL Graff, AA Champbell, RJ Wiacek, L Lee, and A Halverson. 1996. "Nucleophilic displacements in mixed self-assembled monolayers."

Langmuir 11, 318-326.

Gao W, and L Reven. 1995. Langmuir 11, 1860-1863.

Ghazy SE. 1995. "Removal of Cadmium, Lead, Mercury, Tin, Antimony, and Arsenic from Drinking and Seawaters by Colloid Precipitate Flotation," Sep. Sci. Technol., 30(6):933.

Huo Q, et al. 1994. Nature, 368, 317.

Kresge CT, ME Leonowicz, WJ Roth, JC Vartuli, and JS Beck.. 1992. Nature 359:710.

Kumar A, HA Biebuyck, and GM Whitesides. 1994. Langmuir, 10, 1498.

Larson KA and JM Wiencek.. 1994. "Mercury Removal from Aqueous Streams Utilizing Microemulsion Liquid Membranes," Environmental Progress, 13(4):253.

Le Grange JD, JL Markham, and CR Kurkjian. 1993. Langmuir, 9, 1749-1753.

Levy GC, RL Lichter, and GL Nelson. 1980. Carbon-13 Nuclear Magnetic Resonance Spectroscopy, 2nd Ed., John Wiley and Sons, New York.

Liu J., et al. 1996. Adv. Colloid. Interface. Sci. 69, 131.

Liu J, G Fryxell, X Feng, and R Hallen. 1997. PNNL 1997 APTI Laboratory Initiative Project.

Maschmeyer T, F Rey, G Sankar, and JM Thomas. 1995. Nature, 378, 159.

Mitra S. 1986. Mercury in the ecosystem; Trans Tech Publications, USA

Otanl Y, H Eml, C Kanaoka, and H Nishino. 1988. "Removal of Mercury Vapor from Air with Sulfur-Impregnated Adsorbents," Environ. Sci. Technol., 22(6):708.

Pai Corporation. 1993. Non-radiological Wastewater Treatment Plant Upgrade Options for Compliance with Water Quality-Based Effluent Standards, PAI Corporation and AquAeTer, Inc.

Ritter JA and JP Bibler. 1992. Toxic Waste Management in the Chemical and Petrochemical Industries., "Removal of Mercury From Waste Water: Large-scale Performance of An Ion Exchange Process," Water Sci. Technol, 25(3):165.

Sayari A. 1996. Chem. Mater. 8, 1840.

Sayers DE and BA Bunker. 1988. X-Ray Absorption, Principles, Applications, Techniques of EXAFS, SEXAFS, AND XANES. D. C. Koningsberger and R. Prins, Eds. [Wiley and Sons Publishing Co. New York], pp. 211-256 and all of chapter 6. 
Schierbaum KD. 1994. Science 265, 1413.

Schwarzenbach G and M Schellenberg. 1965. Helv. Chim. Acta, 48, 28.

Stern EA and SM Heald. 1979. Rev. Sci. Instrum 50, 1579.

Sindorf, D. W. and G. E. Maciel, J. Am Chem. Soc. 105, 3769 (1983).

Tanev PT and TJ Pinnavaia. 1995. Science, 267, 865.

Tarasevich BJ, PC Rieke, and J Liu. 1996. "Nucleation and Growth of Oriented Films onto Organic Interfaces," Chemistry of Materials, 8: 292-300.

Tripp CP and ML Hair. 1992. Langmuir 8, 1120-1126.

Sindorf DW and GE Maciel. 1983. J. Am Chem. Soc. 105, 3769.

Tian Z, W Tong, J Wang, N Duan, VV Krishana, and SL Suib. 1997. Science, 276, 926.

Ulman A, SD Evans, Y Shnidman, R Sharma, JE Eilers, and JC Chang. 1991. J. Am. Chem. Soc., 113, 1499.

Wang L-Q, J Liu, GJ Exarhos, and BC Bunker. 1996. Langmiur 12, 2663.

Wirth MJ, RW Peter Fairbank, and HO Fatunmbi. 1997. Science, 275. 


\subsection{Patents Publications and Press Highlights}

Patents:

Feng X, J Liu, and GE Fryxell. 1997. "Self-assembled Mercaptans on Mesoporous Silica (SAMMS) for Mercury Separation and Stabilization," U.S. Patent Application filed on February 7, 1997, PNNL \#E-1479.

\section{Publications:}

Feng X, GE Fryxell, LQ Wang, AY Kim, J Liu, and KM Kemner. 1997. "Functionalized Monolayers on Ordered Mesoporous Supports," Science, 276, 923-926.

Feng X, JLiu, and GE Fryxell. 1997. "Self-Assembled Monolayers on Mesoporous Supports (SAMMS) for RCRA Metal Removal," Proceedings of Efficient Separations and Processing Crosscutting Program 1997 Technical Exchange Meeting, January 28-30, 1997, Gaithersburg, Maryland, PNNL-SA-28461, 5.15-5.20.

\section{Press Highlights:}

Science highlighted SAMMS technology for mercury removal in "This Week In Science" on 9 May 1997.

Chemical \& Engineering News published a feature article on 19 May 1997 to hail the SAMMS material as a "supersoaker for heavy metals."

Scientific American (October 1997) featured SAMMS in the "Technology and Business" section as a breakthrough material that "can render hazardous wastewater clean enough to drink." 


\section{Appendix A \\ Production Cost Estimate for SAMMS}




\section{Appendix A \\ Production Cost Estimate for SAMMS}

The production cost of SAMMS was estimated by obtaining estimates from chemical suppliers of the raw materials in bulk. The details of this estimate may be found in Table A1 where the total cost of raw materials is estimated to be $\$ 20.77 / \mathrm{kg}$ of SAMMS. Considering a number of other cost factors, a value of $\$ 50 / \mathrm{kg}$ for the production of SAMMS in bulk is considered reasonable. This corresponds to a volumetric cost of $\$ 1400 / \mathrm{ft}^{3}$, assuming a dry density of $1 \mathrm{~kg} / \mathrm{L}$ for the engineered form of SAMMS.

As a check on the reasonableness of this estimate; several producers of separations materials were queried as to their costs. One vendor, who wishes to remain anonymous, indicated that their production costs of separations materials are typically; $\$ 40,000 / \mathrm{ft}^{3}$ for gram quantities, $\$ 20,000 / \mathrm{ft}^{3}$ for kg quantities, $\$ 2000$ to $\$ 3000 / \mathrm{ft}^{3}$ for a few cubic feet and upper 100 s to lower 1000 s for $1000 \mathrm{ft}^{3}$. Another vendor in the business of producing functionalized silica beads for chromatography applications indicated costs that ranged from $\$ 400 / \mathrm{kg}$ to $\$ 4000 / \mathrm{kg}$. These materials are more expensive than the estimate for SAMMS, but are not produced in large quantities and often require high grade and expensive silica. A final example is Zeolite beta, which is made using an organic template similar to the production of SAMMS. The price was quoted as $\$ 29 / \mathrm{kg}$, which is quite high for zeolites. It can be seen that the cost estimate of $\$ 50 / \mathrm{kg}$ $\left(\$ 1400 / \mathrm{ft}^{3}\right.$ of SAMMS is consistent with the costs of these separations materials. 
Table A-1. Raw Material Cost for SAMMS

\begin{tabular}{|c|c|c|c|c|c|c|c|c|}
\hline Chemical & $\begin{array}{l}\text { Source } \\
\text { of quote }\end{array}$ & $\begin{array}{l}\text { Basis amount, } \\
\text { lb }\end{array}$ & $\begin{array}{l}\text { Price } \\
\$ / / b\end{array}$ & $\begin{array}{l}\text { Shipping, } \\
\text { \$/lb }\end{array}$ & $\begin{array}{l}\text { Delivered Price **, } \\
\$ / 1 b\end{array}$ & $\begin{array}{l}\text { Delivered } \\
\text { price, } \\
\$ / \mathbf{k g}\end{array}$ & $\begin{array}{l}\text { Amount, } \\
\text { kg }\end{array}$ & $\begin{array}{l}\text { Cost per kg of } \\
\text { SAMMS } \\
\$ / \mathbf{k g}\end{array}$ \\
\hline $29 \mathrm{wt} \%$ CTAC & $\begin{array}{l}\text { LONZA } \\
\text { hinc. }\end{array}$ & 40,000 & 0.74 & 0.06 & 0.80 & 1.76 & 2.436 & 4.29 \\
\hline Sodium Aluminate (dry) & $\begin{array}{l}\text { Pfaltz } \\
\text { and } \\
\text { Bauer }\end{array}$ & 40,000 & 8.60 & 0.06 & 1.29 & 2.84 & 0.0528 & 0.15 \\
\hline HiSil 233 & PPG & 30,000 & 0.65 & 0.07 & 0.72 & 1.57 & 0.3036 & 0.48 \\
\hline Soluble silicate, $38 \mathrm{wt} \% \mathrm{SiO}_{2}: \mathrm{Na}_{2} \mathrm{O}$ & $\mathrm{PQ}$ & $20,000-40,000$ & 0.08 & included & 0.08 & 0.18 & 0.448 & 0.08 \\
\hline \multirow[t]{3}{*}{ 3-mercaptopropyltrimethoxysilane } & $\begin{array}{l}\text { HULS } \\
\text { America }\end{array}$ & 40,000 & 10.00 & Included & 10.00 & 22.03 & 0.716 & 15.77 \\
\hline & & & & & & & Total & $\$ 20.77 / \mathrm{kg}$ \\
\hline & & & & & & & & $\$ 588.22 / \mathrm{ft}^{3}$ \\
\hline
\end{tabular}

** Shipping is based on $\$ 1.10 /$ mile and 2000 miles (by truck) 


\section{Distribution}

No. of

Copies

\section{Offsite}

2 DOE/Office of Scientific and Technical Information

John Mathur

U.S. Department of Energy

Office of Science and Technology

Germantown, MD 29874

Jerry L. Harness

U.S. Department of Energy

3 Main Street

Oak Ridge, Tennessee 37830-8620

G.C.S. Ordaz

U.S. Department of Energy

Office of Science and Technology

Germantown, MD 29874

Helen Farrell

ER-13

U.S. Department of Energy

Germantown, MD 20874-1290

Jack S. Watson

Oak Ridge National Laboratory

P.O. Box 2008

Oak Ridge, TN 37831

K. T. Klasson

Oak Ridge National Laboratory

P.O. Box 2008

Oak Ridge, TN 37831

Tom Conley

Oak Ridge National Laboratory

P.O. Box 2008

Oak Ridge, TN 37831
Greg Hulet

Lockheed Martin Idaho Technologies Co.

PO Box 1625

Idaho Falls, ID 83415-3875

Dirk Gombert

Lockheed Martin Idaho Technologies Co.

PO Box 1625

Idaho Falls, ID 83415

Jay Roach

Lockheed Martin Idaho Technologies Co.

PO Box 1625

Idaho Falls, ID 83415

M. J. Steindler

Argonne National Laboratory

BIdg. 205

9700 S. Cass Avenue

Argonne, Il 60439-4837

J. K. Bates

Argonne National Laboratory

Bldg. 205

9700 S. Cass Avenue

Argonne, IL 60439-4837

J. C. Cunnane

Argonne National Laboratory

Bldg.205

9700 S. Cass Avenue

Argonne, IL 60439-4837

M. C. Thompson

Westinghouse Savannah River Co.

Savannah River Technology Center

P.O. Box 616

Aiken, SC 29802

C. M. Jantzen

Westinghouse Savannah River Co.

Savannah River Technology Center

Bldg 707-C, P.O. Box 616

Aiken, SC 29808

Distr.1 
I. L. Pegg

The Catholic University of America

Vitreous State Laboratory

620 Michigan Avenue, N.E.

Washington, DC 20064

D. F. Bickford

Westinghouse Savannah River Co.

Savannah River Technology Center

Bldg 707-C, P.O. Box 616

Aiken, SC 29808

\section{A. Barkatt}

The Catholic University of America

Vitreous State Laboratory

620 Michigan Avenue, N.E.

Washington, DC 20064

Y. N. Chiu

The Catholic University of America

Vitreous State Laboratory

620 Michigan Avenue, N.E.

Washington, DC 20064

J. B. Hunt

National Science Fundation

4201 Wilson Blvd.

Arlington VA 22230

R. E. Sassoon

Science Applications International Co.

555 Quince Orchard Rd. Suite 500

Gaithersburg, MD 20878

\section{R. E. Sassoon}

Science Applications International Co.

555 Quince Orchard Rd. Suite 500

Gaithersburg, MD 20878

P. Hart

U.S. Department of Energy

MS-E06

P.O. Box 880

Morgantown, WV 26507-0880
B. M. Frankhouser

U.S. Department of Energy

3610 Collins Ferry Rd

PO Box 880

Morgantown, WV 26507-0880

Norman $\mathrm{Li}$

50 E. Algonquin Rd.

Des Plaines, IL 60017

Rod Ewing

Dept Nuclear Engineering and

Radiological Sciences

The University of Michigan

2355 Bonisteel Boulevard

Ann Arbor, Michigan 48109-2104

W. Lutze

University of New Mexico

Department of Chemical and Nuclear

Engineering, Farris Engineering Center

Room 209

Albuquerque, NM 87131-1341

D. M. Strachan

Argonne National Laboratory

Chemical Technology Division

9700 S. Cass Avenue

Argonne, IL 60439-4837

D. Clark

University of Flordia

Dept of MSE

136 MAE, PO Box 116400

Gainesville, FL 32611-6400 
No. of Copies

T. M. Kafka

3M Center, Bldg. 209-1 W-24

St. Paul, MN 55144-1000

S. L. Stein

Greenhill Technologies

PO BOX 5395

4000 NE 41st St.

Seattle, WA $98105-5428$

P. J. Usinowicz

505 King Avenue

Columbus, Ohio 43201-2693

W.C. MacDonald

505 King Avenue

Columbus, Ohio 43201-2693

S. Cohen

505 King Avenue

Columbus, Ohio 43201-2693

W.W. Simmons

505 King Avenue

Columbus, Ohio 43201-2693

N. K. Chung

Metcalf \& Eddy

30 Harvard Mill Square

PO Box 4071

Wakefield, MA 01880-5371

Ken M. Kemner

Argonne National Laboratory

9700 S. Cass Ave.

Argonne, Il 60439
No. of

Copies

Onsite

4 DOE Richland Operations Office

T. L. Aldridge, K8-50

R.A. Pressentin, K8-50

S.N Saget, K8-50

D. A. Brown, K8-50

\section{Pacific Northwest National Laboratory}

E. G. Baker, K2-12

S. Baskaran, K2-44

Bill Bonner, K9-14

Jim Buelt, P7-41

B. C. Bunker, K2-45

X. Feng, P8-37 (30)

G. E. Fryxell, K2-44

C. S. Ghormley, P8-37

M. Gong, P7-41

R. T. Hallen, K2-12

Bill Kuhn, K8-93

D. E. Kurath, P7-28

Jun Liu, K2-44

Mike Lilga, P8-38

Nick Lombardo (6)

S. V. Mattigod, K6-81

Z. Nie, K2-44

Joe Perez, P7-41

John Sealock, K2-10

Terri Stewart, K9-69

Rod Quinn, K9-69

Jud Virden, K2-44

L-Q. Wang, K2-44

Technical Report Files (5) 